\title{
Machining Ornament
}

An investigation into contemporary machining

practices and the creation of patterned ornamental surfaces

Samuel Saunders 


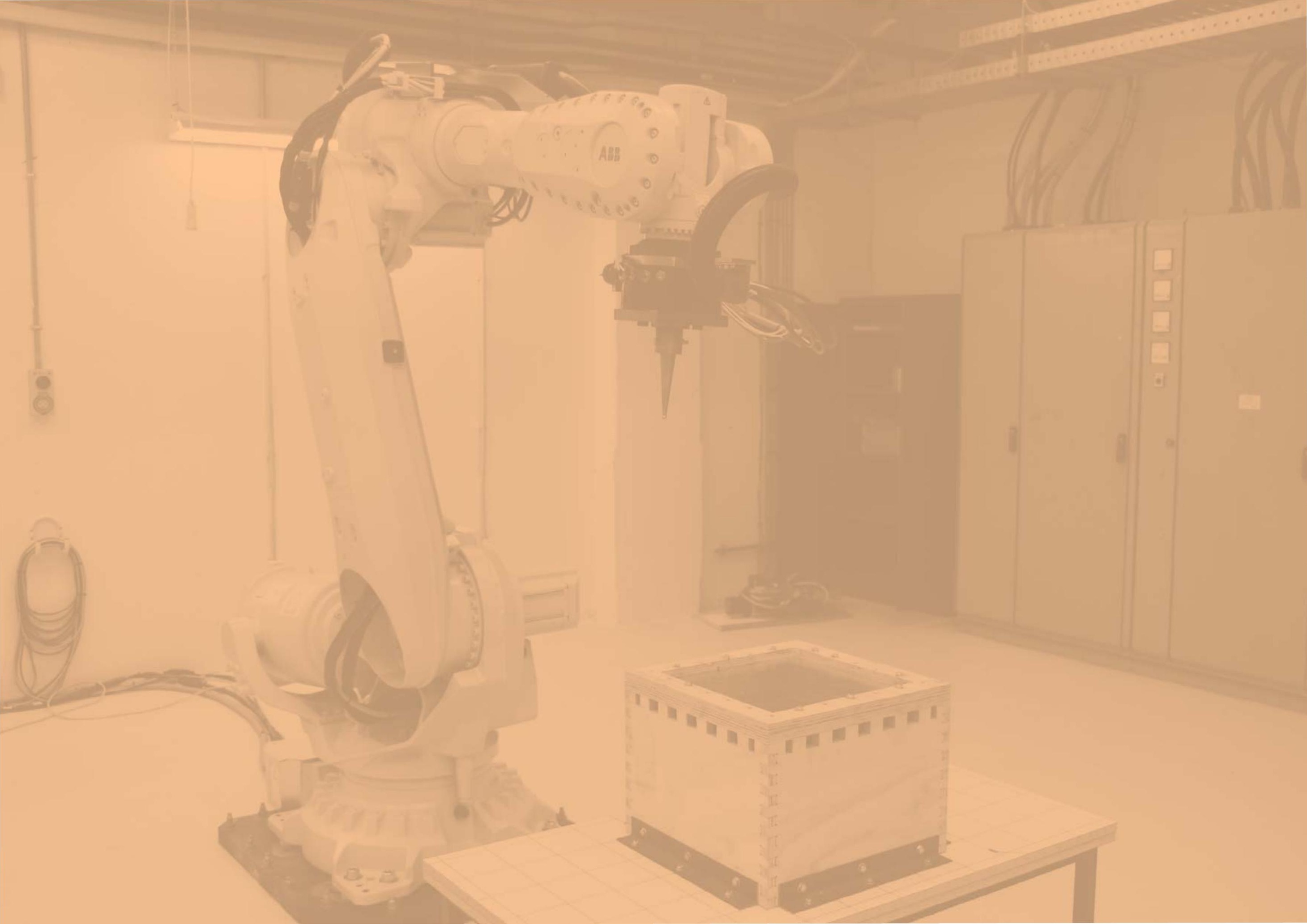




\section{Machining Ornament}

An investigation into contemporary machining practices

and the creation of patterned ornamental surfaces

A 120 point thesis submitted in partial fulfi Ilment of the requirements of the degree of Master of Architecture (Professional)

Victoria University of Wellington School of Architecture

2018

\section{Samuel Saunders}




\section{Illl Abstract}

Robotic tools open a new frontier in surface articulation. The combination of computer modelling with robotic tools allows the transfer of digital information onto physical objects with comparative ease. This permits a more intricate approach to building; where the architect can incorporate new ornamental effects onto surfaces increasing the diversity of our built environment. This use of contemporary tools to articulate surfaces has heralded a return of ornament to the artistic repertoire of the architect. Once again, the architect can be involved in the intricacies of instilling narratives into material surfaces.

This thesis identifies this resurgence in ornamental effects and aims to question how robotic tools facilitate the creation of ornamental architecture. This thesis involves the digital creation of patterns

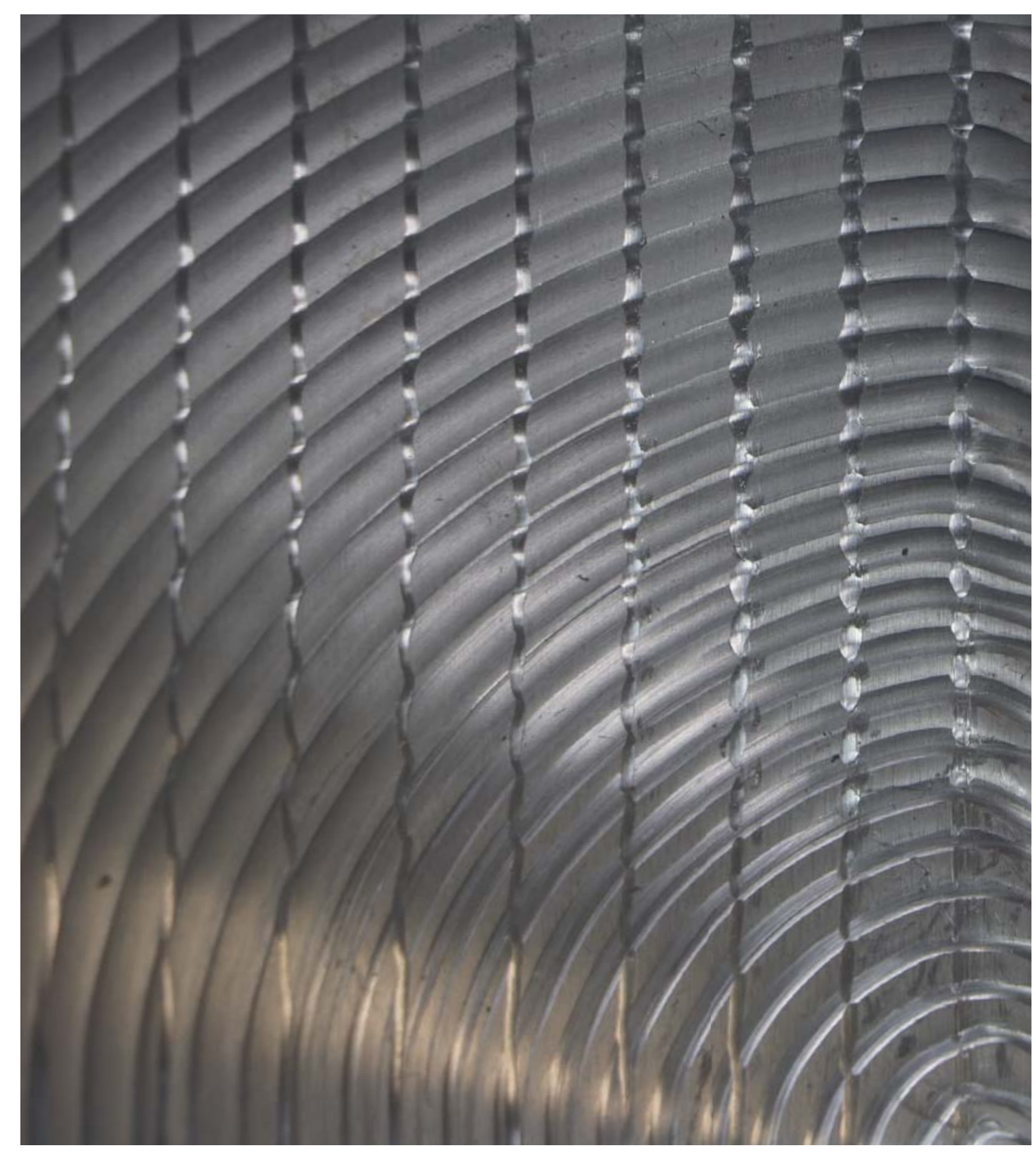

人 Fig 01. Incremental sheet form with double pass, first vertical contours followed by a pass of widely spaced horizontal contours 
which considers the creation of parametric designs that hold a particular narrative.

This thesis also experiments with the potential of metal sheet forming to identify the parameters that guide the sheet form. These two topics work in unison whereby the digital design has been limited by the parameters discovered through physical experimentation. The machining process of Incremental Sheet Forming (ISF) is investigated as to its potential in the manipulation of sheet metal. Specifically, the robot is used to discover the potential of sheet forming through the creation of a full-scale prototype.

This practical research shows how considered use of robotic tools can bring greater connection to our built environment. Intricate detailing of architecture boosts the experiential connection between the building and inhabitant, strengthening a person's

attachment to their physical environment. 


\section{IIl Acknowledgements}

I would like to thank my parents for their guidance through the varying time called the thesis. Their encouragement, investment of time and money has been fundamental to my success.

I would like to thank my supervisor Kevin Sweet for his professional advice and constant availability. This made the thesis exciting at the best of times and bearable at the worst.

My friend John Dennison for a listening ear and persistent encouragement, not to mention the coffee breaks that gave a much needed escape from school.

My peers who worked alongside me and helped invigorate our working environment. Thank you for grounding my studies.

Lastly my thanks goes to the creator of all good things, who through this season has remained a constant source of inspiration whenever I have been lacking. 



\section{Il Table of Contents}

Abstract $\quad 5$

Acknowledgements 9

Table of Contents 11

List of Figures 14

Introduction 19

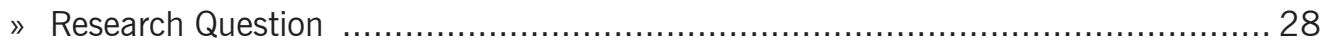

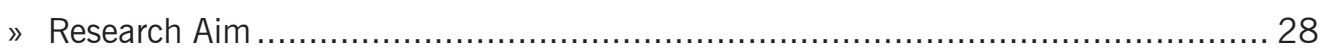

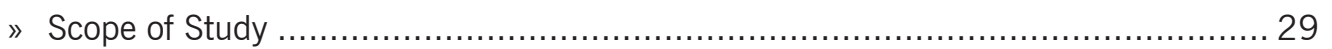

Literature Review $\quad 31$

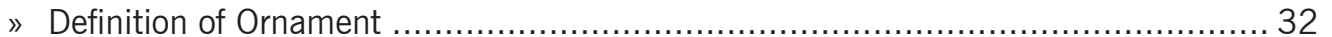

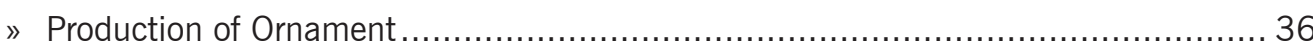

Research Methodology $\quad 43$

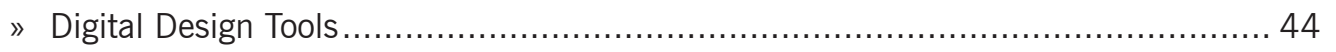

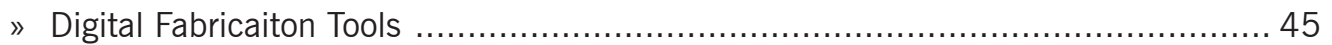


» Design and Fab Process........

»Workflow case study.

»ISF Case Study .

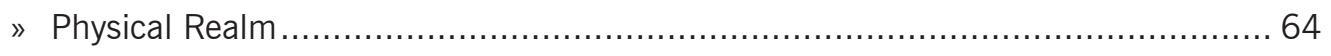

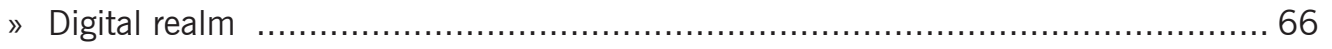

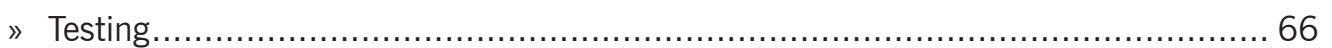

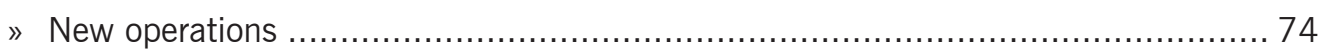

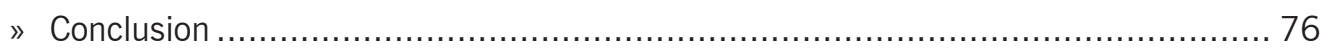

Phase 2 - Prototyping $\quad 79$

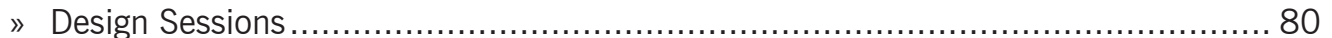

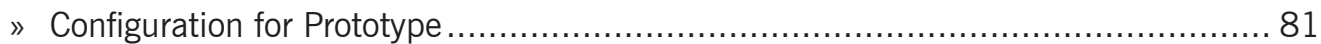

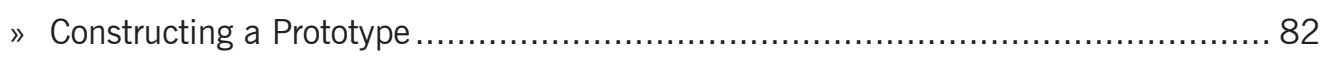

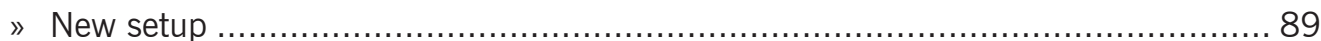

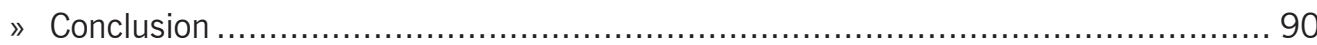




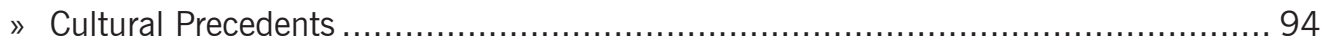

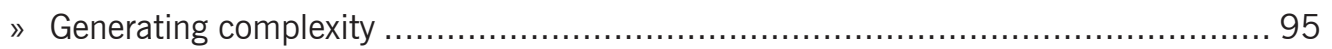

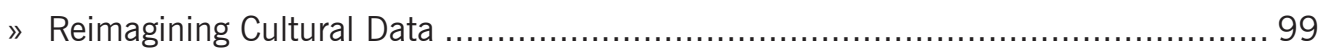

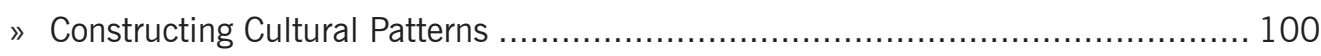

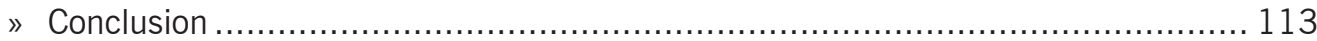

Discussion 115

Bibliography 123 


\section{List of Figures}

Fig 02. Xipe Totec39, "Hand prints", Flickr, 21 October 2006 Web. Accessed 1 August 2017. <flickr.com/photos/71804756@N00/275823019/in/photostream/>

Fig 03. Wellington Art, Whisky \& Wry, 31 August 2011 Web. Accessed 1 August 2017. $<$ whiskyandwry.com/category/new-zealand/wellington/>

Fig 04. Electric robot pioneer dies, ABB, 16 October 2013 Web. Accessed 1 August 2017. <abb-conversations.com/2013/10/electric-robot-pioneer-dies/>

Fig 06. Alessio Cuccu, "Sauerbruch Hutton", Flickr 17 April 2010 Web. Accessed 1 August 2017. <flickr.com/photos/23675203@N06/4589252010>

Fig 07. Gary Fong, M.H. de Young Museum | HERZOG \& DE MEURON, ARCH2O (Andreas Leonidou) Web. Accessed 1 August 2017. < arch2o.com/m-h-de-youngmuseum-herzog-de-meuron/>

Fig 08. John Wahler, M.H. de Young Museum | HERZOG \& DE MEURON, ARCH2O (Andreas Leonidou) Web. Accessed 1 August 2017. < arch20.com/m-h-de-youngmuseum-herzog-de-meuron/>

Fig 09. Geometry defintion of truss supporting roof, Architecture in the Digital Age, (Taylor \& Francis Group, 2003), p. 19; LibreArchi, < librearchi.umontreal.ca/>
* All other figures in this thesis are the authors own work or have been photographed by the author 
Fig 10. Interior view of Waterloo International Terminal, Walker Construction, 2017 Web. Accessed 14 September 2017 < walker-construction.co.uk/case-studies/case/waterloointernational-station.html>

Fig 12. Ammar Kalo, Michael Jake Newsum, Single point incremental forming with a custom forming end effector, Robotic Fabrication in Architecture, Art and Design 2014, p. 33-49; Springer Link, <doi.org/10.1007/978-3-319-04663-1_3> Copyright 2014 by Springer International Publishing Switzerland

Fig 13. Grasshopper, Graphisoft, 18 Sep 2015 Web. Accessed 27 September 2017.

$<$ blog.graphisoftus.com/graphisoft/graphisoft-introduces-rhino-grasshopper-archicadconnection $>$

Hal, food4rhino, Web. Accessed 27 September 2017 < food4rhino.com/app/hal-robotprogramming-control>

Robotic Control Pendant, RobotWorx, Web. Accessed 27 September 2017 < robots.com/ articles/viewing/abb-used-robot-controllers>

Fig 14. Rhinoceros, Omega Multimedia, Web. Accessed 27 September 2017 < http:// www.omegamultimedia.com/rhinoceros_nurbs_mcneel.html> 3D DassaultSystemes, Prototype Today, Web. Accessed 27 September $2017<$ http:// www. prototypetoday.com/dassault-systemes/dassault-systemes-introduces-unique-3d- 
sketching-experience>

Fig 15. Rhinoceros, Omega Multimedia, Web. Accessed 27 September $2017<$ http:// www.omegamultimedia.com/rhinoceros_nurbs_moneel.html>

Fig 16. Structural Diagrams of HL 23, Digital Workflows in Architecture: Design - Assembly - Industry, (Birkhauser, 2012), p. 35; De Gruyter Web. Accessed 1 August 2017 < degruyter.com/downloadpdf/boo ks/9783034612173/9783034612173.28/9783034612173.28.pdf>

Fig 17. CNC Machine ( Elumatec, made in Germany ) for 5 axis tooling with capabilities up to $8 \mathrm{~m}$ in length, Dante Tisi: Custom Metal Manufacturers Web. Accessed 1 August $2017<$ dantetisi.com/index.php?/howwedoit/equipment/>

Fig 18. Milled steel dies, Digital Workflows in Architecture: Design - Assembly - Industry, (Birkhauser, 2012), p. 37; De Gruyter Web. Accessed 1 August 2017 <degruyter.com/ downloadpdf/books/9783034612173/9783034612173.28/9783034612173.28.pdf>

Fig 19. Atlas of Megapanels, Digital Workflows in Architecture:

Design - Assembly - Industry, (Birkhauser, 2012), p. 37; De Gruyter

Web. Accessed 1 August 2017 < degruyter.com/downloadpdf/boo 
ks/9783034612173/9783034612173.28/9783034612173.28.pdf >

Fig 20. Construction of East Facade, Digital Workflows in Architecture: Design - Assembly - Industry, (Birkhauser, 2012), p. 41; De Gruyter Web. Accessed 1 August 2017 <degruyter.com/downloadpdf/boo ks/9783034612173/9783034612173.28/9783034612173.28.pdf>

Fig 21. East Facade of HL 23, Digital Workflows in Architecture: Design - Assembly - Industry, (Birkhauser, 2012), p. 42-43; De Gruyter Web. Accessed 1 August 2017 <degruyter.com/downloadpdf/boo ks/9783034612173/9783034612173.28/9783034612173.28.pdf>

Fig 22. Incremental Sheet Metal Forming in Architecture, KALO, 2017 Web. Accessed 1 August 2017 < ammarkalo.com/Incremental-Sheet-Metal-Forming>

Fig 23. Ammar Kalo, Michael Jake Newsum, Comparison of overall geometric improvements with the 'ribbing' system, Robotic Fabrication in Architecture, Art and Design 2014, p. 33-49; Springer Link, <doi.org/10.1007/978-3-319-04663-1_3> Copyright 2014 by Springer International Publishing Switzerland 

Introduction 
Historically, humanity has had a natural

tendency to decorate themselves and their

environment (Morris). Cave drawings first made an appearance 40,000 years ago (Aubert) amongst early Homo sapiens who left paintings of animals, depictions of animal hunts and hand markings in caves. As with all prehistoric art, the exact purpose of these paintings is not clear. However, three different theories have persisted over recent years. Some anthropologists and art historians theorize that the paintings either evoke potential hunting success or allude to past endeavours (Curry). Curry says others suggest Palaeolithic 'shaman', or ancients who seek to connect with the spirit world, were responsible for the drawings while in some sort of trance. More recently the drawings have been associated with young men and are part of a fertility ritual. The common factor was the painting represented part of the culture and environment of ancient humanity. They painted and sketched what was important to them at the time. One could say cave drawings in prehistoric times were a means of decorating space.

This tendency to make markings, transfers to our built environment today where blank walls and deserted places have become sites for graffiti: an act of vandalism that seeks to add something to spaces which hitherto lacked any form of symbolism. Theodore Dalrymple suggests graffiti and tagging often deface ugly surfaces found in modern urban spaces. A more appropriate means of decoration in modern days is to decorate walls and buildings by applying a layer of paint, often coloured. This reflects humanity's need to adorn surfaces but also illustrates the added bonus that 
ヘ Fig 02. Ancient cave ᄀ Fig 03. Tagging painting presumed to be of 7 or graffiti is often female hands illustrating found in blank spaces one method of decorating or impoverished

their environment.

environments.

1) Fig 04. Bjorn

Weichbrodt with the first Weichbrodt with the first
robotic arm developed by ASEA in 1974. 
such ornamental effects can give to surfaces, for by doing so the durability of that surface is increased. By adding graffiti or a layer of paint also imparts an individual's or collective identity, therefore ornamentation can be seen as an attempt at personalisation or branding.

\section{People's natural tendency to ornament} objects distinguishes those objects from the ordinary. This distinction by decorating objects has helped to organise different social groupings through history often uniting them by a particular style. Owen Jones illustrates this tendency in The Grammar of Ornament published in 1856, which identifies a wide variety of ornamental styles. These are then associated with a particular geographical region, or country and respective culture with its own agendas and social priorities. This leads to the ornament gaining value as a social identifier. From the hieroglyphics of Egypt to tartan bearing clans of Scotland and to the complex social groupings formed by branding today, ornamental styles encourage a sense of collective pride for those wearing their symbols.

Modernism was a period that sought to remove ornament from the face of architecture. Ornament was surplus to the communication of architecture for economic, social and moralistic reasons (Trilling, 118). It was also a time where the ethics of architecture was a point in question. Adolf Loos, a major proponent of the removal of ornament, saw the 'evolution of culture [as] synonymous with the removal of ornament from the objects of daily use' (167), while an ability to mass produce parts saw the rejection of ornament as a moral duty 
to create affordable dwellings for the masses. While it was technology that instigated the rise in modernism, so too it is technology that has led to a return of ornamentation. The undisputed return of ornament to contemporary architecture is related to the tools of production that are employed today (Picon, Digital Culture in Architecture, 138). It is these tools and the failure of modernism, as described by Picon (Ornament, 15), that have prompted this ideological shift from the purity of modernism. New parametric tools that can construct multiple model variations in one data set and machines that are easily programmable, together enable an ability to adorn architecture with extra qualities, now more than ever.

It was feared that the popularity of the modern movement would remove ornament from architecture altogether and lead towards an increasingly homogenous built environment with little or no unique identifiers. However, ornament remained vaguely present in modernism even if under a different guise (Picon, Ornament, 97). This increasing homogeneity in design has been noted as recently as 2014 by key figures such as Koolhaas in the 2014 Architectural Biennale. However, the increasing literature on ornament in architecture today has led to recent contemporaries acknowledging the return of ornament (Picon, Digital Culture in Architecture, 138). Ornaments' role in reviving the heterogeneity of the built environment is undisputed. Therefore, promoting ornament as a counter to modernist homogenous architecture is crucial to the welfare of the discipline and the expression of architects.

Leading to the return of ornamentation 
Ornament shapes, straightens and stabilizes the bare arid field on which it is inscribed. Not only does it exist in and of itself. but it also shapes its own environment - to which it imparts form.

Henri Focil1on (66) 
has been the development of digital design and fabrication tools that have made ornamentation easier. After the rise of mass production in the early 20th century there has been a trend towards mass-customisation; manufacture which maintains the cost advantages of mass production but retains an ability to create unique products with little setup and pack down costs (Kolarevic, Architecture in the Digital Age, 52). One tool that has been fundamental in this shift has been the robotic arm. First produced in 1974 , this tool allows a range of movements that can theoretically be layered together or programmed to produce complex and unique movements. The true benefits of robotic tools in architectural production are just being realised today as universities, artists, furniture makers and some architectural firms are exploring these technologies in innovative new situations. One new method of production of increasing importance in the last decade is Incremental Sheet Forming (ISF). A method which highlights the ornamental nature of sheet metal when formed under pressure. This can be seen as a result of the development of tools in the 20th to 21 st century along with a continued need to experiment.

Architecture is a great experiment for humans. It is in constant flux as new architects 'push open the envelope' of what architecture is by testing new materials and developing new techniques to form buildings. As architecture reached the turn of the 20th century, architects like Le Corbusier and Mies van der Rohe decided that architecture needed to find itself in terms of space, pure and volumetric (Holston, 133). With that period of experimentation coming to a 
conclusion the return of ornament can be seen as a continuation to humans' need to experiment with rising technologies that open fields of surface articulation. The need to experiment with new texture technologies and materials in visceral and ornate ways has returned as architects look to increase the expression of architecture with new digital tools.

This thesis will examine how subjective ornamental styles can communicate the delicate intricacies of the individual designer. The return of ornament allows the creation of architecture that once again encourages individual expression and collective pride. This thesis takes particular interest in this tendency to ornament our environments and how this can be used to once more create beautiful and unique designs that encourage a sense of cultural pride. It includes communicating the intricacies of working to design and build a contemporary piece of architecture that is based on customised ornamentation, while also making a case for highly customised and unique ornamentation.

This thesis benefited from the collaboration of the first group of students working together with the robotic arm at Victoria University of Wellington's School of Architecture. The research team faced many challenges that increased the production timeframe due to being the first adopters of this technology at the school. However, the success and failure of this project is not to be measured by the time frame of the output but rather the ability of the structure to represent complex and unique ornament. 

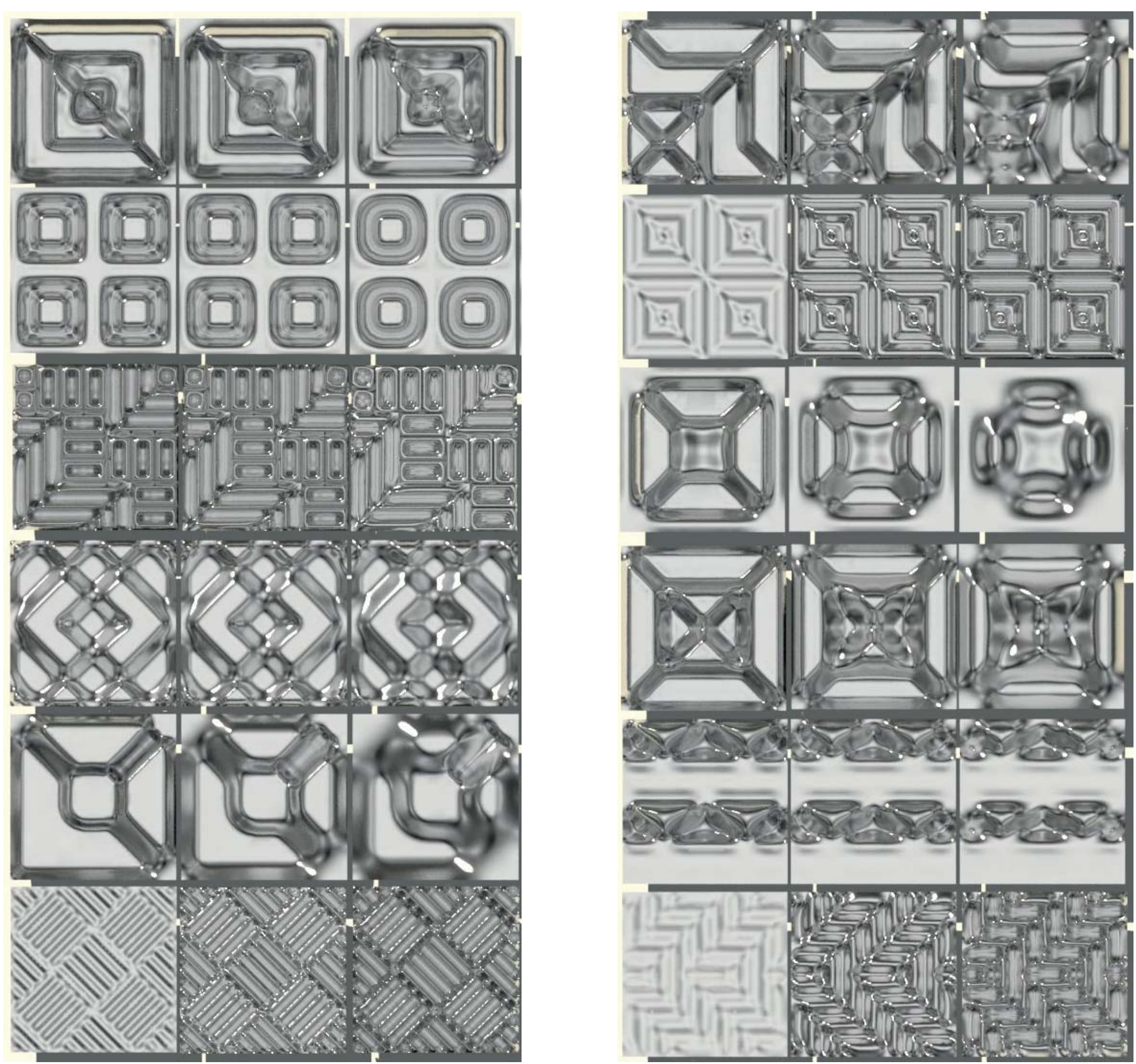

《 Fig 05. Depiction

of Maori Panel design

showing range of

parametric variation within

each model

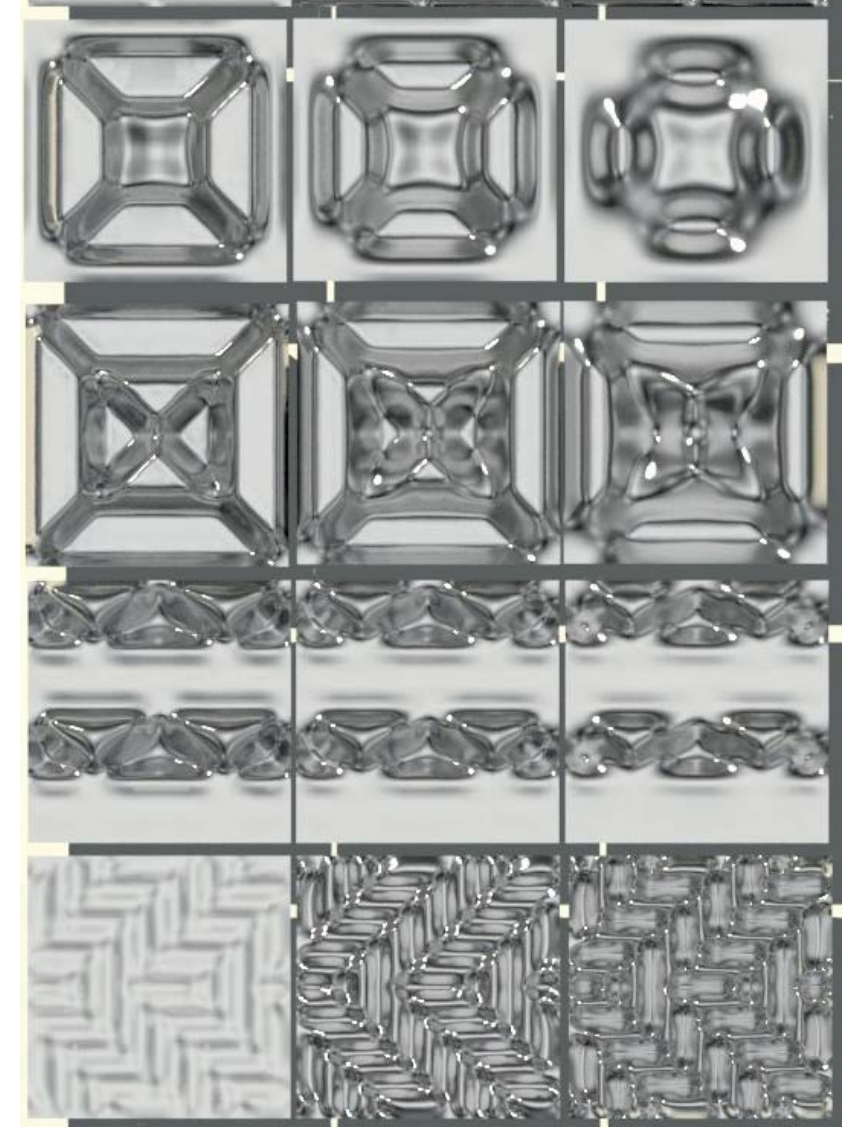




\section{Research Question}

How can Incremental Sheet Forming (ISF) aid in the production and communication of ornamental patterns to advance the resurgence of ornamentation and expression in contemporary architecture?

\section{Research Aim}

The aim of this study is to explore how robotic tools could facilitate the creation of ornamental architecture in contemporary society. It seeks to develop an argument promoting the benefit of ornament in contemporary society to promote its growth and revival.

The specific objectives of this study are: - Analyse the historical presence of ornament and its definition in today's society.

- Create a full-scale prototype using a robotic arm which demonstrates the feasibility of ISF as a fabrication process that honours ornamentation.

- Create a catalogue of ornamental patterns that relate to cultural motifs to illustrate the process of creating meaningful contemporary ornament. 


\section{Scope of Study}

The scope of this study is to research, develop and fabricate ornamental patterns within the constraints of operating an Industrial Robotic Arm (IRB). It includes defining the position that ornamental forms have in today's society determined by our social acceptance and machining capabilities. To limit the scope within the large variety of operations available to a robotic arm (shown by the extensive research of Gramazio and Kohler) a specific operation was chosen that could communicate an ornamental character in its fabrication. The specific operation was Incremental Sheet Forming (ISF). ISF is an operation which can be seen to have architectural applications in the generation of panel components for a facade system. The final outcome of the research will be culturally sensitive examples that can direct one to applying the concept of ornamentation in their research both through fabrication and the creation of ornamental catalogues of design.

This thesis aids the development and expression of this new form of ornament, starting with a fundamental examination of the technique of ISF entitled 'Exploration'. The research progresses into the creation of a full-scale prototype illustrating the potential of ISF. The final stage of design research explores parametric patterning, a phase that builds on the lessons learnt from the previous sections to develop digital models that effectively communicate cultural motifs. 

Literature Review 
The following section explores the theoretical framework of ornament in an attempt to critique the purpose of ornament in contemporary society.

\section{Definition of Ornament}

In order to understand the trajectory of contemporary ornament in today's society the historical definition of ornament must be contrasted against its contemporary condition.

\section{Pre-modern notion}

In the 19th century, ornament was seen as the 'art we add to art: shapes and patterns worked into an object or building for the pleasure of outline, colour, or fantasy' (Trilling, XIII). This definition describes ornament as a superficial condition, an element added to structure. From this ornament can be seen as an adornment that makes objects more desirable; however none the less crucial despite this definition. Ornament was seen as a vital part of a building's presence in the late 19th century symbolising political and subjective aspects of society (Picon, Ornament). Ornament was an element applied to the surface of architecture to communicate the owner's social rank, express an aristocrat's power or illustrate an architect's personal signature. To design a building without ornament was unthinkable. To the influential characters promoting ornament at the time such as John Ruskin, Gottfried Semper and Owen Jones, it would have been seen as an unspeakable rudeness to omit ornament, likened to an object thrown at one's face (Spuybroek, 75). A building without ornament showed a lack of empathy and poverty of the human spirit.

In the opening of his book, Ornament, 
Antoine Picon makes his stance clear,

'What if architecture was ultimately about ornament?' (9). This statement revives a notion that was prevalent during the 19th century. Buildings, to some degree, stood so that they could be covered in ornament. While superficial, ornament was crucial to the communication of the building both socially and politically. Picon uses Oleg Grabar's conclusions in The Mediation of Architecture that 'architecture is a true ornament' and adds quality to life. This gives us some perspective as to what ornament meant for 19th century Europe. Oleg Grabar continues that architecture has no greater purpose than to adorn man's activities on earth (193). All this to say that ornament in pre 20th century Europe was seen as an essential adornment that aided the communicative value of art and architecture. The absence of ornament, which was not acceptable to society at large, indicated a lack of care by the artist which was seen as reprehensible to others in the profession. This view changed drastically with the rise and fall of modernism.

\section{Contemporary notion}

Ornament has adapted to today's age, taking on a more pluralistic meaning. After modernism, a period that rejected ornament as extraneous and wasteful, ornament morphed into forms more ambiguous than the 'added decoration' it used to be. The rise of the computer has enabled architects to play with a wider range of decorative elements in new ways incorporating new materials and effects. Lars Spuybroek defines ornament in the 21st century as being "profoundly related to matter'. He suggests one must resist the urge to separate ornament as an applied state stuck onto surface. 
Spuybroek says that this is what led to adopting the naked forms modernism promoted as honest expression to the downfall of architecture (77). The idea that ornament is mutually dependant on matter helps to understand the more pervasive sense of ornament that Antoine Picon describes in Digital Culture in Architecture, 'ornament is today generally conceived as an integral part of a pervasive condition that brings it closer to a pattern than to a sculpted decoration.' Seen in this light buildings such as Sauerbruch Hutton's Pharmacological Research Laboratories (Fig 06.) seem to approach the addition of pattern as an ornamental feature covering the whole of the building's facade. Today pattern appears to supersede ornament, or in other words contemporary ornament is closer to the definition of pattern than ever before. This rise in pattern can be explained by the computer's ease in generating these through computer aided design (CAD) but also in an increased ability to manufacture such patterns through computer aided manufacture (CAM).

Since the demise of modernism and its obsession with architectural space, the importance of the envelope seems to have superseded that of its counterpart, structure. Antoine Picon points to Gehry's work on the Guggenheim and the Walt Disney Concert Hall as evidence to this increased importance of surface (Ornament, 26). In addition many contemporary buildings by Hezrog \& de Meuron also show this sensibility (Fig 07). While this attitude is not prevalent everywhere it points to a new concern with architectural surface. Ben Pell in The Articulate Surface begins to communicate 
Fig 07. The De Young

Museum by Hezrog \& de Meuron consists of a perforated skin acting as a veil for the large form

prioritising the display of the

surface rather than the structure

\) Fig 08. A perforated facade

screen with added punching

operation created by use of

Computer Aided Manufacture

入 Fig 06. The Sauerbruch Hutton's Pharmacological Research Laboratories. This building adopts an ornamental character through its use of coloured glass panels some of which operate as louvres adding to the dynamic effect of the facade 
this new found meaning in surface by attempting to categorise the range of fabrication techniques that are now available to the adept architect. Farshid and Kubo relate to surface and ornament in The Function of Ornament which categorises different buildings under the topics of form, structure, screen and surface. Their work creates a catalogue of buildings which transmit different affects through the use of different techniques made available with the rise of CAD/CAM technology. They suggest that it is through ornament that material transmits affects, arguing that ornament is necessary and even inseparable from the object (8).

It can be seen that a contemporary definition of ornament sees no difference between the matter that constitutes a building and the materiality that transmits sensations and affects. It is rare in contemporary practice to define ornament as a noun. Therefore, it may be more appropriate to consider ornament as an action. Deniz Balik and Açalya Allmer define ornament as an intention of contemporary architects to demonstrate their virtuosity in designing and producing surface effects. This perspective of ornament as an attitude rather than a physical materiality simplifies the concept of ornament in the 21st century and opens the definition to the broad range of materialisation and fabrication techniques available today.

\section{Production of Ornament}

Pre-modern ornament is different to ornament's contemporary state not only in definition but in terms of design and production. As it has been noted, the production of ornament today relies largely on CAM machines that can 
manipulate resilient materials with accuracy through computer programming and CAD. Prior to the postmodern era and the rise of CAD and CAM, ornament used to be constructed by skilled workmen. Sculptors, hand weavers and other artisans practiced the craft of ornament with their hands, manipulating material at an intimate level. Because of the close association of workmen and material, ornament symbolised important ideas to pre-modern society significant to their quality of life: personal involvement in work, pride in a job well done and love of beauty in the built environment (Trilling, 116). When Modernism arrived, craft based skills were devalued; new workers were needed for the operation of machines which had overtaken slower forms of handicraft. Pre-modernists feared that the rise of the machine would lead to the loss of ideals fundamental to their quality of life. However today, machines, through programmed intelligence, have redefined fabrication providing a more efficient means to create ornament, redefining many of the ideals present in pre-industrial time. The return of ornament has been heralded by the rise of digital fabrication processes utilising CAD/ CAM technology. The computer generated and fabricated patterns change the way we interact with ornament, reducing the tactile understanding but with improved material and processes knowledge, increasing the accuracy of detail in ornamental expression.

\section{CAD}

The computer has introduced a range of new concepts to the way we design and understand ornament. Since their introduction in the 1960s architects recognised the benefit of computers for 
their graphical capabilities. However, it was the computational power of computers that soon began to simulate new fantasies for designers. A process now possible with of the increase in computational power of the computer has been that of parametric design. Parametric design is different to traditional design in that it is not the form that is defined so much as it is the parameters, relationships and their associated geometry (Kolarevic, Architecture in the Digital Age, 17).

Parametric design prompted a shift from the conventional view of architecture as an object to architecture as a system that encompassed a series of interconnected components. This has influenced the definition of ornament redirecting its meaning from an applied object to a pattern that is inherent to the quality of the architecture manifesting in unique ways. One such example of the application of parametric design is apparent in Waterloo station (Fig $09,10)$. The roof consists of a series of 36 dimensionally different but identically configured three-pin bowstring arches illustrating how variance can occur that encourages bespoke articulation (Kolarevic, Architecture in the Digital Age, 18).

Parametric design has an ability to create multiple similar iterations in quick succession by adjusting the parameters. Kolarevic notes that 'Parametric design calls for the rejection of fixed solutions and for an exploration of infinitely variable potentialities' (Architecture in the Digital Age, 18). This exploration of variable potentialities means that the design of ornament is not limited to a standardised component, rather it is encouraged to take on non-standard manifestations 
人 Fig 09. Geometry organising the definition of the two trusses that constitute the support system for Waterloo International Station
ヘ Fig 10. The Waterloo international Station illustrating the parametric series of bowstring arches designed to change size over the $400 \mathrm{~m}$ length of the terminal building 
of shape and form. When the method of parametric design is combined with current CAM processes, a large variety of bespoke objects can be generated within a short timeframe. This ability to produce a range of unique, highly variable components, has led to the concept of 'mass customisation' through which 'it is just as easy and cost-effective for a CNC milling machine to produce 1,000 unique objects as to produce 1,000 identical ones' (Kolarevic, Architecture in the Digital Age, 52).

\section{CAM}

The rise of CAM has meant new ground in the production of ornament has been discovered. This is primarily due to digital fabrication machines opening up a much larger array of operations available to manipulate a vast range of materials. Historically architecture has built what is possible with the design tools available at the time. Up until recently the propagation of Euclidean geometry was all that could be imagined with standard drafting equipment. However the arrival of 3D modelling and digital fabrication machines offer rich opportunities in the exploration of new geometries. If one can compute the complex forms of contemporary architecture then one can inevitably create it through transferring that design data to a digital fabrication machine. As Nick Dunn puts it 'the potential to make things directly from design information has precipitated a transformation in design disciplines, as it allows the designer to engage with the entire process from concept to final product in an unprecedented manner' (20). This amalgamation of design and fabrication into one discipline dramatically diverges away from the historical 
understanding of producing ornament. In pre-modern times, architects would design and craftsmen would make. Rarely would an architect be in charge of both designing and fabricating. However, digital fabrication machines condense the process of design and making to where if it can be modelled in computer software and created through the process of CAM.

A consequence of this transition away from handcraft to digital fabrication is the loss of organic growth of the ornament. The artist or artisan could once make choices mid-fabrication and use the qualities of the material to his advantage. For example, upon discovering a piece of marble had a denser area in part of the stone, the artist could include more intricate detailing. Now, the fabrication process occurs automatically and changes to the design rarely occur during the process of fabrication. In addition, the regular composition of manufactured material, such as plywood whose strength is consistent throughout the material, has all but negated this opportunity. Instead the consistency of manufactured materials, such as an aluminium sheet or a piece of plywood opens new opportunities, allowing multiple operations by a programmed machine which can produce two or more effects on the same piece of material. 

Research Methodology 
The method for this research was both digital and physical, operating through digital design as well as the area of fabrication. Through both digital and physical means this research aimed to explore how robotic tools could facilitate the creation of an ornamental architecture. In all phases of research, the Industrial Robotic Arm (IRB) is considered as the main design and fabrication tool. The IRB is intrinsically involved with the field of computer aided design (CAD) and computer aided manufacture (CAM), meaning an understanding of physical and digital parameters were necessary to operate the machine. Much of this research was conducted by a team of students. Each team member explored a specific topic for their personal thesis but various roles were shared during the initial learning and understanding of the IRB and construction of the full- scale prototype. To achieve the aims set out in this thesis I undertook the role of programming specialist. This allowed me to define the patterns that the robot extruded onto the sheet metal, giving me control of the ornamental investigation.

\section{Digital Design Tools CAD}

The digital tools used in all phases included Hal, Grasshopper (a plugin for Rhinoceros 3D), Rhinoceros 3D, and Computer Aided Three-dimensional Interactive Application (CATIA). Hal is a library of components for Grasshopper that allows communication with the IRB by translating data to the robot's proprietary programming language. It was a necessary application for the operation of the robotic arm as it allows users to create the programming for the robot without having to learn the 
language. Grasshopper was chosen as it is a relatively simple parametric design tool that can simulate 3D forms with ease. This would be fundamental for the realisation of patterns to be fabricated by the robotic arm. Rhinoceros 3D was useful for the representation of incrementally formed sheets and robotic simulation. As it worked in unison with Grasshopper it was inseparable from the design process as a visualisation software for Grasshopper. CATIA by D'assault Systemes is an advanced CAD program which can simulate the whole design process from design to fabrication. While CATIA is a software not widely used within the architectural sectors because of its complexity, it is particularly useful for simulating the joint conditions (explored by a team member) as it can process large amounts of data quickly.

\section{Digital Fabricaiton Tools CAM}

The Computer Numerical Controlled (CNC) machines used in the first and second phases of production were the IRB 6700 (robot), Up Box 3D printers and the Techno CNC router. A commonality of all these machines is their ability to be controlled by numeric data produced from 3D modelling and create physical objects with relative ease. In addition, each machine operates with high precision and accurate geometric output. As such these tools are known as digital fabrication tools. The use of these digital fabrication tools allows full scale production to occur in multiple iterations with minimal effort, which can change the architectural outcome.

Industrial robotic arms are unique in the fact that each can operate as different machines depending on the setup of the machining cell. While this thesis primarily 
looks at the operation of Incremental

Sheet Forming (ISF) it should be noted that this is just one such use of this

machine. By changing the end effector, one can allow the machine to function in a variety of roles.

\section{Incremental Sheet Forming}

ISF is a process which extrudes sheet metal into a shape through the pressure of a ballpoint operated by a machine. The ballpoint on the end of the machine acts in a rotational motion, stepping down every time it makes a complete fulfilment of the form's path. ISF is an operation which requires three elements to function. The first is the jig, a frame of reference in which the sheet of metal can sit securely in place. The second is a multi-axis CNC machine. This is so the shape could be programmed by the machine to be formed. Often a six-axis robotic arm will be used as it is faster, more flexible and are much more robust and reliable when compared to standard industrial CNC machines, according to Kevin McManus (Butcher). The final element is a forming head or tool. This should be capped with a ball point head so that the head will roll off the surface without friction if sufficiently lubricated.

The choice of ISF as a research topic was selected as a means for exploration over many other processes that have been well documented at research labs such as Gramazio Kohler Research. The process of ISF was chosen due to its cheap setup costs and highly visible ornamental results in sheet manipulation. Since the use of an IRB was already in place, setup costs amounted to a rod of steel and one sheet of plywood. Compared to other methods of metal sheet forming, the low cost made 


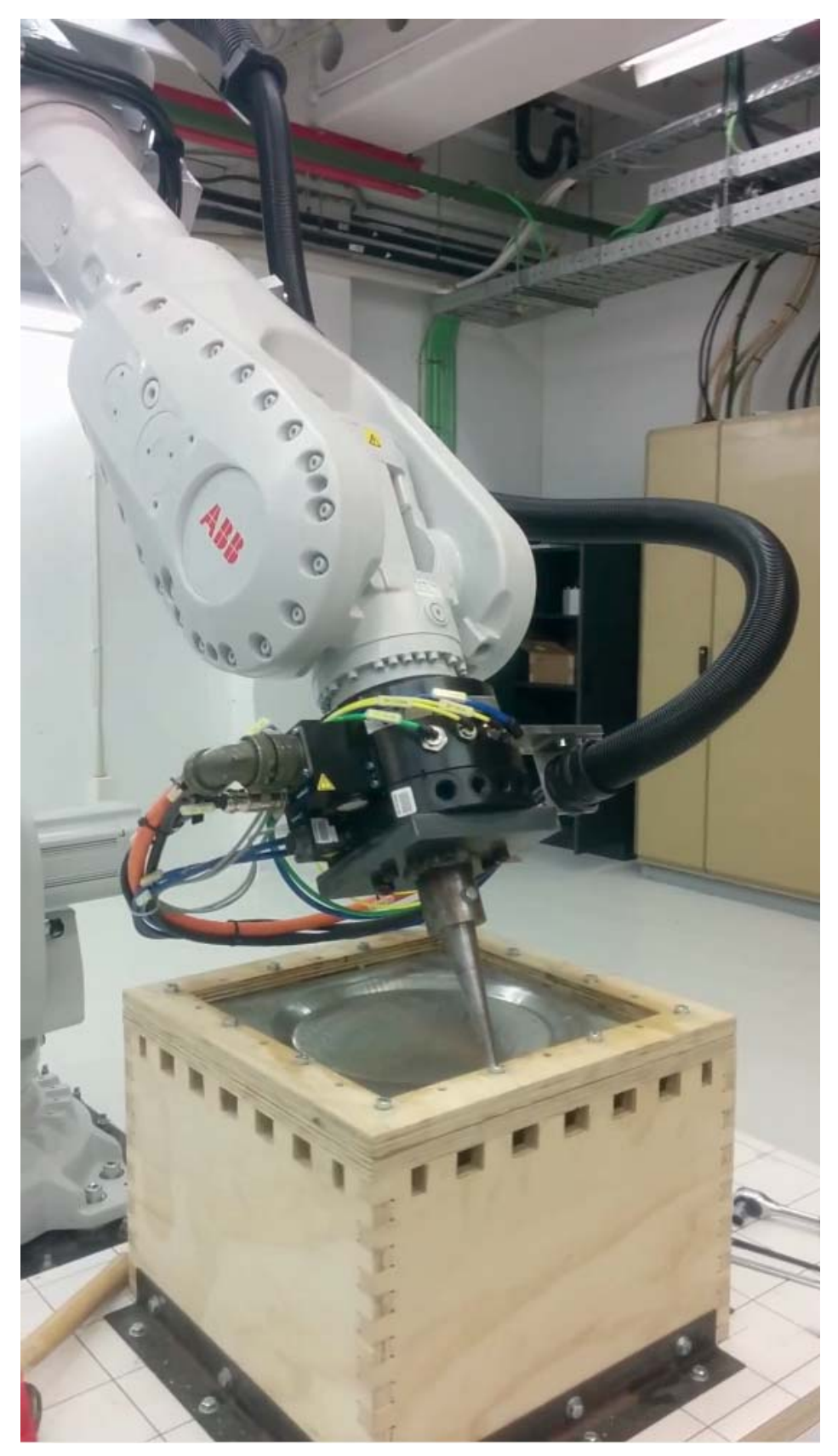

《 Fig 11. Depicting the ABB Robotic Arm with end effector mid-way through the process of Incremental Sheet Forming

人 Fig 12. Diagram of Incremental Sheet Forming indicating the parameters needed to conduct operation. 
ISF an attractive option for metal working. As this was the first project in the School of Architecture to use the robot, ISF was chosen as a process to learn and experiment with the robot due to its costs, ease of learning and quick, tangible results.

\section{Design and Fab Process}

This research had varying methodologies over the three phases which are described below.

The first phase involved learning and exploring the technique of ISF while working on aluminium sheets. The aim of this phase was to identify parameters that limited the application of design in the manufacture of the sheets. As the programming specialist, I programmed the various digital design forms to create a list of manipulations possible on the sheets.
These designs were made in Grasshopper and output through $\mathrm{Hal}$. They were then sent to the robotic arm operating on the sheet metal (Fig 11). Together, the team determined the desirable qualities imparted to the surface effect of the sheet metal. These were noted and recorded as parameters to be applied in the next phase of creating the full-scale prototype.

The second phase involved the prototype construction. This was a group effort with each member holding a specialisation in this construction. As a means to maintain the direction of this thesis, my role was defined as the ornamentation expert. The aim of this phase was to justify the feasibility of ISF as a fabrication process which related to ornament at a material level. The method for designing the pavilion started with preliminary group design sessions where general concepts
Г Fig 13. (Next page) Illustrating the design and fabrication process of phase one

Fig 14. (Next page) Illustrating the design and fabrication process of phase two

L Fig 15. (Next page) Illustrating the design process of phase three 

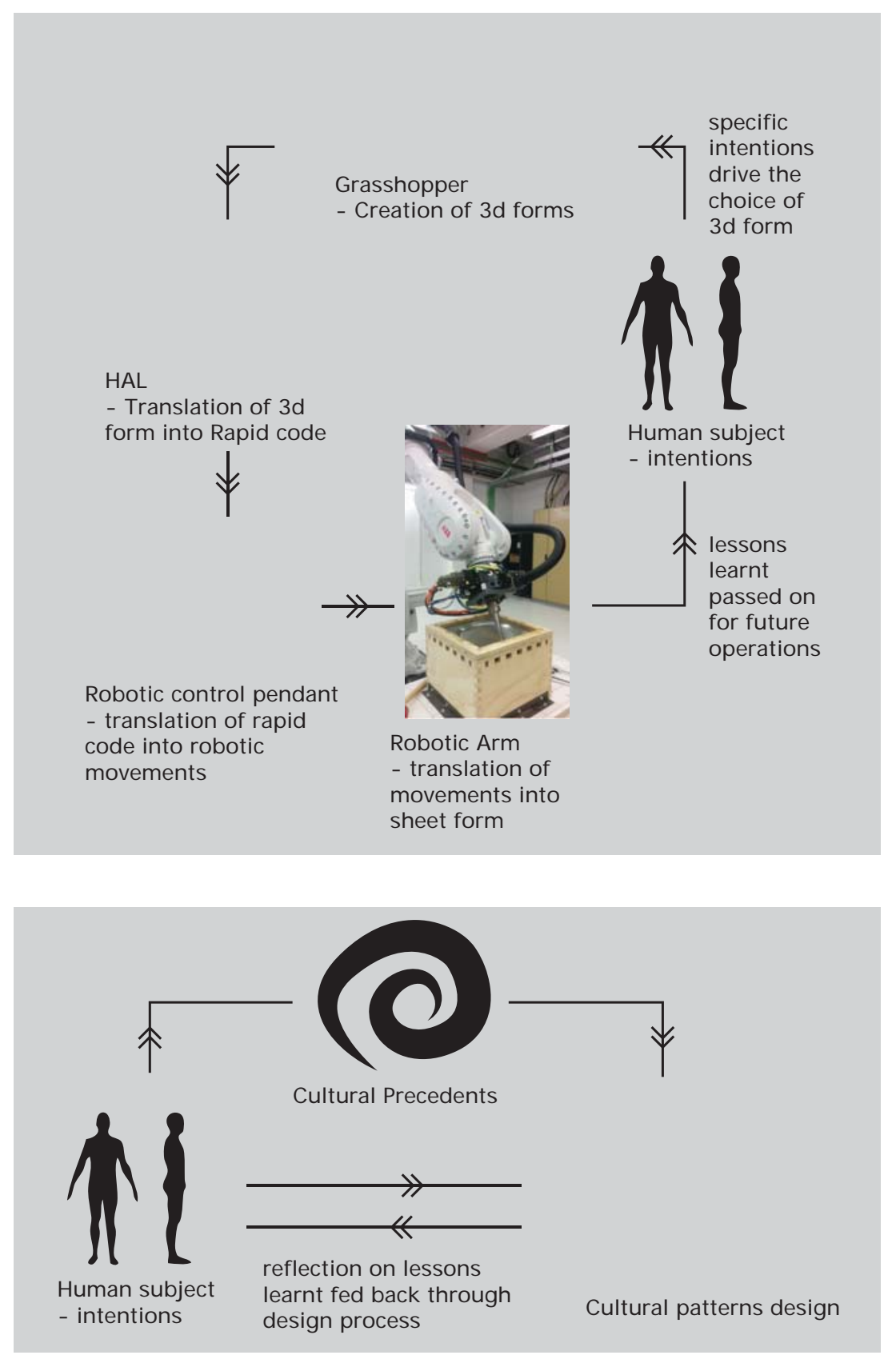

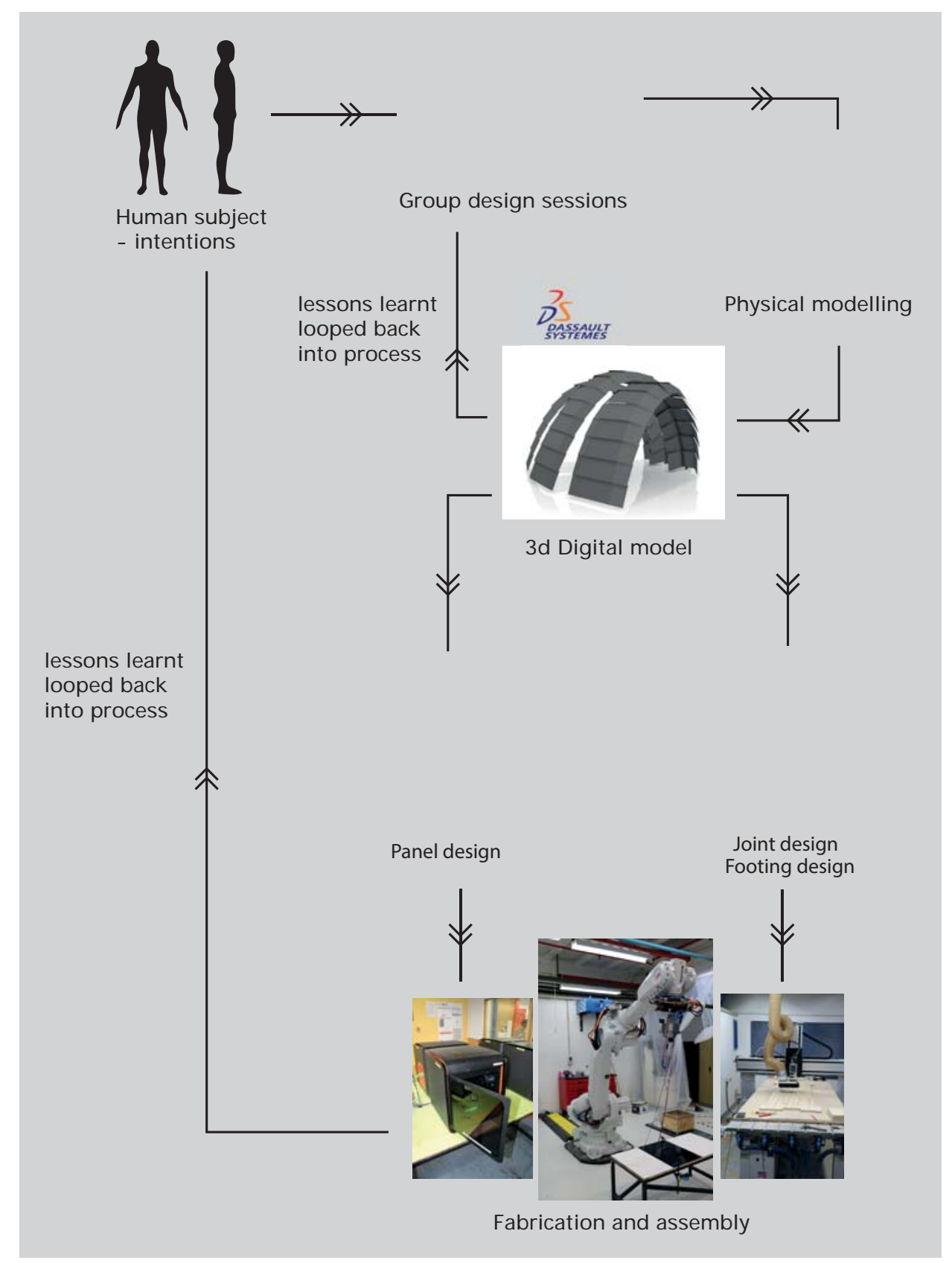


were sketched onto paper without indication to the forms extruded onto the sheets. This was followed by physical modelling (conducted by the group) which more thoroughly communicated the design intent. Once the structural system for the prototype was determined through group discussions, the 3D model was constructed in CATIA by another group member. After the 3D model was constructed the design process was split into three sections: one focussed on the operations on the panels (my role), another on the jointing condition (team member's role) and the third focussed on the footing or foundation of the model (shared role). Testing prototypes for all three phases occurred simultaneously through various software and digital fabrication machines. The panel design was created through Grasshopper. The footing for the pavilion was designed through CATIA and output through CAM software. Because of the parametric nature of the design tools, decisions that changed the design - either by my work or a team member's - were able to be made right up to the fabrication of the pavilion as the model could adjust itself to compensate for any change in design. This meant that team reflection could happen throughout the process therefore creating feedback loops which then aided the success of the design communication.

The method for the final stage of research was the development of digital 3D models conducted by myself. The aim of this phase was to illustrate the process of creating meaningful contemporary ornament that had cultural references. The contemporary ornament was evaluated to ensure they embraced a "careful balance" between complexity 
and order (Gombrich). The process was then to display this balance on forms that could be processed by the robotic arm into incrementally formed sheets. As Gombrich suggests this need for balance is an intrinsic need for the human mind (Kolarevic, Manufacturing Material Effects Rethinking Design and Making in Architecture, 20). This design method relied on the analysis of cultural patterns which would then be abstracted into a parametric design in Grasshopper. This process was highly experimental and involved stages of reflection to ensure the right design intentions were communicated through the parametric model. These stages of reflection allowed for the re-evaluation of the model and a change of direction throughout the process as necessary. 

Case Studies 
This section will discuss the practical applications of ornamentation through analysis of precedents. These case studies give insight into the contemporary workflow adopted in this thesis as well as more detail as to the intricacies of Incremental Sheet Forming.

\section{Workflow case study}

The High Line 23 (HL 23) by Neil M. Denari Architects (NMDA) is an example of the current industry and tools available to construct contemporary architecture.

As one of the objectives of this thesis was to construct a full-scale prototype, this project gave insights as to strategies to make the prototype construction possible. Of particular importance in $\mathrm{HL} 23$ is the embossed panels on the east facade (Fig 21). These panels are the result of multiple iterations of material expression before the final choice was selected. The superficial condition of ornament enabled an openness in design that allowed the panel design to be decided independently from the structural considerations. Ultimately this allowed the materials expressing the ornament to be explored thoroughly, eventuating in successful communication of a 'fluid' ornamental surface defined in the brief (Kolarevic, Manufacturing Material Effects Rethinking Design and Making in Architecture, 278).

The facade development of $\mathrm{HL} 23$ began with a preference for cast concrete panels (Kolarevic, Manufacturing Material Effects Rethinking Design and Making in Architecture, 278). Prototypes of this idea were tested and found to lack the aesthetic qualities desired. Therefore, a shift to metal panels occurred. The metal panels were tested by A. Zahner Company in Kansas City. Here they 
《 Fig 16. A working digital model of the

structural steel fram

with digital diagrams (fa

left) illustrating structura

performance of framing

system.

》) Fig 17. CNC Machine

(Elumatec, made in

Germany) for 5 axis

tooling with capabilities

up to $8 \mathrm{~m}$ in length.

ل Fig 18. View of the

milled steel dies for the

stamped stainless-steel

rain screen panels for the

east facade. 
developed a range of folded origamilike panels which corresponded more closely to the desired effect. However, the design progressed further and settled on stamped panels that held a subtle surface undulation. These were produced by Dante Tisi using 3-dimensional CNC die milling (Fig 18). From here the embossed panels were arranged into mega-panels which contained groupings of three individually moulded panels ordered into four different configurations. Each panel was labelled on an atlas (Fig 19) to guide the construction of the mega-panels and prefabricated by Dante Tisi in their factory to allow for a close inspection of joint consistency and surface finish qualities (Marble, 36). The arrangement of panels created a field effect similar to an avantgarde garment, changing its visual quality as its body changes shape underneath

(Fig 21). This can be seen as a successful investigation by the architect into the "fluid" ornamental qualities prescribed at the beginning of the project.

The inclusion of sub-contractors with knowledge of digital fabrication techniques is increasingly common if the architecture firm has no experience in-house. HL 23 managed to produce a piece of architecture that maintained its original design intentions with accuracy standing as a testament to contemporary workflows. Neil Denari commented on his achievement noting, "It is rare that a building is built as it was designed without compromise" (Welch). This was, in part, due to the accuracy of digital fabrication machines and the resilience of a contemporary workflow this building implemented. While this was clearly a feasible approach to a contemporary workflow it should be noted that the 
《 Fig 19. Atlas of organised mega panels showing construction order and details
$\Downarrow \quad$ Fig 20. Construction of the East facade, installing the mega panels. 
prototype constructed in this thesis was fabricated with in-house machines.

Therefore, little outside contact was required, costing less and speeding up the fabrication process.

This case study highlighted the need for a flexible design program that did not limit design thinking in the early stages of design. Whatever design software that was used for the HL 23 project would need to compartmentalise each different design element so that their design communication, which is paramount to architecture, could be well established without sacrificing the efficiency of the project. It was decided from this case study that a program called CATIA would be most effective to communicate the design intent of the prototype.
今 Fig 21. HL23 east Facade showing embossed metal panels produced by a die stamping. 


\section{ISF Case Study}

Another project that illustrated the potential of metal forming for performative facade design is the research by Ammar Kalo and Michael Jake Newsum. In their paper, An Investigation of Robotic Incremental Sheet Metal Forming as a Method for Prototyping Parametric Architectural Skins, Kalo and Newsum explored the reality of using ISF to create architectural skins, discovering the limitations and benefits of such production. They make it clear ISF cannot compete in terms of mass production with the speed in which stamped panels are produced, or their extreme precision and low tolerances, however, the ability to produce mass customised components quickly was unmatched. ISF when compared to more traditional methods of spinning, deep drawing and stamping is notable for its' ability to prototype designs quickly and produce highly variable and cost-effective components (Kalo).

Kalo and Newsum identified and researched the inaccuracy of the forming process when cutting out forms from the sheet, adopting multiple strategies to overcome this deformation. These strategies included multiple passes over the same tool path, dual side incremental forming (DSIF) where two robotic arms operate from each side one as the positive forming head and the other as the negative mould; and the use of ribbing or structuring textures to add structural qualities to the sheet. The use of ribbing proved to be most effective at reducing spring back from $73 \mathrm{~mm}$ to $15 \mathrm{~mm}$ in one test (Fig. 23). Most significantly their research proved the viability of single point incremental forming as a technique to produce highly variable, double curved panels in sheet materials without the use 
of expensive forming dies (Kalo).

Kalo and Newsum tested a range of materials in their experimentation. The range of sheet metal included cold rolled steel, aluminium, copper and brass. Cold rolled steel was used in most of the forming as it was more ductile and strong when compared to other metals. This allowed for deeper extrusions to be made. The deeper the part, the more it would resist the spring back that occurred when cutting the form out of the sheet (Kreimeier et al.). Their research was tested with the creation of a performative system. This system was an aggregation of multiple panels overlapping the valleys and peaks before tack welding the surfaces together. The successful aggregation of the sheets allowed speculation on the production of high performance facade systems directly from digital models. This speculation fuelled the research for this thesis as ISF becomes the experimentation ground to develop a high-performance facade system.

The studies conducted by Ammar Kalo and Michael Jake Newsum provided a precedent towards our intent to use ISF. The study proved that ISF was a relevant field of research in contemporary architecture. Not only did this research provide a precedent but it provided a model to follow as to its intent to create a high-performance façade system. The choice to use cold rolled steel however was not adopted into our design approach, as aluminium proved to be lighter, hold a more attractive surface quality and be easier to handle. 
《 Fig 22. Performative facade,

an aggregation of multiple formed sheets tack welded together.

ヘ Fig 23. Research by Kalo and

Newsum illustrating the benefit of ribbing the sheets with a second pass reducing deformation 

Phase 1 - ISF Exploration 
To initiate the investigation, a team of four individuals was created. The team specialised in operating the IRB to achieve proficiency with it and construct an architectural prototype. Each member of this group had a different specialisation and task in the operation of the robot.

\section{Physical Realm}

The First Tools

Before our experimentation with ISF three elements needed to be prepared: the robot, the jig and the end effector. Since the robot was in place, the research progressed with the other two elements.

The first jig was designed by a team member and constructed by the team from plywood. The jig was a box milled by a CNC router with an open top to allow the sheets to be suspended. The top of the box was framed with plywood to allow the aluminium sheet to be clamped in place. This sheet was then sandwiched in place and bolted down to prevent any movement. There was a total of 10 bolts on each side that slotted through holes drilled in the aluminium sheet. To enhance the strength of the box, finger joints were used around the perimeter. This box was then attached to a steel framed table to raise the work level off the floor. The steel end effector was also designed and constructed by a team member from plywood and steel. It was crafted from two circles of plywood that made the facing plate. As the tools were experimental the inclusion of plywood material sped up construction and kept the costs down. A mild steel rod was milled by a Haas Lathe with a ball tipped head to form the end effector. This head, when sufficiently lubricated, could form the sheet metal. The head was attached
1) Fig 24. (Next page) Machining Cell with ABB Robotic arm fitted with incremental forming head and first jig set up for an operation. 


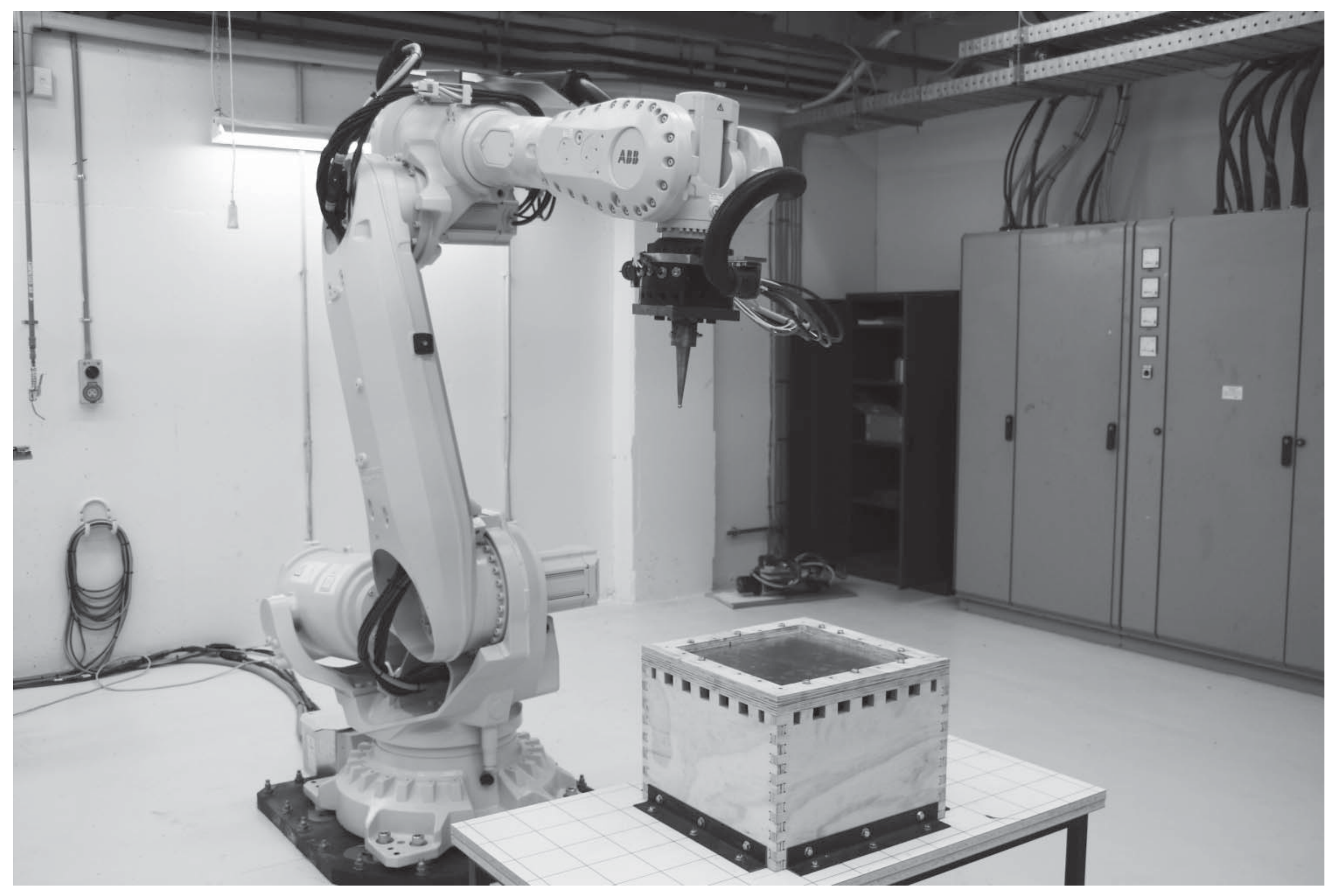


to the plywood facing plates with strong adhesive which was then bolted to the head of the robot. The creation of these tools allowed the first phase to begin.

\section{Digital realm} Operation through the Computer

After production of the hardware the digital process for creating forms needed to be addressed. As programming specialist, I headed the creation of the digital interface and performed all of the work in this area. The operating programs for the robot were created through a library of components called HAL, running through a program called Grasshopper. HAL was a purpose-made library that allowed the conversion of Grasshoppers visual coding into Rapidcode, the language that the robot operated through. What started as a 3D form in Grasshopper could then be translated into a toolpath, then points and planes where it would finally be organised into Rapidcode.

HAL also permitted the user to simulate operation of the robot in Rhinoceros 3D and check for errors in the code before running the operation. This reduced the time needed for manual troubleshooting and streamlined the robotic function.

\section{Testing}

The first batch of tests were to experiment with the potentials of form that could be created with our configuration.

This contained forms that were easily generated in Grasshopper through the loft component, merging two or more planar curves into a surface or volume. The first test involved a truncated cone that was contoured or sliced at $3 \mathrm{~mm}$ intervals. The success of this first test was encouraging, however fastening all the bolts took a significant period of time. To speed up the 

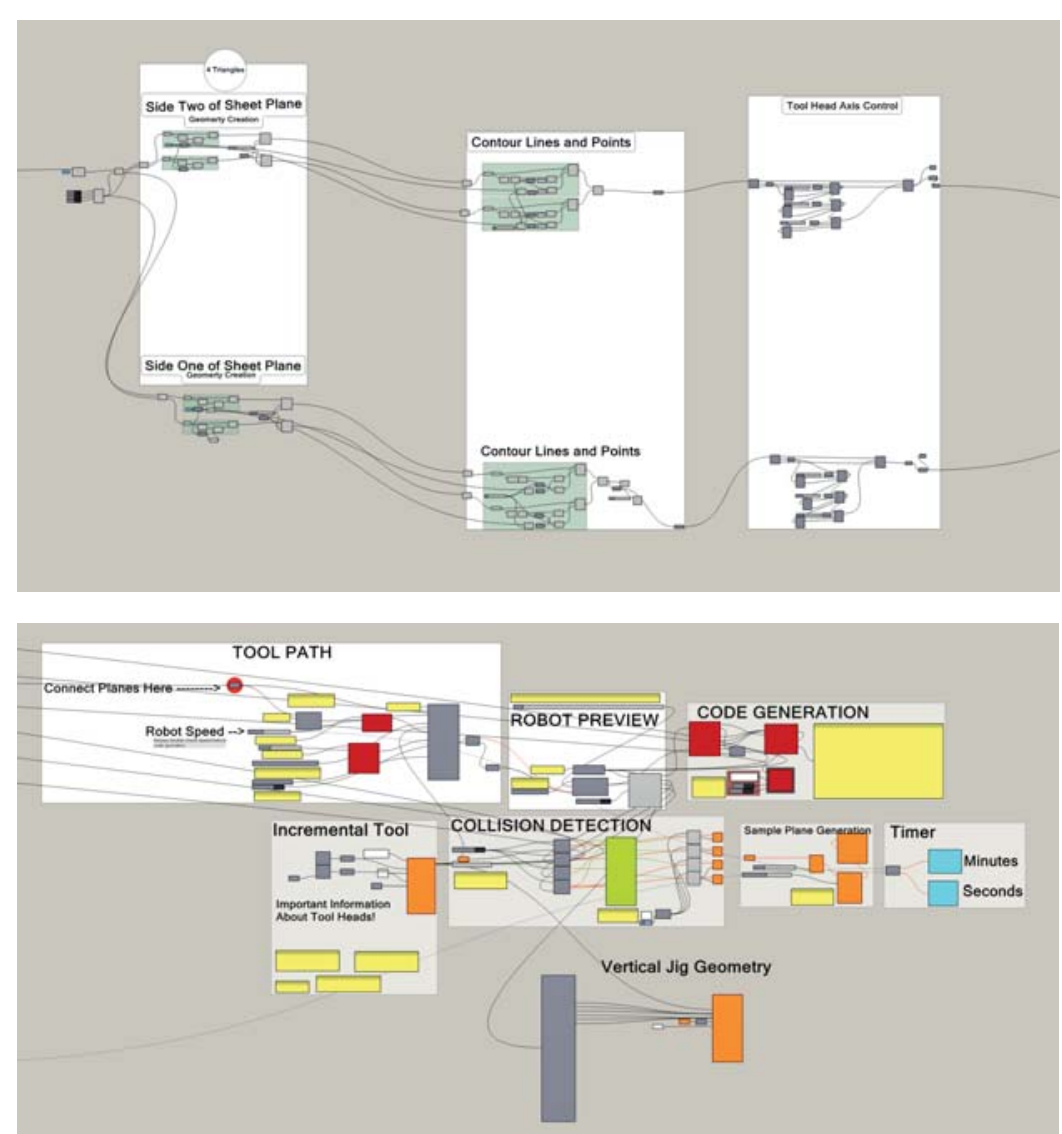

人 Fig 25. Hal components (Below) prepared to convert $3 d$ form

components (Above) into Rapidcode

ready for operation through robotic

\) Fig 26. Digital simulation of Machining Cell with ABB Robotic arm fitted with incremental forming head midway through an operation.

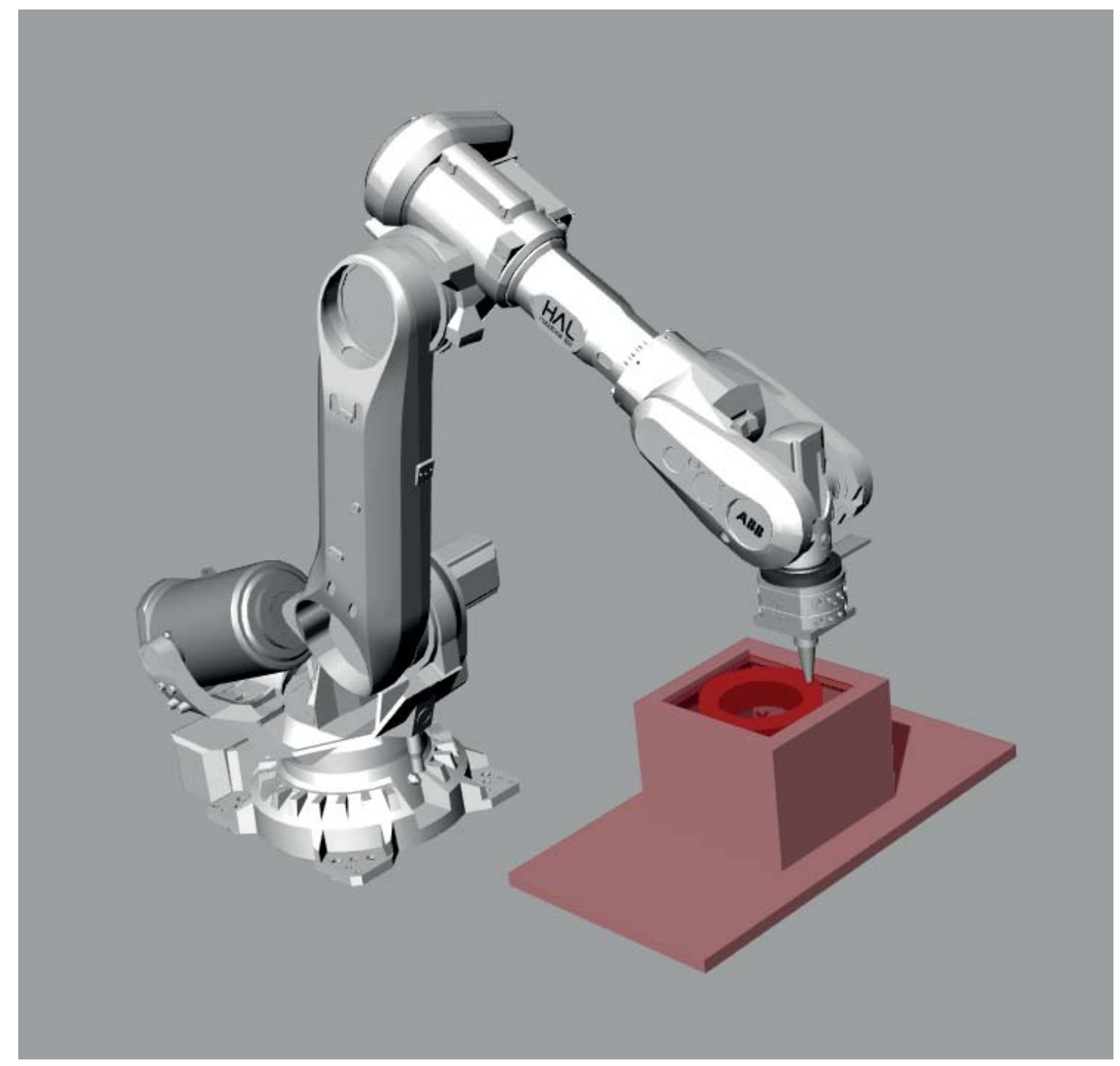


process on the second sheet every second bolt was fastened to fix the sheet in place. This consideration would later affect the design for the second jig. The second test was a loft from a rounded square to a circle sliced at $1 \mathrm{~mm}$ intervals. Another successful test confirmed the minimum number of fastenings which would adequately hold the sheet. The third and fourth tests comprised five polygon shapes extruded to reducing sizes. It was discovered from these tests that the method of setting up the points that the tool path follows is crucial to the definition of the shapes. Because the toolpath was defined by a division of the contour lines into a set number of points the corners often lacked points, hence the path would cut off an edge of the corner producing the uneven surface quality seen in Fig 31. This was remedied with a component that set points at the end of straight lines

\begin{tabular}{|c|c|c|c|c|c|c|c|}
\hline $\begin{array}{l}\text { Base } \\
\text { Shape }\end{array}$ & Description of Form & Pass/ Fail & $\begin{array}{l}\text { Material } \\
\text { Thickness }\end{array}$ & Depth & Increment & Speed & Angle \\
\hline 001 & Truncated Cone & Pass & 0.9 & $80 \mathrm{~mm}$ & $3 \mathrm{~mm}$ & $?$ & - \\
\hline 002 & Square to Circle & Pass & 0.9 & $120 \mathrm{~mm}$ & $1 \mathrm{~mm}$ & $?$ & - \\
\hline 003 & 5 voronoi & Fail & 0.9 & $?$ & $2 \mathrm{~mm}$ & $?$ & - \\
\hline 004 & 5 voronoi & Pass & 0.9 & $?$ & $0.2-0.8 \mathrm{~mm}$ & $?$ & - \\
\hline 005 & Square to Square & Pass & 0.9 & $120 \mathrm{~mm}$ & $2 \mathrm{~mm}$ & $?$ & - \\
\hline 006 & Square to Square & Pass & 0.9 & $160 \mathrm{~mm}$ & $2 \mathrm{~mm}$ & $?$ & - \\
\hline 007 & Sqaure to Square & Pass & 0.9 & $180 \mathrm{~mm}$ & $2 \mathrm{~mm}$ & $?$ & - \\
\hline 008 & Square to Square & Pass & 0.9 & $200 \mathrm{~mm}$ & $2 \mathrm{~mm}$ & $?$ & - \\
\hline 009 & blob & Fail & 0.9 & $?$ & $?$ & $?$ & - \\
\hline 010 & Bowl & Fail & $?$ & $120 \mathrm{~mm}$ & $1 \mathrm{~mm}$ & 200 & - \\
\hline 011 & Bowl & Pass & $?$ & $120 \mathrm{~mm}$ & $1 \mathrm{~mm}$ & 200 & - \\
\hline 012 & Bowl & Pass & $?$ & $120 \mathrm{~mm}$ & $0.5 \mathrm{~mm}$ & 200 & - \\
\hline 013 & Bowl & Pass & $?$ & $120 \mathrm{~mm}$ & $4 \mathrm{~mm}$ & 200 & - \\
\hline 014 & Bowl & Fail & $?$ & $120 \mathrm{~mm}$ & $1 \mathrm{~mm}$ & 200 & - \\
\hline 015 & Dome & Pass & $?$ & $100 \mathrm{~mm}$ & $1 \mathrm{~mm}$ & 240 & - \\
\hline 016 & Hexagon & Pass & $?$ & $?$ & $?$ & $?$ & - \\
\hline 017 & Dome & Fail & 1.2 & $120 \mathrm{~mm}$ & Exponential & $?$ & - \\
\hline 018 & Hexagon & Fail & 1.2 & $?$ & $?$ & $?$ & - \\
\hline 019 & Truncated Cone & Pass & 1.2 & $60 \mathrm{~mm}$ & $1 \mathrm{~mm}$ & 120 & 30 \\
\hline 020 & Truncated Cone & Pass & 1.2 & $60 \mathrm{~mm}$ & $1 \mathrm{~mm}$ & 120 & 45 \\
\hline 021 & Truncated Cone & Pass & 1.2 & $60 \mathrm{~mm}$ & $1 \mathrm{~mm}$ & 120 & 60 \\
\hline 022 & Truncated Cone & Pass & 1.2 & $60 \mathrm{~mm}$ & $1 \mathrm{~mm}$ & 120 & 70 \\
\hline 023 & Truncated Cone & Fail & 1.2 & $60 \mathrm{~mm}$ & $1 \mathrm{~mm}$ & 120 & 80 \\
\hline
\end{tabular}

人 Fig 27. Table of Tests conducted. ? means no data was recorded 

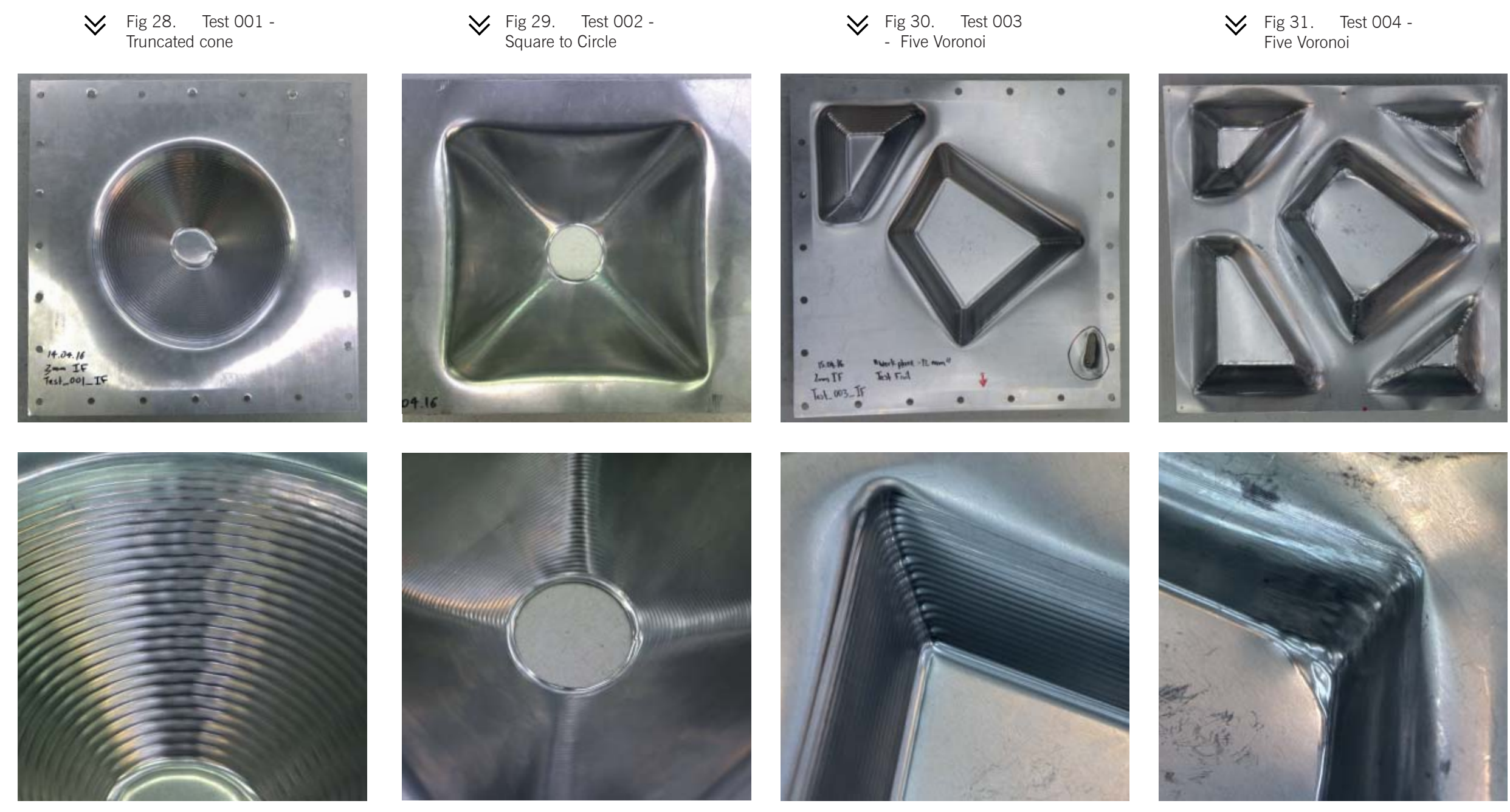
$\Downarrow$ Fig 32. Test 005 -

$0 \mathrm{~mm}$ deep Square
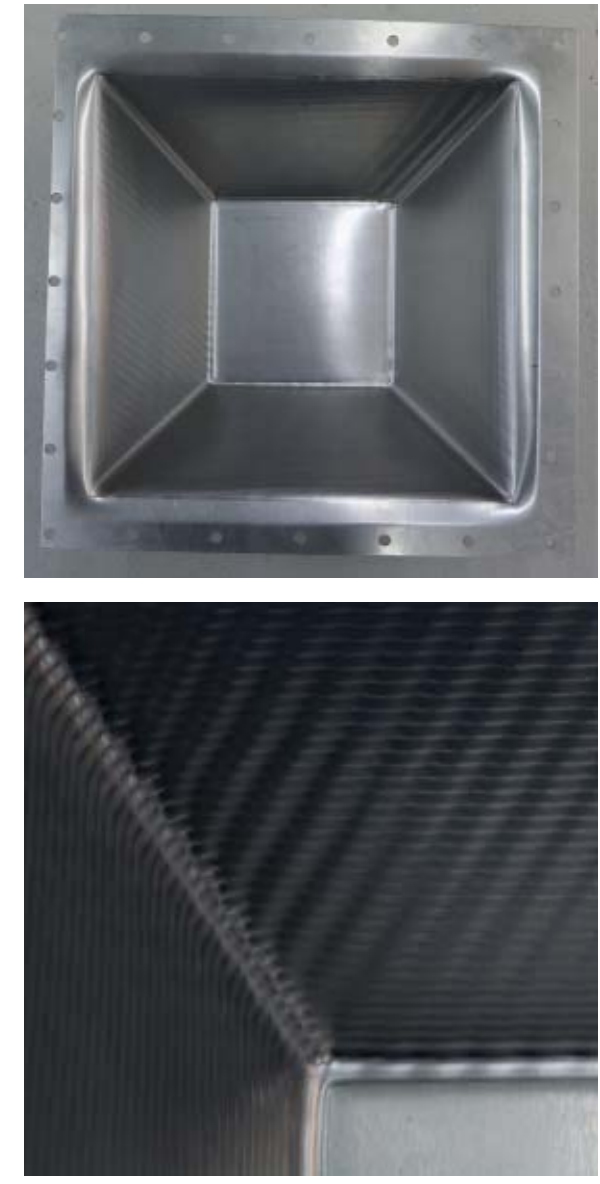

$\Downarrow \quad$ Fig 33 . Test 006 -
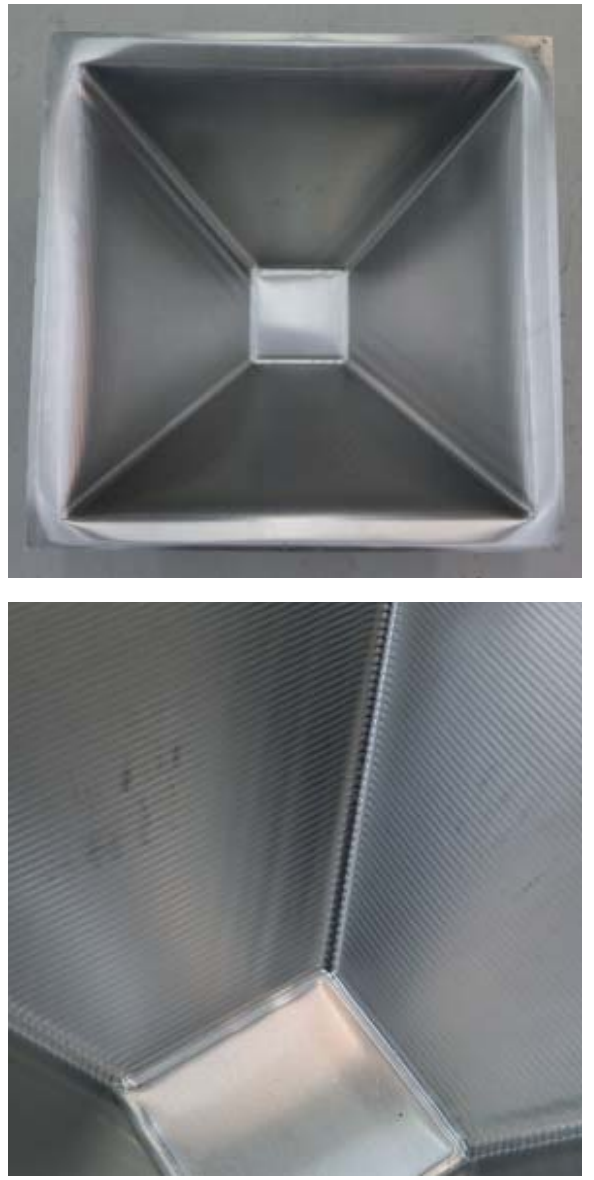

$\Downarrow \quad$ Fig $34 . \quad$ Test 007
$180 m m$ deep Square
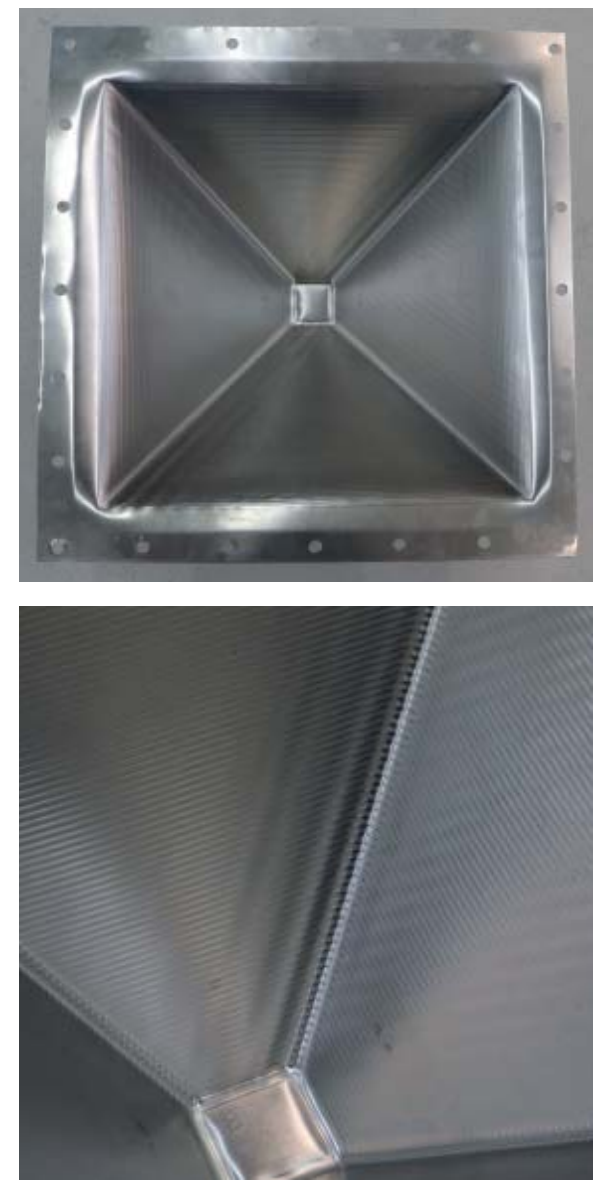
$\Downarrow \quad$ Fig $35 . \quad$ Test 008 -
200mm deep Square
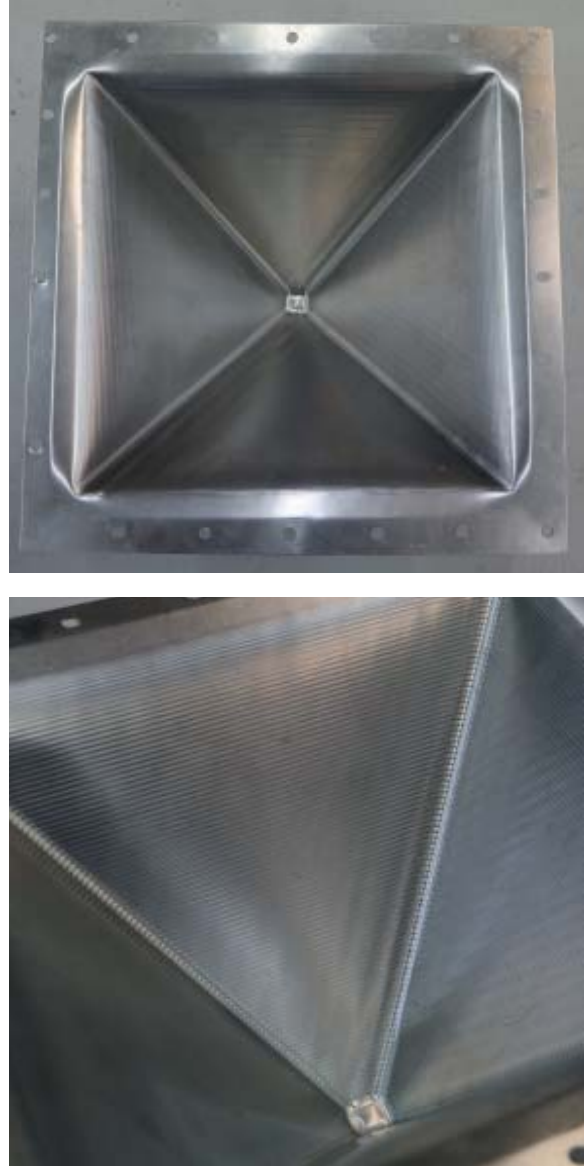

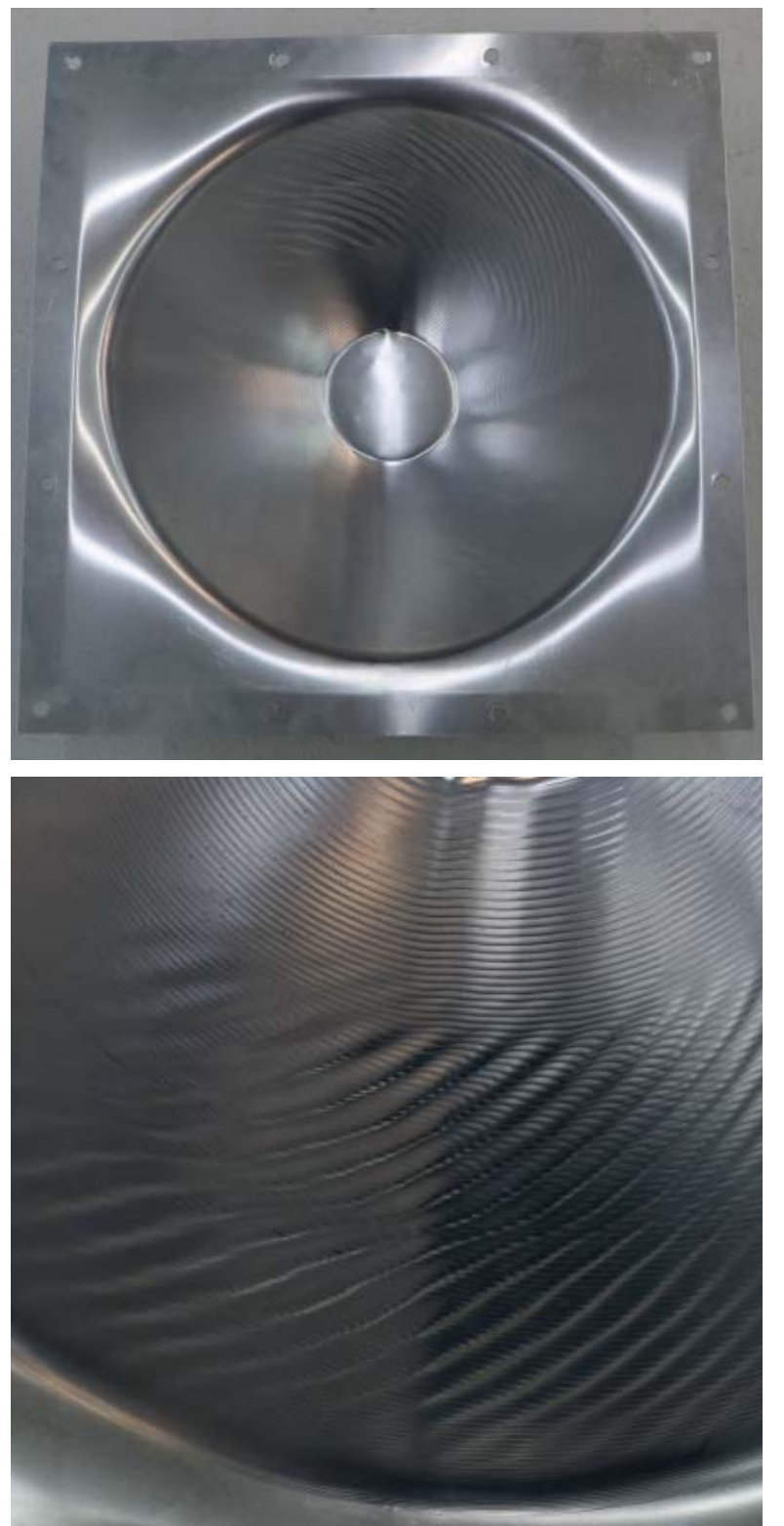

$\Downarrow \quad$ Fig 37. Test 012

- $0.5 \mathrm{~mm}$ Increment Bow
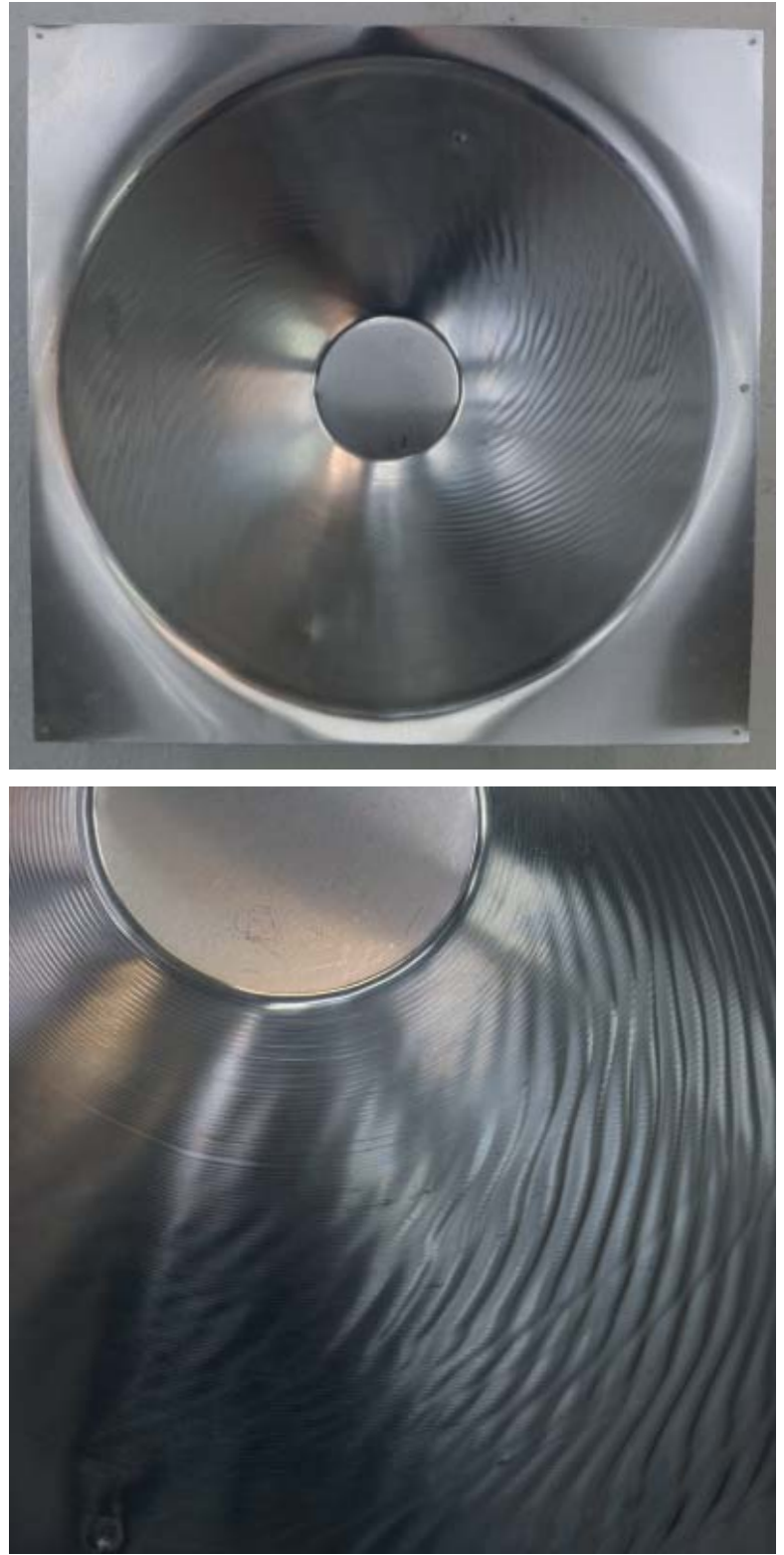

$\Downarrow \quad$ Fig 38. Test 013 $4 \mathrm{~mm}$ Increment Bow
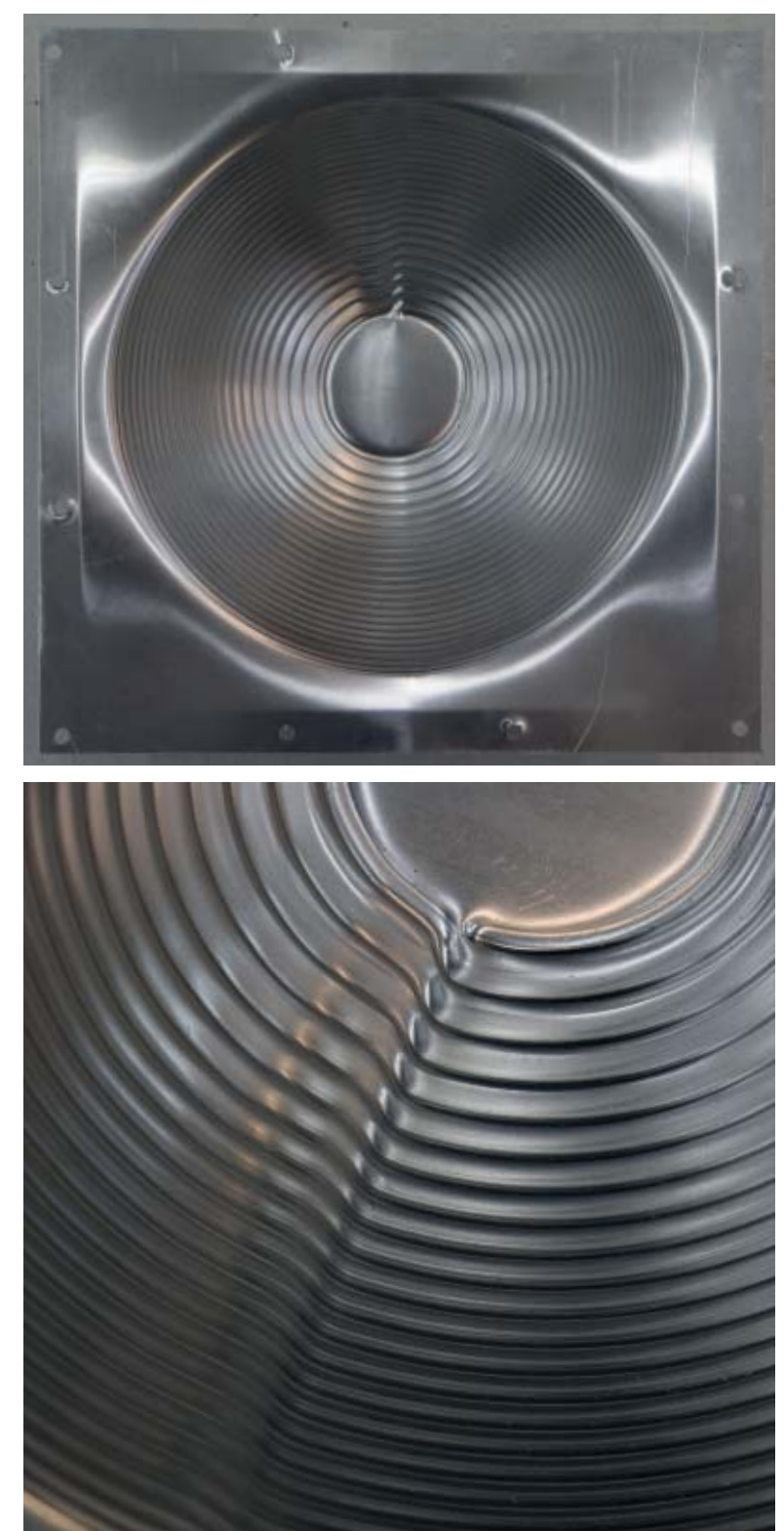
rather than dividing the line evenly.

The second batch of tests was designed to test the maximum depth the aluminium sheets could extrude to. All tests were run at $2 \mathrm{~mm}$ increment on $0.9 \mathrm{~mm}$ thick aluminium sheets. The depths tested were from $120 \mathrm{~mm}$ to $200 \mathrm{~mm}$. None of the tested sheets failed so it was concluded that depth was not a limiting factor to the sheet forms as $200 \mathrm{~mm}$ was deeper than any conceivable design. However, it was established from this series that while depth may not be an issue the angle of the extruded shape may cause local failures in the sheet.

The third set of tests were designed to test the maximum and minimum slicing or stepping increment. The increment variable was determined by the contour component in grasshopper which sliced the surface into even, defined increments. While other investigations into ISF have managed to develop toolpaths scripts which overcome the limitations of contouring the forms, contouring proved the most effective means available for us to communicate the forms with our limited (at this stage) knowledge in scripting. The limitations of using the contour component was that every revolution of the desired shape held a step down in the metal which produced a visible line most clearly seen in Fig 38. Contours from $0.5 \mathrm{~mm}$ to $4 \mathrm{~mm}$ were tested in this batch. The testing was concluded at a minimum depth of $0.5 \mathrm{~mm}$ as going beyond this increment would produce little to no difference in the physical output. The maximum depth was capped at $4 \mathrm{~mm}$ when the likely depth of contouring was surpassed. This was a means to speed up the testing and avoid 
$\Downarrow \quad \begin{array}{ll}\text { Fig 39. Test } 019 \\ \text { Truncated Cone } 30^{\circ}\end{array}$
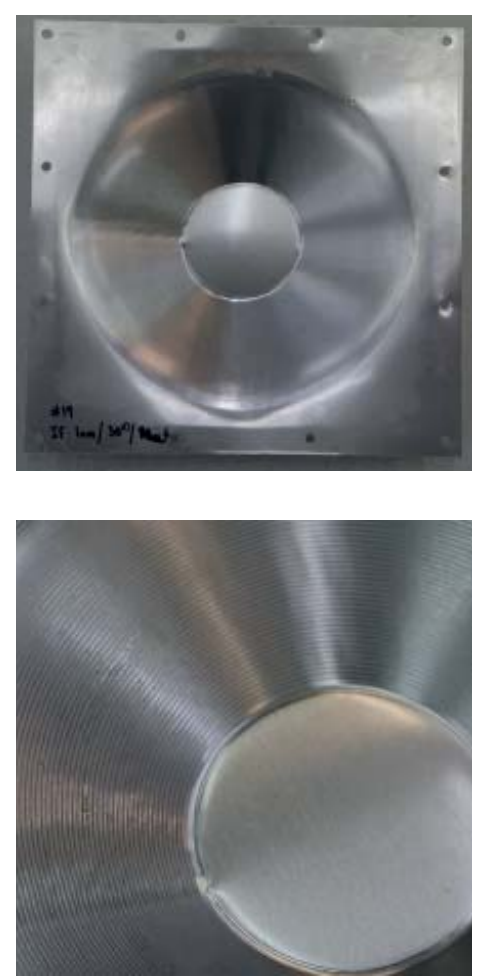

Fig $40 . \quad$ Test $020-$
Truncated Cone $45^{\circ}$
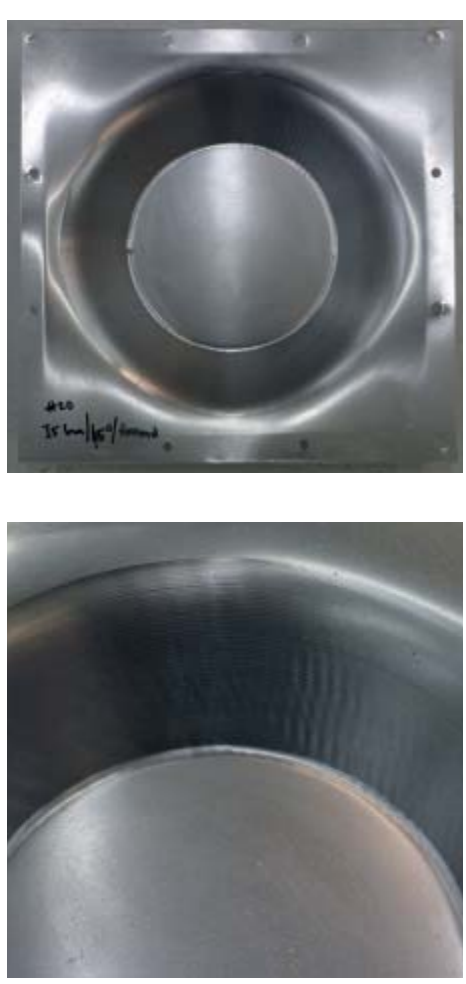

$\Downarrow \begin{aligned} & \text { Fig } 41 . \quad \text { Test } 021 \\ & \text { Truncated Cone } 60^{\circ}\end{aligned}$
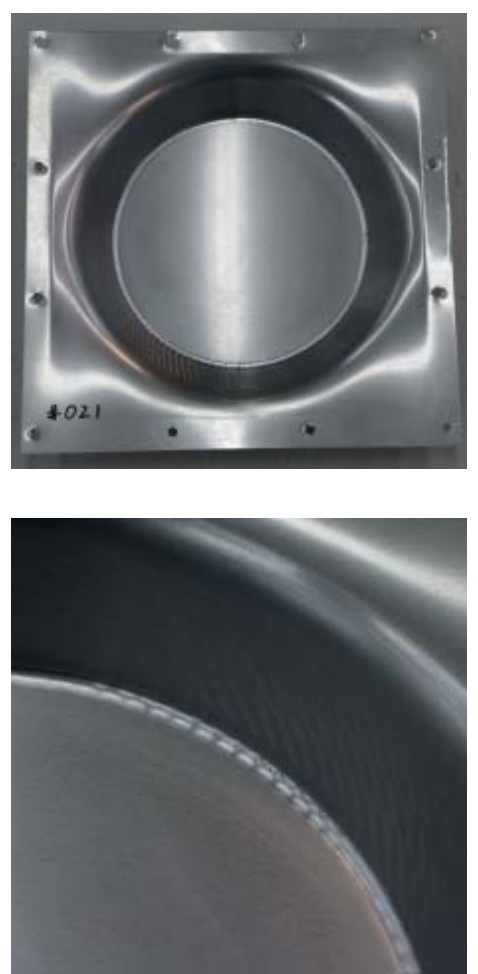

$\Downarrow \begin{array}{ll}\text { Fig } 42 . \quad \text { Test } 022 \\ \text { Truncated Cone } 70^{\circ}\end{array}$
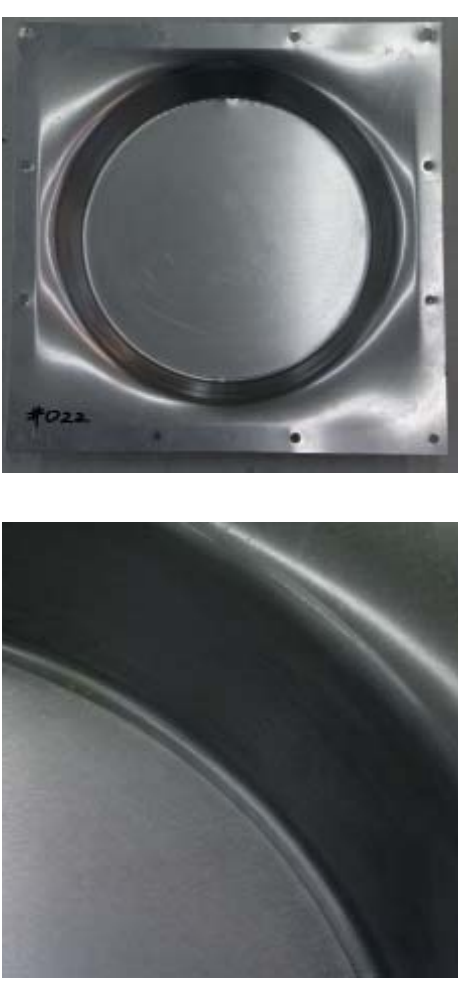

$\Downarrow \quad \begin{array}{ll}\text { Fig } 43 . \quad \text { Test } 023- \\ \text { Truncated Cone } 80^{\circ}\end{array}$
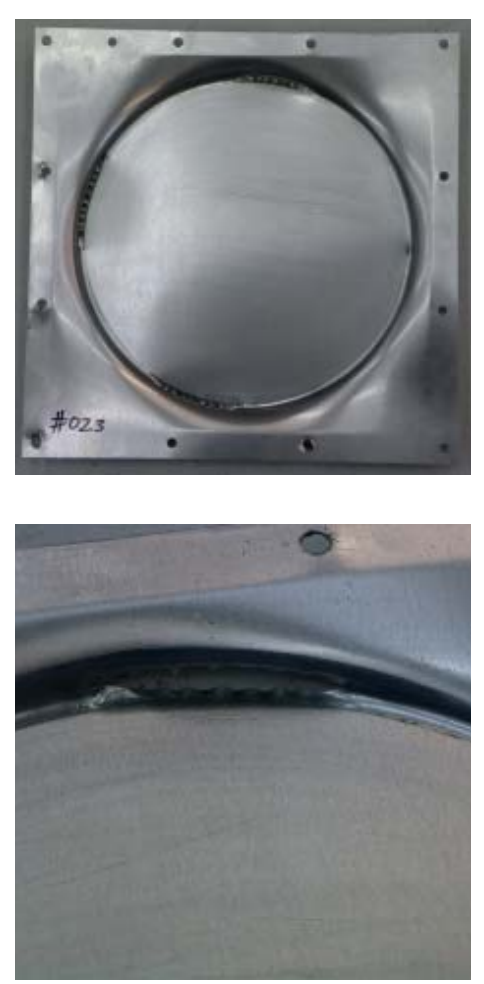
excessive wastage of test sheets. These tests produced interesting surface qualities in localised areas of the sheets that looked like waves in the sheets surface. There were a few theories to explain these waveforms, the most likely being that the movement of the robot in certain areas equalled the resonance of the table (holding the jig) producing a juddering in the tool head that formed notable waves on the sheets surface.

The fourth batch of studies involved the angle of extrusion. These tests produced five different sheets extruded at $30^{\circ}, 45^{\circ}$, $60^{\circ}, 70^{\circ}$ and $80^{\circ}$. This study identified that sheets can be formed all the way up to $70^{\circ}$ before they failed. After this test it was decided to test the reliability of the jig to see whether there was any degradation in the jig that would cause in discrepancies. Therefore six sheets holding a grid of nine hexagonal extrusions were created to see if there was any differences between the first and the last extrusion confirming the reliability of the configuration. It was concluded from this test that the jig and tool head created consistently similar sheets over time. This concluded the first phase of testing where time was spent reviewing the progress to determine the next phase of the study.

\section{New operations}

It was noted that the forming tests left a permanent trace of the toolpath. This toolpath trace was a desirable quality because it left a memory of the path that formed the extruded shape adding to the poetic nature of the ornament. To enhance the effect, a second tool head was developed to inscribe the surface of the sheet leaving a purposeful marked toolpath. This new end effector was 
$\Downarrow \quad$ Fig 44. Test scribe -
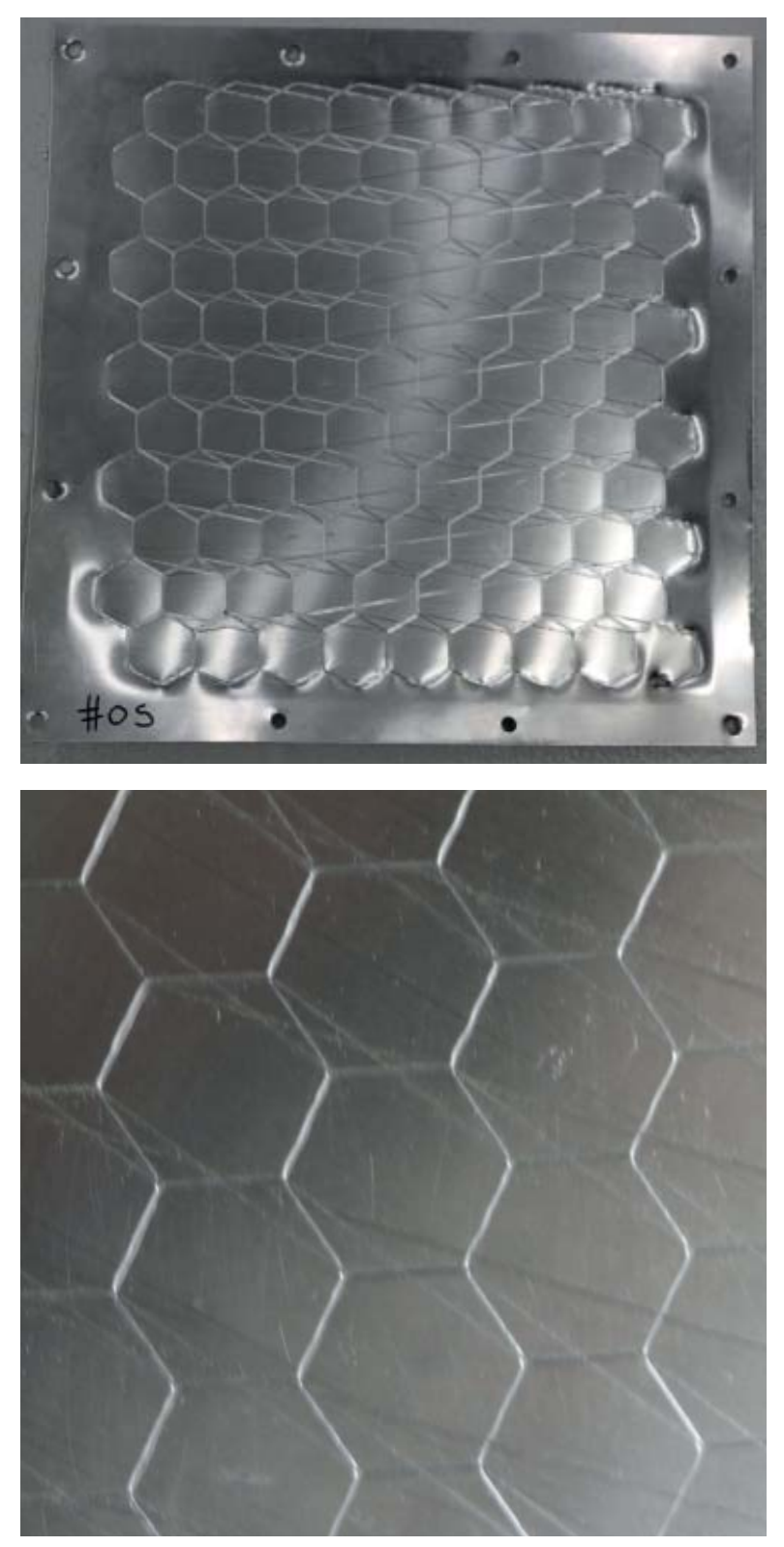

$\Downarrow \quad$ Fig 45. Test punching Punched Holes
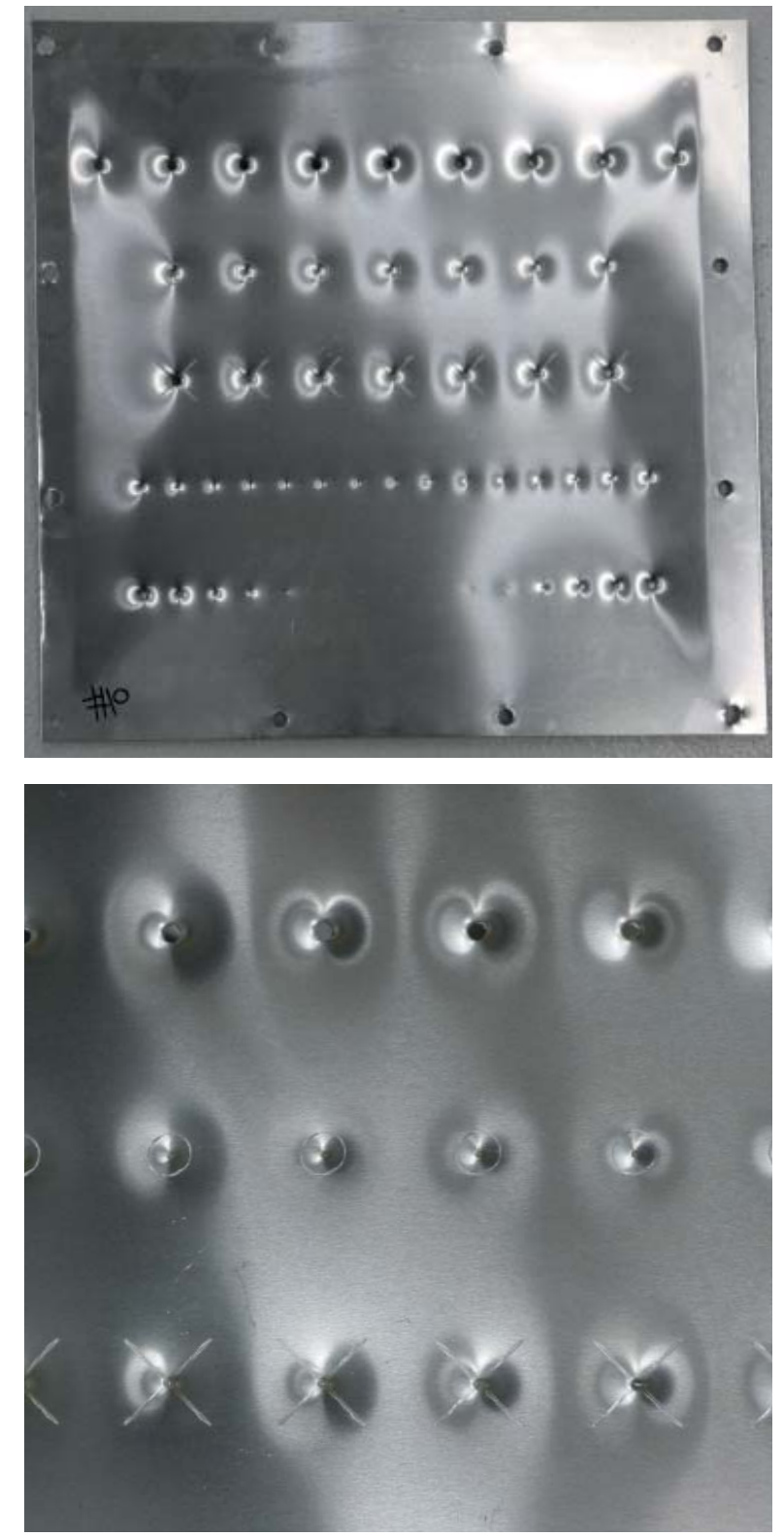

$\Downarrow$ Fig 46. Test forming Hexagon Grid
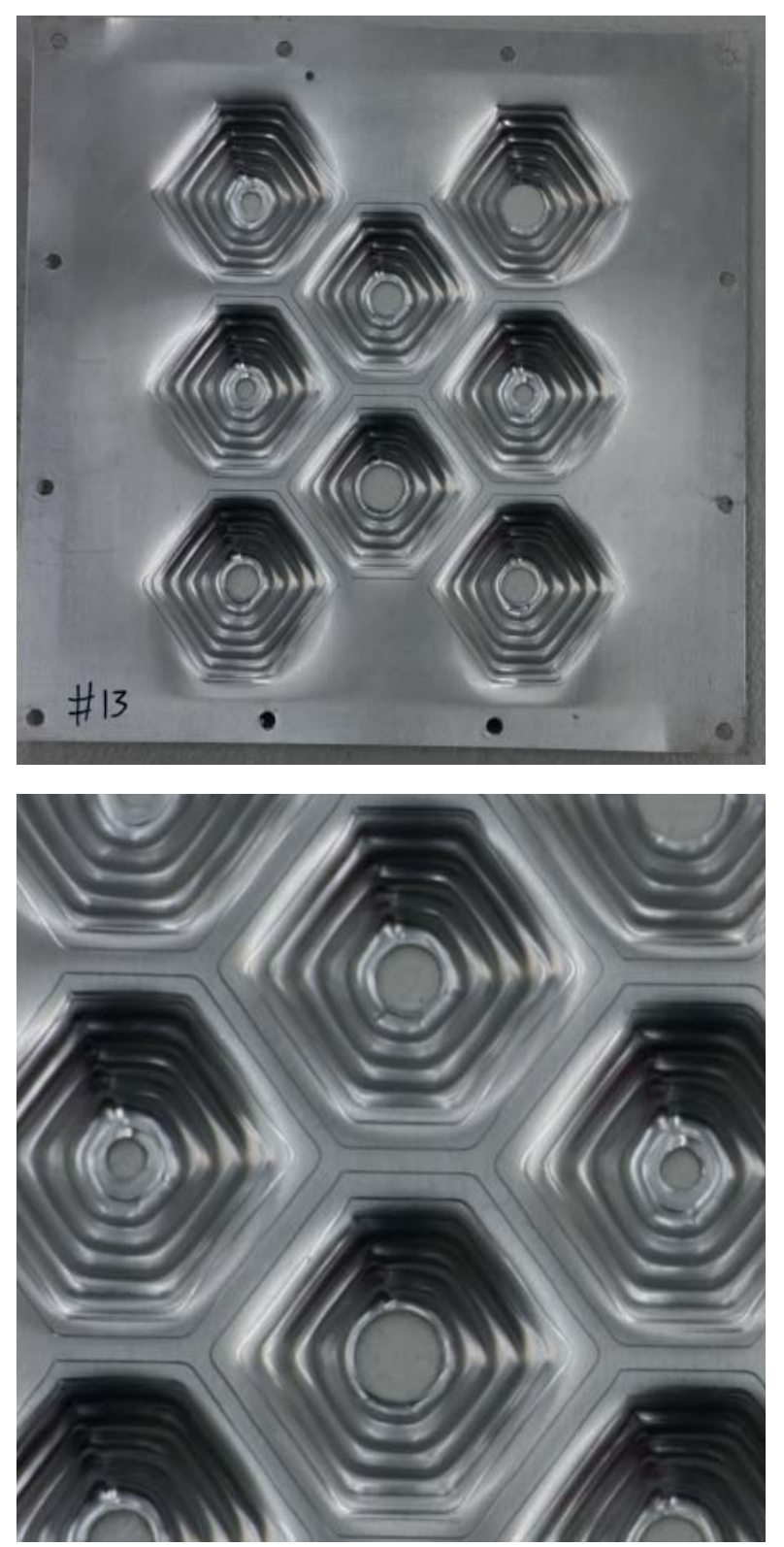
known as the scribe head. This new head created two new operations for the robotic arm: scribing and punching holes. Scribing proved to be a novel and effective method of imbuing the sheet with interesting surface qualities. However, perforating the sheet, while effective, made it difficult to control the degree of sheet distortion. Ultimately this meant perforation would not be considered when creating the prototype.

\section{Conclusion}

Phase one of the research defined the guiding parameters that would inform the creation of the prototype. These parameters would be inserted into the Grasshopper definition that outputted the robotic operations as limiting factors to help the design process. Local failures of the sheet metal set up the limitations of the sheet forming to be converted into parameters for the future projects. One success of this phase was the ability to determine parameters from empirical investigations and feed these values back into the digital interface. This was defined as the feedback loop which helped make each new iteration more considered and functional.

Empirically exploring the limitations of the ISF process through machine, material and programming parameters allowed for a more robust, designed Grasshopper script that was part of the investigative feedback loop. The script was reprogrammed with these parameters allowing the focus of the work to be on the design rather than the physical limitation of the material or the manufacturing environment. 


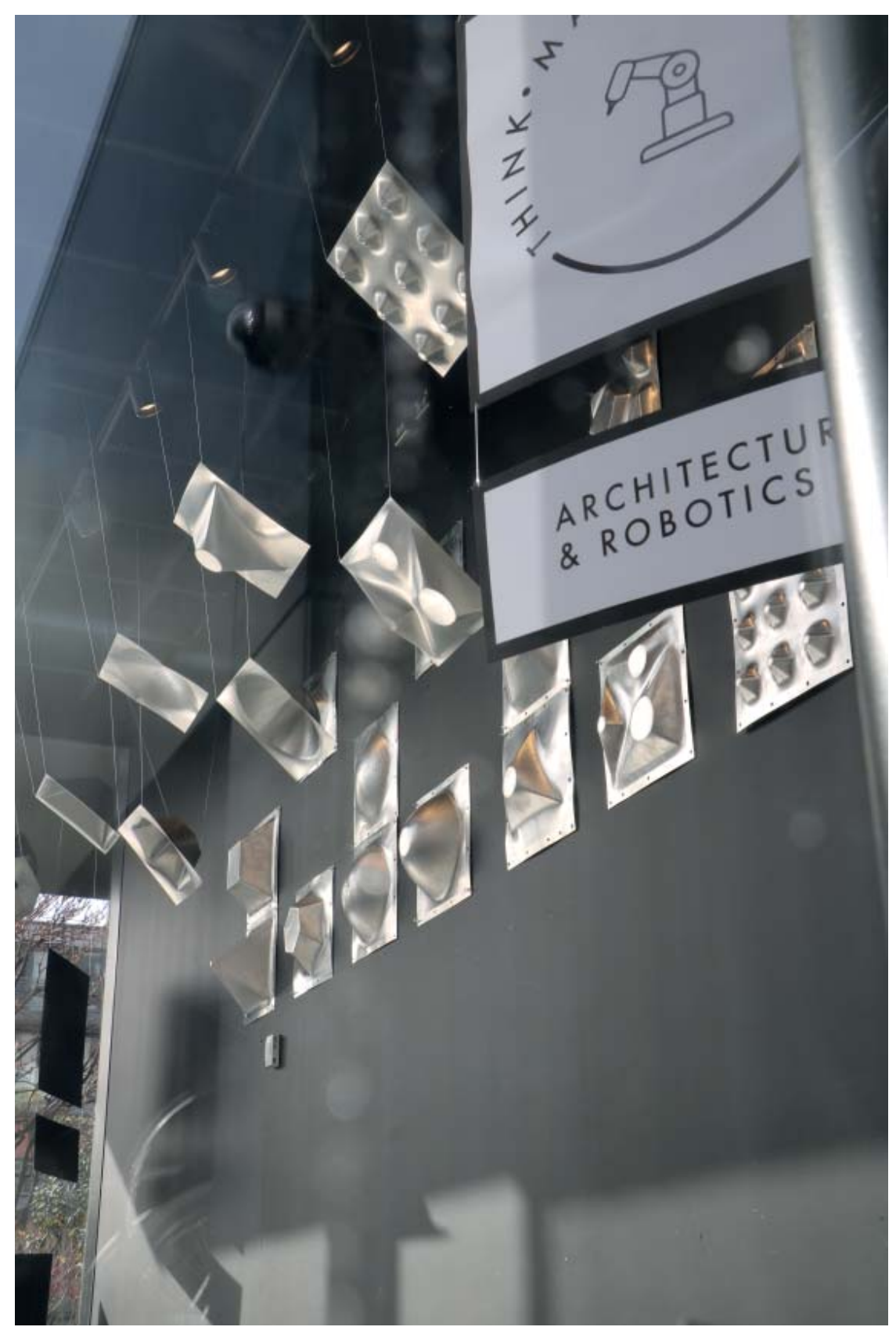

《 Fig 47. (Left) Think

7 presentation from outside

(Top, Right) Exhibition

」 presenting incrementally illustrating a potential

configuration for practical

application (Bottom,

Right) array of metal

Right) array of meta
sheets from inside
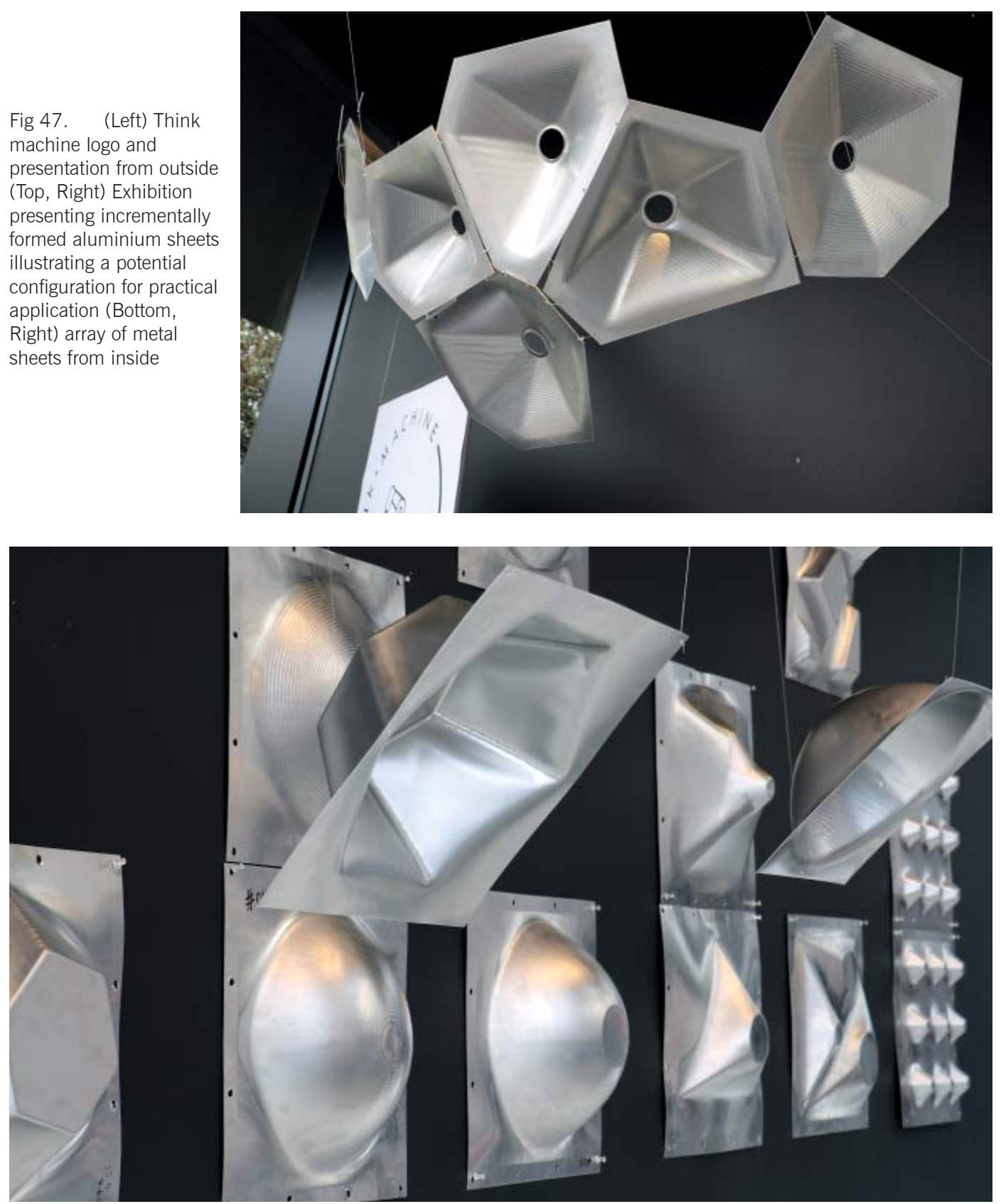

Phase 2 - Prototyping 


\section{Design Sessions}

The design of the prototype started out with group discussions to set up the brief. It was decided that the final output should function as a sunshade because a potential client needed one. From the client's requirements, the brief was augmented to be a self-supporting "proof of concept", taking into account all of the lessons learned from the initial explorations. Other specifications considered to be important were the ability to perform as a lightweight structure, cheap manufacture and rapid construction. The final condition and arguably the most important for this thesis was that it communicated a parametrically articulated fully customised ornamentation. From this point, the dimensions of the project's floor area were considered. It was decided that the pavilion should not exceed the limits requiring a building consent. Therefore, the limit of a $10 \mathrm{~m} 2$ for a single storey dwelling was applied.

The tools from the exploration phase of the project were designed to produce $400 \mathrm{~mm} \times 400 \mathrm{~mm}$ sheets. When considering the number of sheets required to cover an area of $10 \mathrm{~m} 2$ it was decided that the sheet size for the pavilion needed to be increased in order to reduce the number of individual sheets. The original sheet size was increased to $1200 \mathrm{~mm} \times 400 \mathrm{~mm}$ from $400 \mathrm{~mm} 2$. This meant that six sheets could be cut from the manufacturer sheet $(2400 \mathrm{~mm} x$ $1200 \mathrm{~mm})$. This sheet size was deemed the maximum size possible before the deformation incurred on the sheet became too significant. This larger size would ultimately mean less joinery would be needed resulting in an economic design. The increased sheet size meant that an 
additional jig needed to be constructed, allowing opportunity to incorporate the lessons learnt through exploration.

\section{Configuration for Prototype}

Given the success of the last jig, the new jig was constructed (with group consultation by a team member) from plywood to the new dimensions of $1200 \mathrm{~mm} \times 400 \mathrm{~mm}$. The same framing system was used with a slightly revised clamping method. Ten perimeter bolts were used that slotted through the metal sheet while another six bolts clamped the wooden frame directly to the jig box. This was a significantly reduced number of bolts from the original jig which allowed panels to be produced faster. Having built the second jig, it was ready for testing. The preliminary tests illustrated that the sheet underwent significant deflection near the centre of the sheet. This was undesirable and so two braces were designed to be added to the centre of the sheet. This kept surface tension on the sheet while only minimally reducing print area.

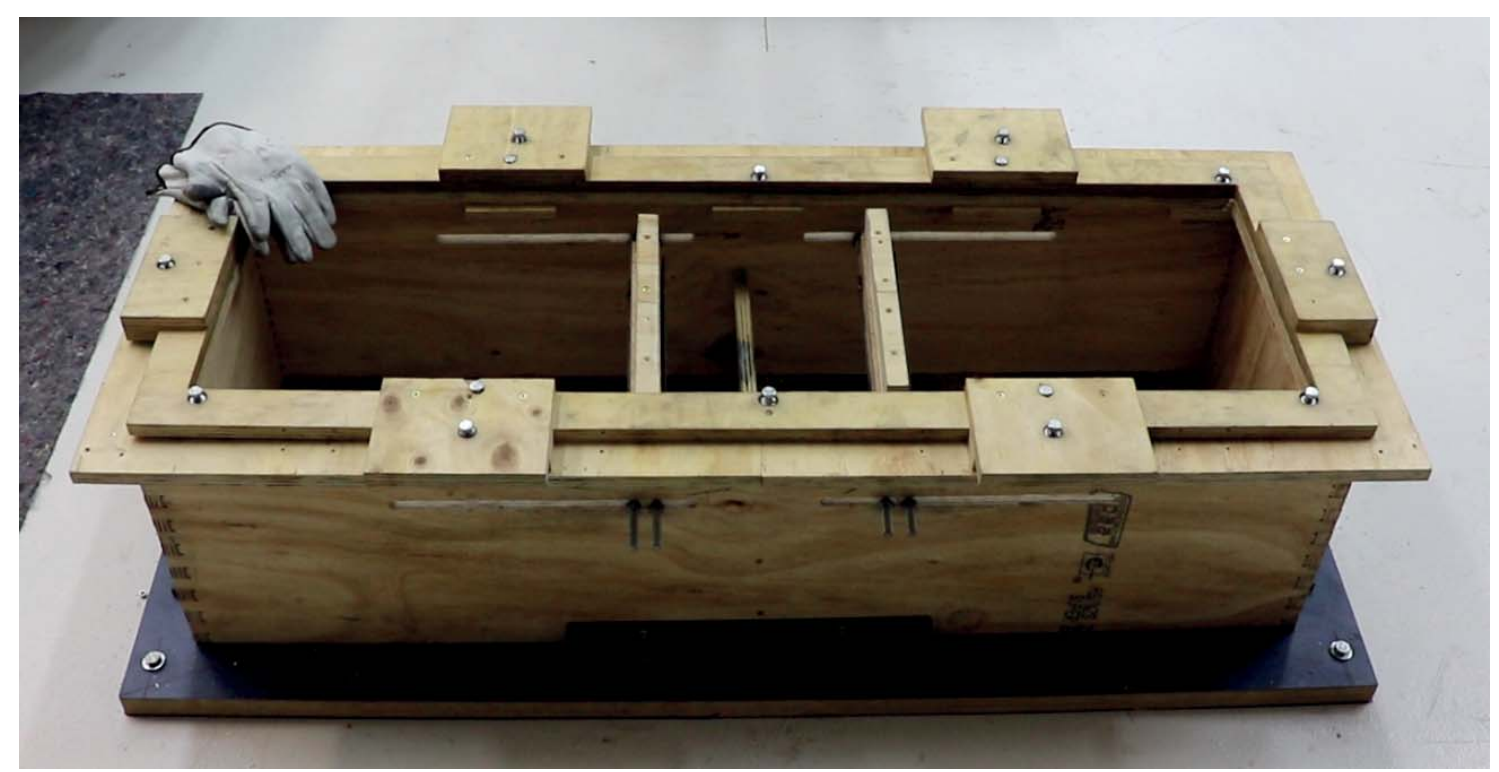

Fig 48. Second jig showing

bolted frame and two supporting

braces which were an addition to the original design. 


\section{Constructing a Prototype}

The panels required a significant number of modifications from flat sheets to

become structurally performative. It was decided that the operation of folding could limit the deflection of the sheet and add structural integrity. If folded twice the sheet size could effectively be reduced from $1200 \mathrm{~mm} \times 400 \mathrm{~mm}$ to three parts of $400 \mathrm{~mm} 2$. Folding was tested on multiple sheets to determine the feasibility and benefit of the operation (Fig 49).

From this point, the team took design into physical modelling. After this phase I took control of the design through 3D digital modelling in Rhinoceros 3D where it could be decided how the folds could best communicate the bespoke nature of the sheet design. The whole team worked together in the fabrication of the prototype.

It was determined that two folds would

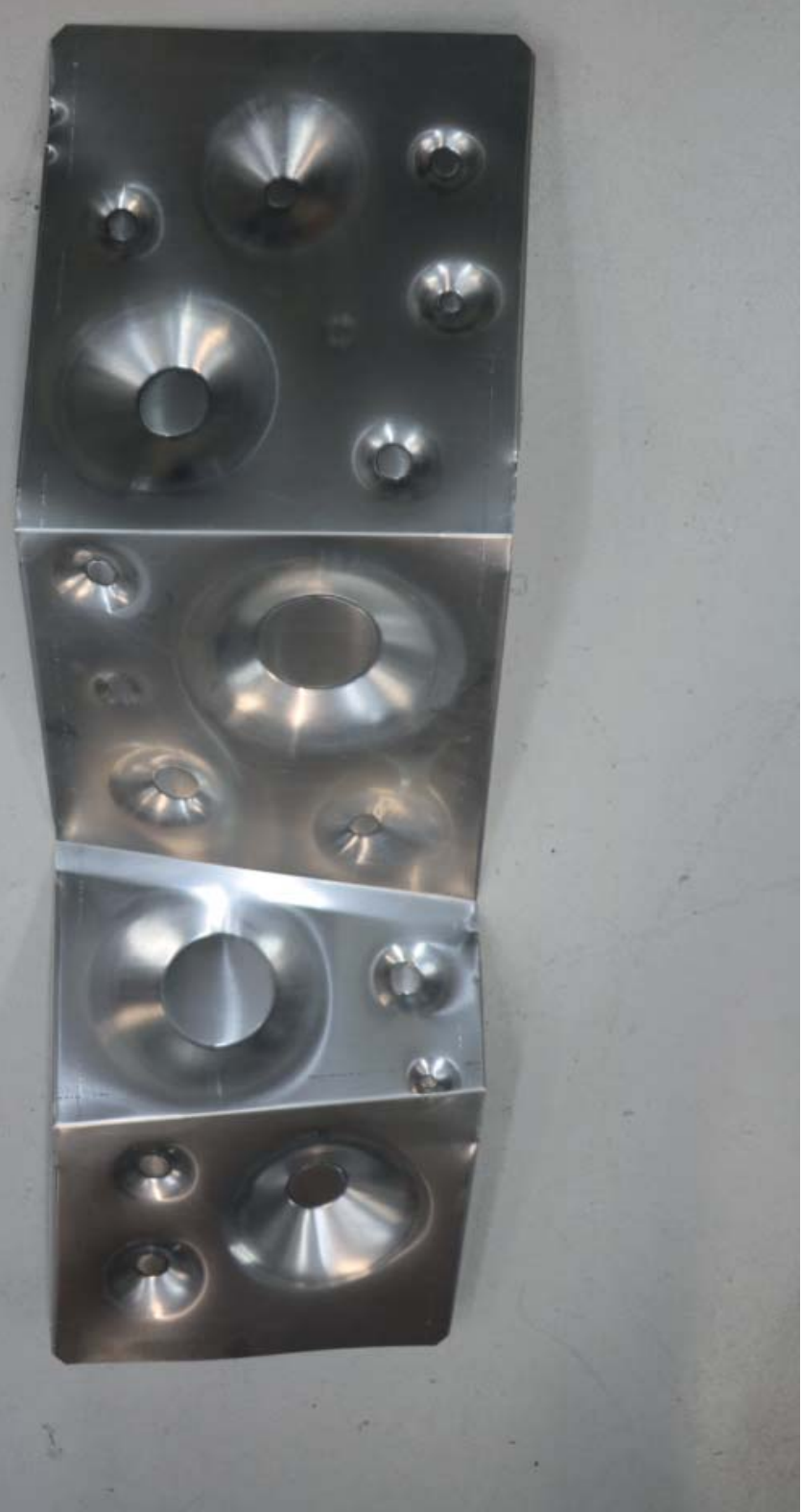




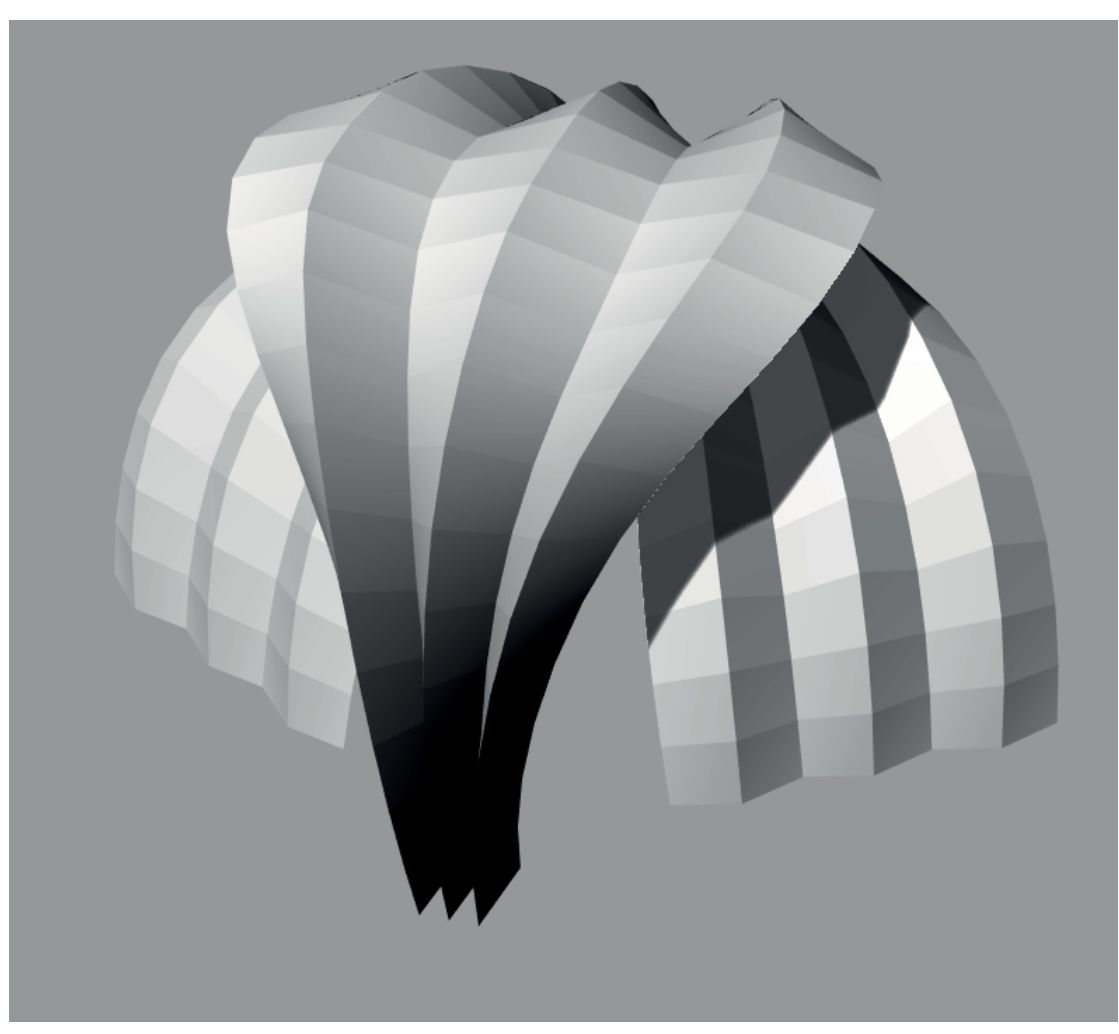

^ Fig 50 Preliminary static

Rhinoceros 3D model exploring

different numbers of folds in the

large sheets.

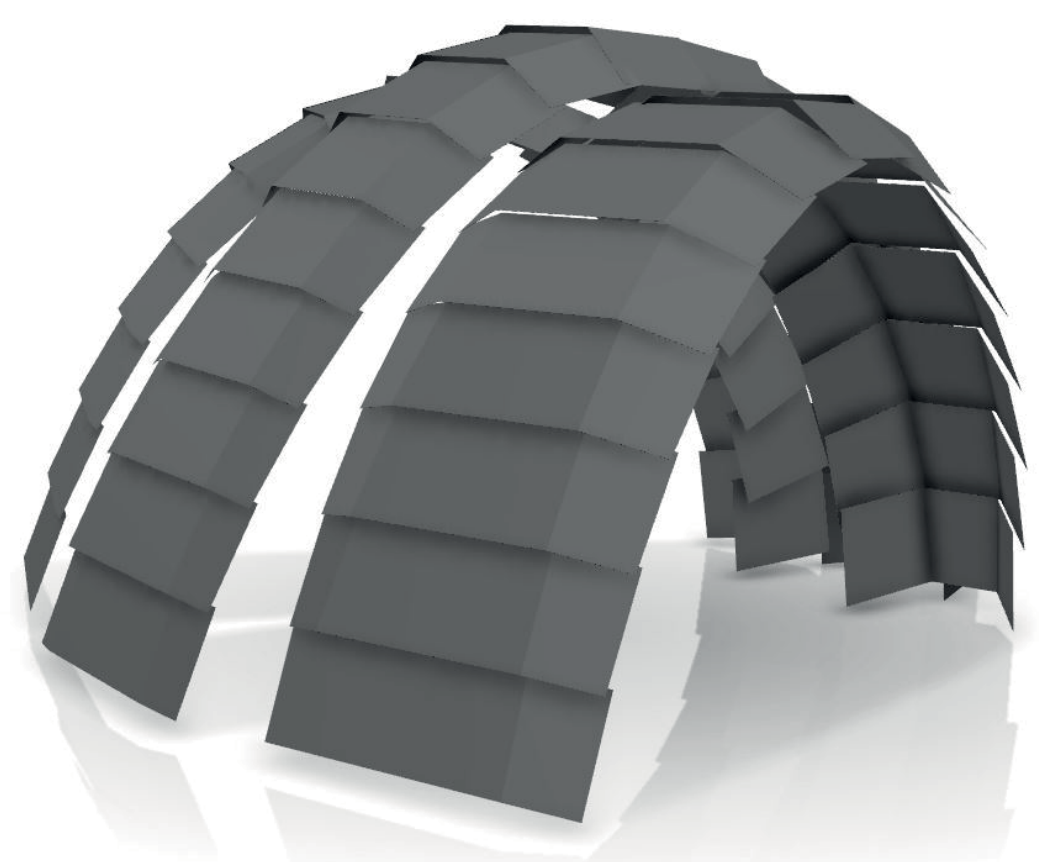

入 Fig 51 Resolved CATIA parametric model illustrating three parametric model illustrating three
separate structures with folded panels 
improve the rigidity of the sheet enough to transform the raw material into structurally performative architecture and not limit the design significantly. This number of folds would work effectively with the bracing developed in the jig so that each fold line could be supported underneath (Fig 48). From this point the design was transferred into CATIA (by a team member), a parametric software, to help realise the design. The parametric nature of the software allowed each design decision to be added sequentially to the model. This allowed the project to separate into the different design components that would constitute the final design. These components were first the panel design (designed and fabricated by myself), second the joinery (completed by a team member) and last the footing (completed by the group). To initiate panel design, decisions were made by analysing the brief. To permit some sun to enter through the canopy it was decided that these sheets needed some form of aperture. The limiting design factor for the apertures were the techniques available to create holes in the sheets. The most effective method available for creating holes was drilling discovered through testing different tools such as tinsnips and hole punches. Formwork on the sheets now had to compliment both the fold in the sheets and the apertures.

Through ISF Exploration it was thought that the sheets strength increases from extruding the panels. This has been confirmed by Paul Nicholas et al whose research involved similar investigations into ISF. This research noted an increase of strength from 220 to $410 \mathrm{MPa}$ in low carbon steel after forming. Using the parameters defined in ISF Exploration, 
the forms on the sheets were chosen to be triangular extrusions tessellated on the surface. This was chosen as tessellated triangles cover a large amount of surface area. The more surface area formed over the sheet would mean more rigidity to the whole of the structure. The aesthetic of the triangle was chosen as it has connotations of strength and rigidity. Another defining parameter of the formwork on the sheets was decided by the circular apertures. Because the holes had to be circular the extrusion had to morph from a triangular shape to a circular one where the holes were present (Fig 54,55 ).

The step to digitising the sheet designs involved importing the folded sheets from CATIA and ordering them into layers in the Rhinoceros 3D model this was conducted by myself to maintain control

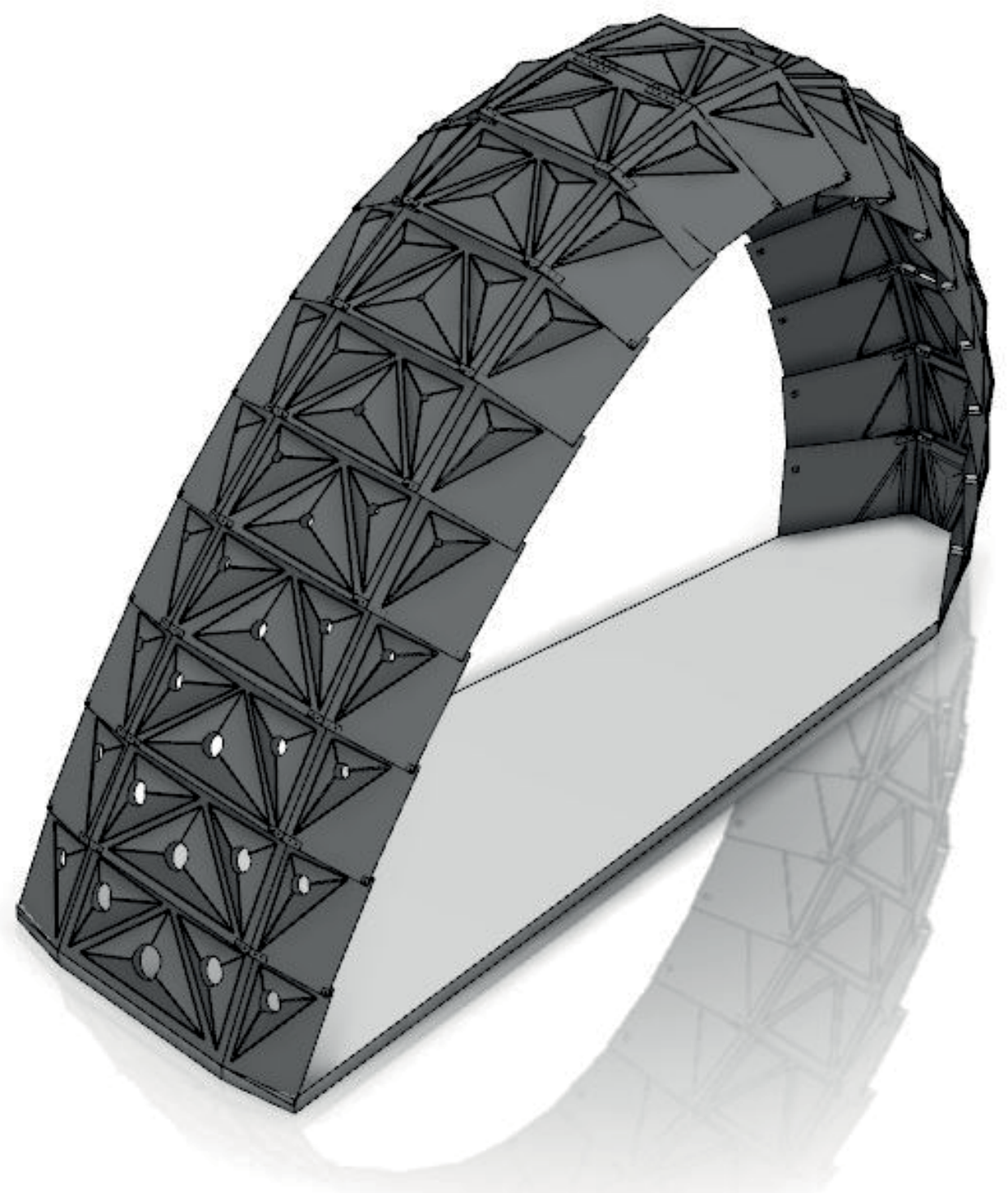

人 Fig 52. Final CATIA model illustrating panel extrusions and apertures 
of the panel fabrication. The 18 sheets were then referenced in Grasshopper to create the triangular 3D forms that were parameterized to change size and shape over the entire form.

Once the robotic programs were prepared for operation, the design process was established for running the sheets. The sheets design incorporated five different operations: cutting, scribing, drilling, forming, and folding (Fig 53). Scribing and forming involved an operation by the robotic arm, processes defined by code described in Grasshopper. The other operations were completed manually through the use of other machines of production. The sheets were first cut to size, from there they were transferred to the jig to be scribed upon. The scribe set the position of the holes for drilling. From here the sheets were transferred to the drill press where the holes were drilled. The drilled sheets were transferred back to the jig to be formed. After being formed the edges of the sheet were trimmed to remove the evidence of being fixed to the jig. After this the sheets were moved to the sheet folder where they were folded to their specific angle.

The formwork was parameterised to change in size, depth and shape over the entirety of the design. These changes meant that every sheet expressed a unique state conveying the concept of a customised design and producing unique, one-off panels. Parameters that changed throughout the design included: angle of fold of sheet, position of fold on sheet, depth of extruded form, shape of extruded form, size of apertures and the number of apertures. 

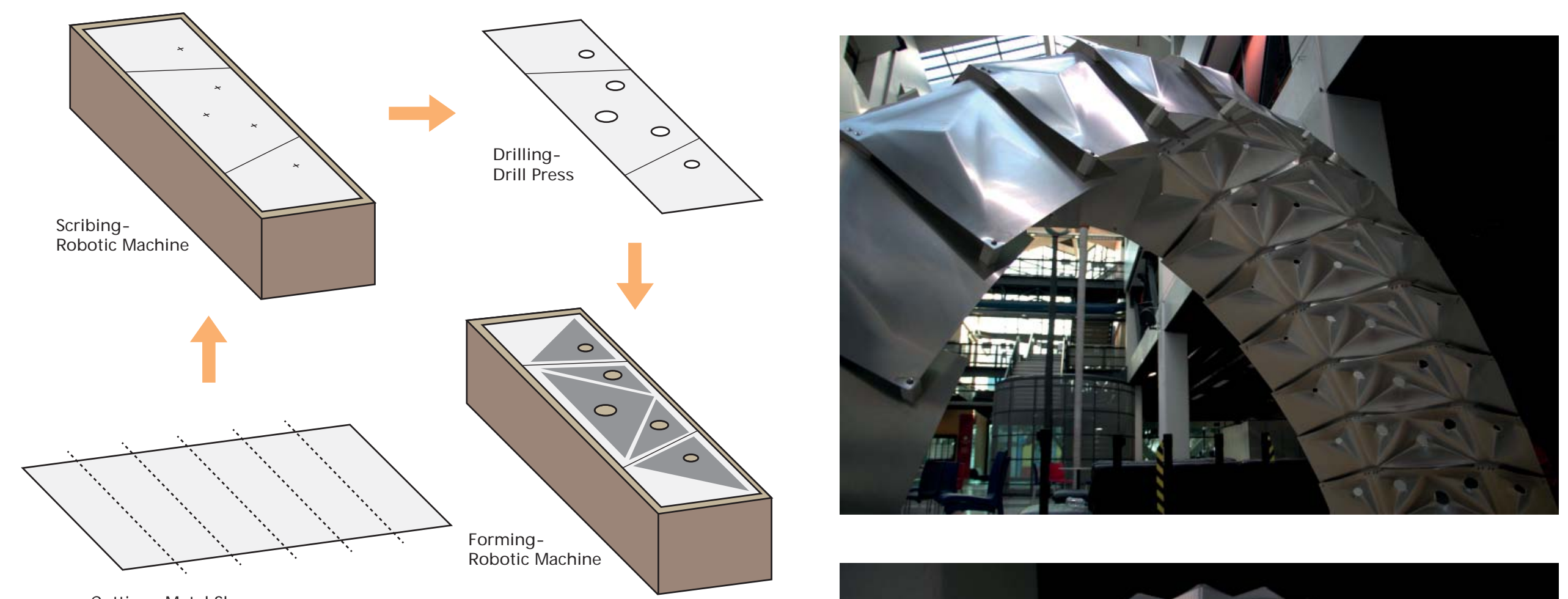

Cutting- Metal Shearer
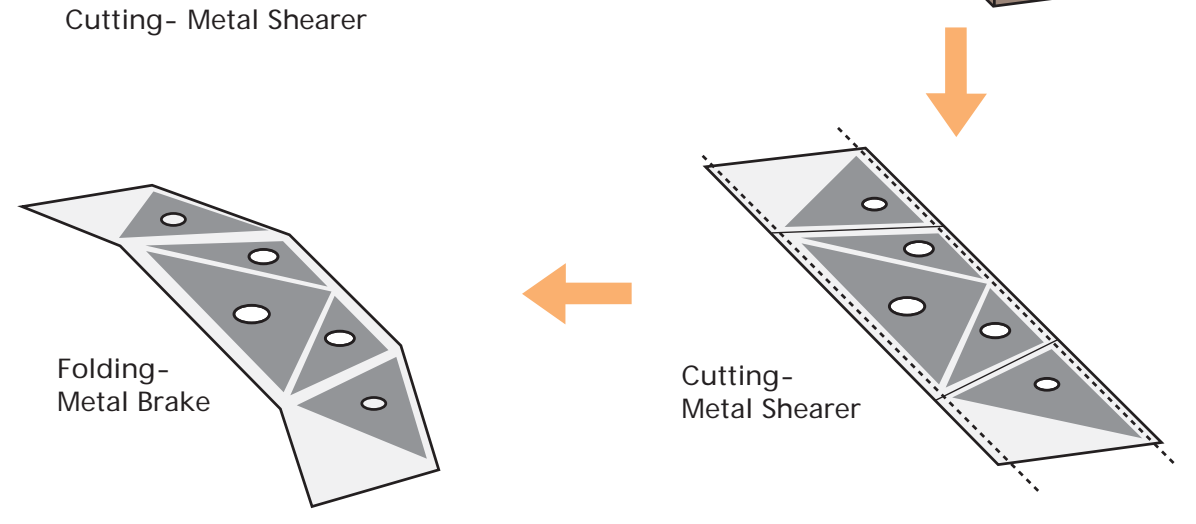
ヘ Fig 53. Diagram illustrating workflow

$\neg$ لـ Pig 54. (Top, Right) Arch of the individual Panels

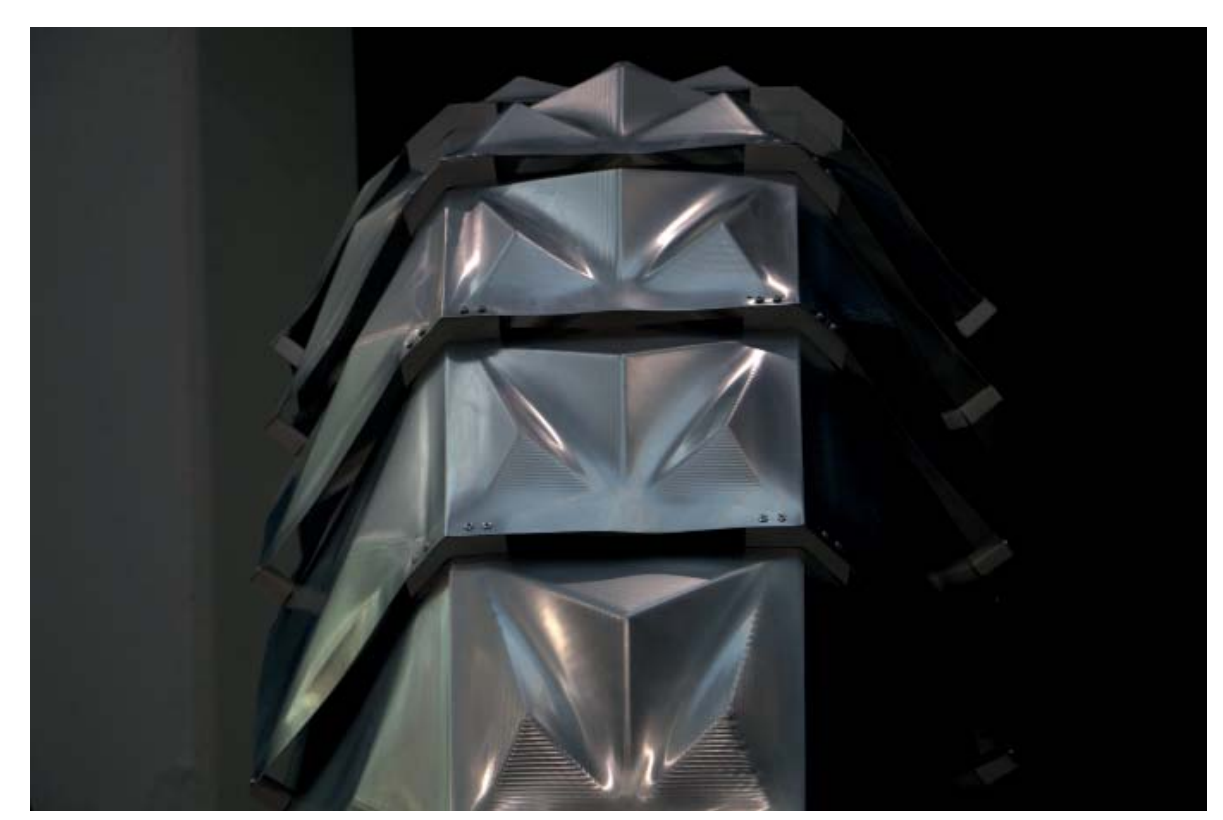



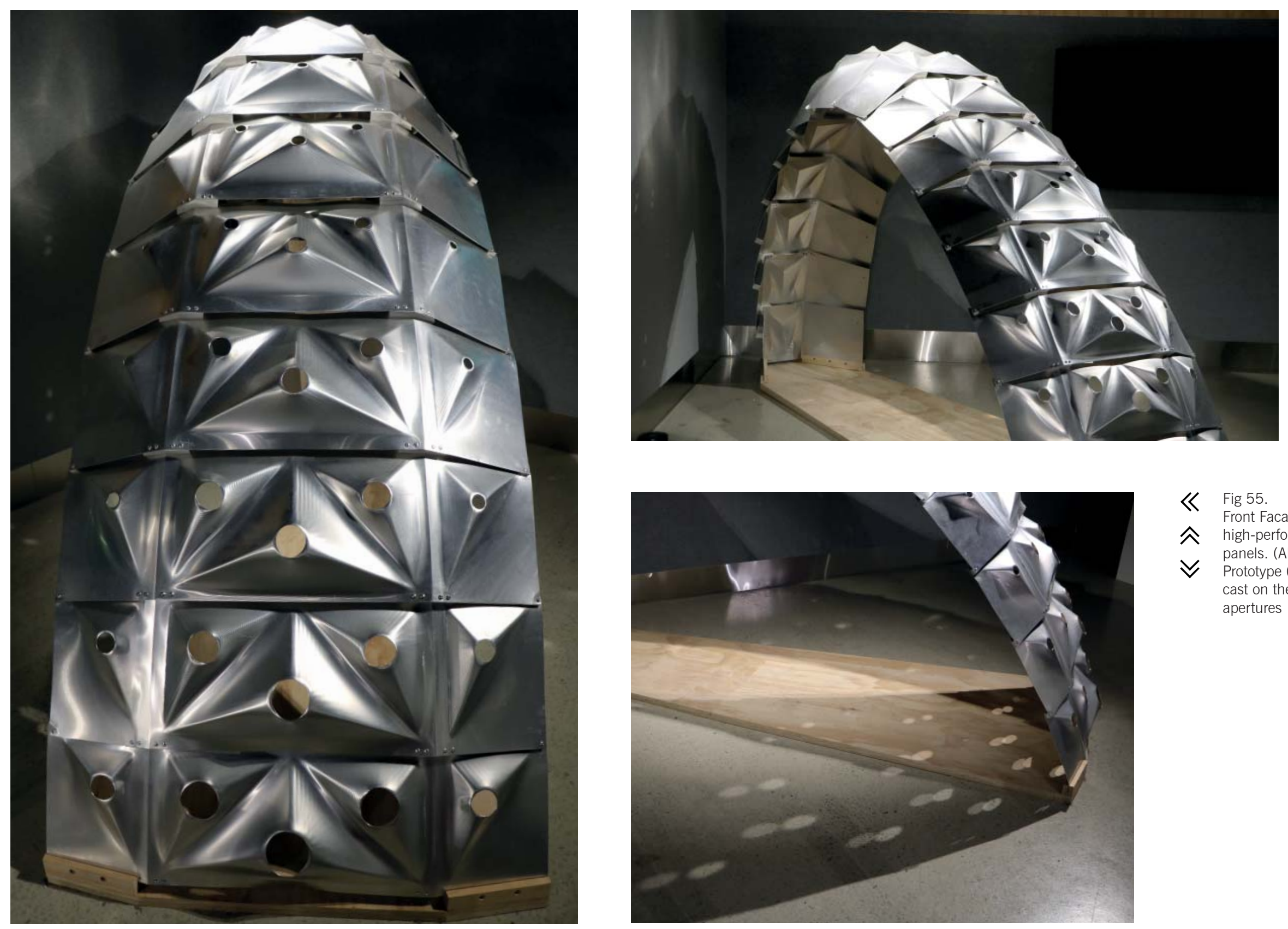

《 Fig 55. (Left)

^ high-pefonter

入 high-performance

$\Downarrow \quad$ Prototype (Below) Light cast on the ground from apertures 


\section{New setup}

After completing the prototype there was another phase of team reflection. This was primarily around the question of how we could continue to develop the process of ISF. Examination of the jig after completing the prototype showed signs of wear particularly around the bolt holes. It was decided that to maintain progression with ISF a new jig needed to be developed out of a more resilient material. It was also decided that bolt holes through the sheet were unnecessary to hold the sheet in place, rather bolts clamping the sheet around the perimeter would suffice. The new material chosen was square steel tubes. The creation of a new jig (by a team member) allowed a redesign in the forming method from a horizontal plane to a vertical plane. This allowed access to both sides of the sheet opening up the possibility of forming both sides of the sheet. Along with the change in sheet plane, the jig was developed to allow two additional sheet sizes $200 \mathrm{~mm}$ $x 1200 \mathrm{~mm}$ and $600 \mathrm{~mm} \times 1200 \mathrm{~mm}$ as well as the original $400 \mathrm{~mm} \times 1200 \mathrm{~mm}$.

Along with the new jig the tool heads were also developed (by a team member). They were redesigned to fit into the tool changer. This would open up the possibility of running multiple tool heads in one operation without human intervention, making the process of forming more efficient. The standardised tool heads included, the standard incremental forming head, the scribing head and the large incremental forming head (Fig. 57). These heads were all crafted in the Haas CNC lathe from mild steel. These tools would set the theoretical potential of tools to inform the newly imagined forms in 'Parametric Patterns'. 


\section{Conclusion}

The construction of a prototype was a complex process that relied on a combined team effort. The focus of this thesis involved specialisation into the panel design, contemplating the ornamental configuration of the sheets. The final design resulted in fully customised sheets that had triangular extrusions with apertures at the apex of the triangle. Parametric controls of the design were crucial in creating the final product, notably the changing gradient of forms over the whole of the prototype. Each sheet held forms which changed marginally from the previous sheet allowing the subtle gradient that was aesthetically desirable. The parametric tools also permitted the substitution of any pattern into the panels forms prompting the next phase of research into potential cultural patterns that could be used instead. Following the creation of the prototype the incremental forming setup was augmented to create a more resilient and further functioning jig. We learnt we could form more dynamic patterns on the sheet by forming from both sides of the sheet.

Fig 56. Illustrating the final jig and setup of the machining cell.

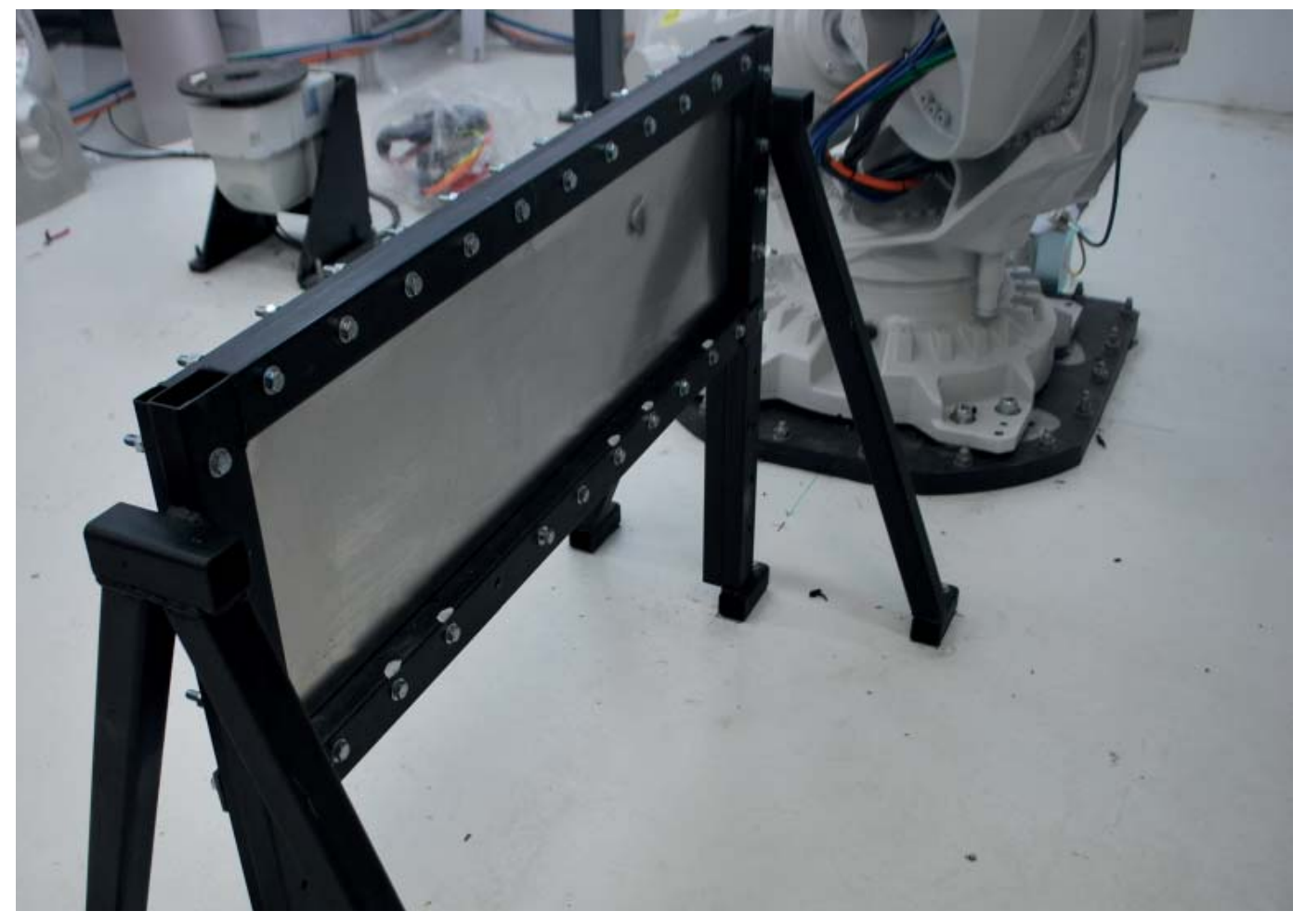




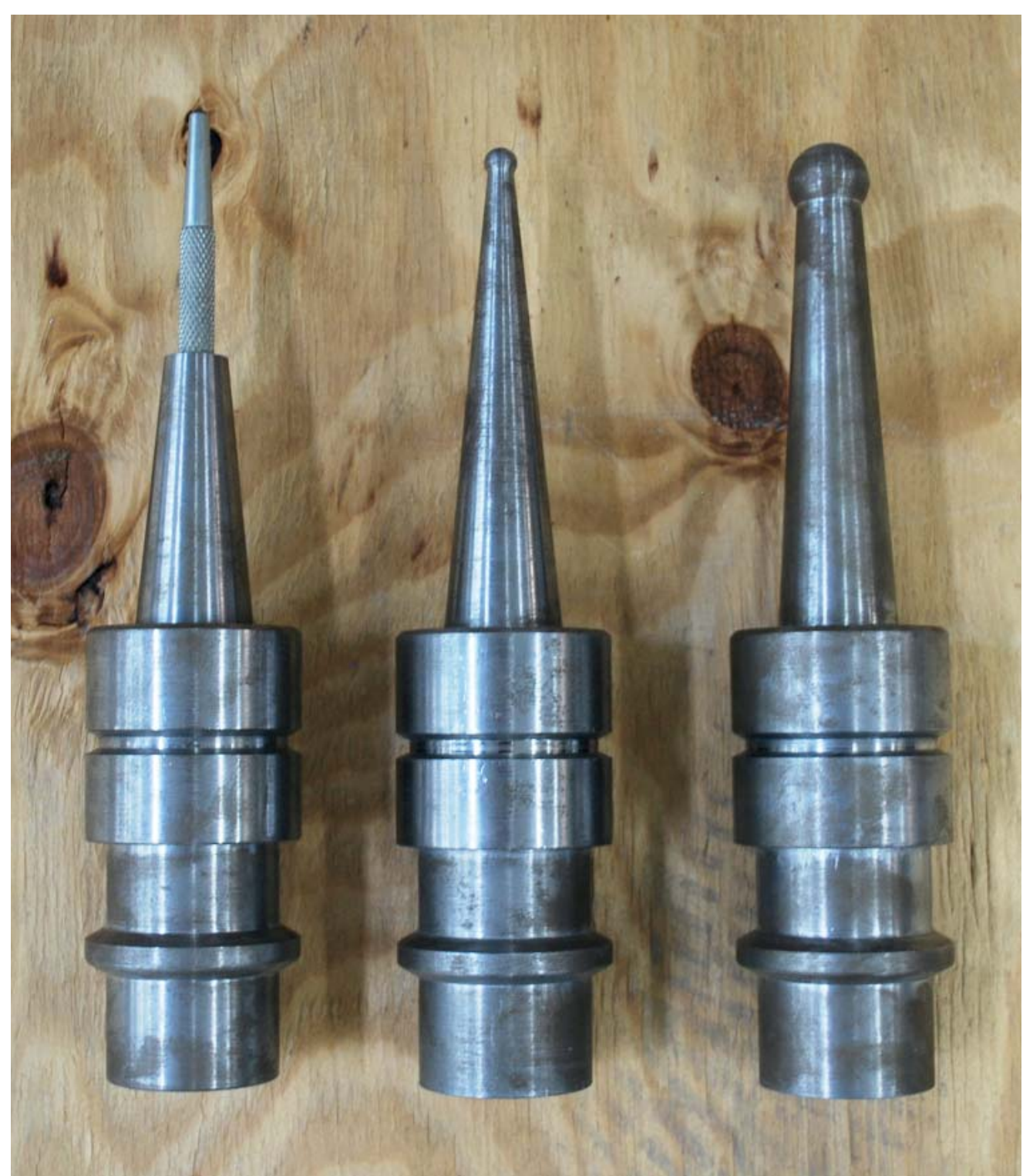

人 Fig 57. Illustrating the different tool heads available at the end of phase two

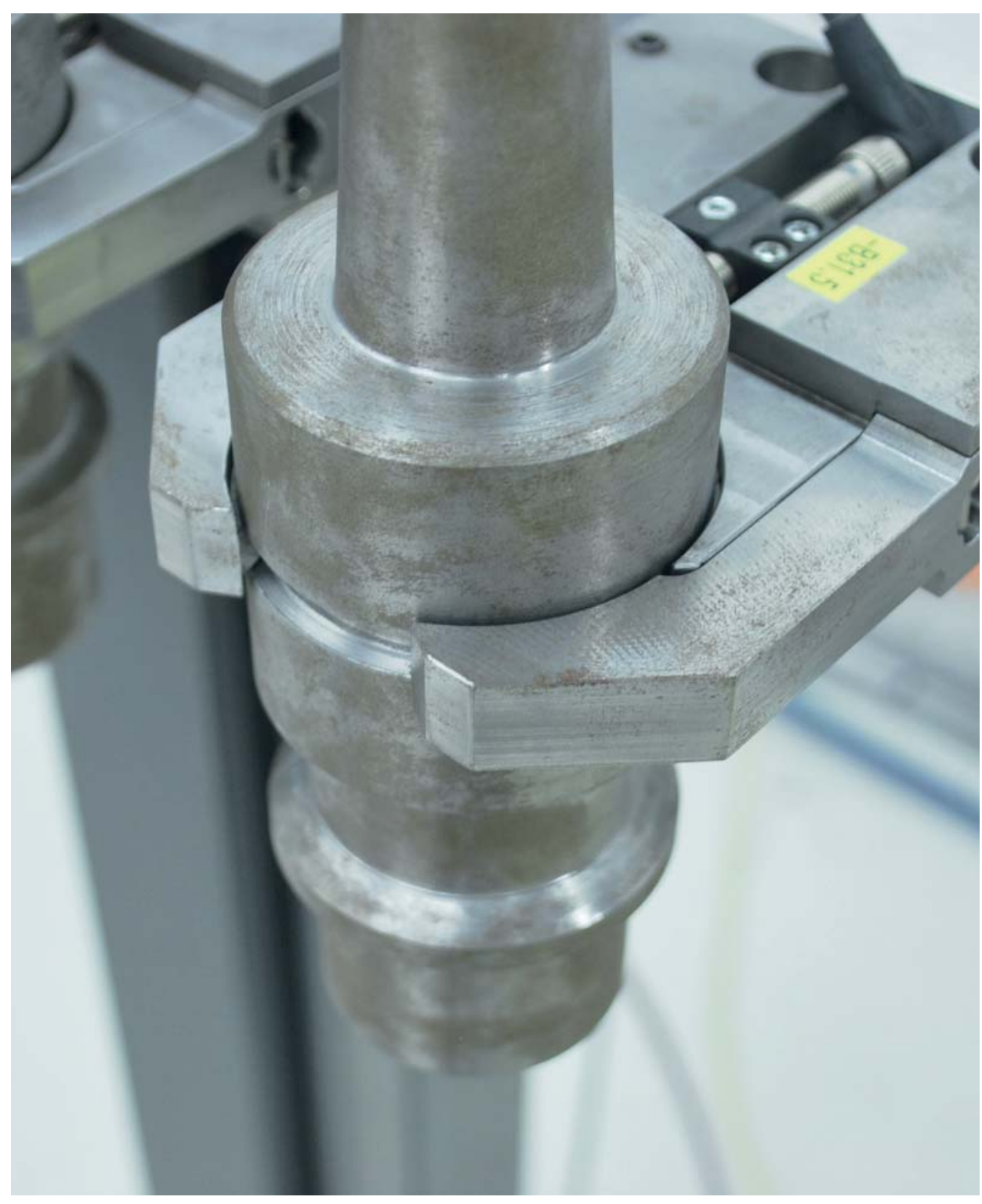

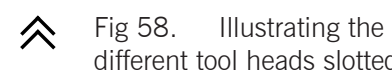
into tool changer 

Phase 3 - Parametric Patterns 


\section{Cultural Precedents}

After completing the prototype and realising ornamental forms through ISF the final stage was to develop a library of ornamental patterns that connected with an audience. After reviewing The Grammar of Ornament it was decided that the best way to form meaningful narratives in ornament was through cultural allusion. Maori and Scottish cultures were chosen as a basis to start this investigation. Maori patterns were chosen due to the pivotal nature of Maori culture in the context of a study in New Zealand. Scottish designs were chosen because of the historic relevance of the culture to the author of the thesis. It was identified that each of these cultures implemented pattern and ornament in fabrics. Each culture had a strong history in patterning fabrics: the Scottish with their development of Tartan, a pattern consisting of criss-crossed horizontal and vertical bands in multiple colours, the Maori with their use of raranga whakairo or patterned weaving.

Differences between the styles of weaving became apparent through analysis of these modes of ornament. Historically the raranga patterns commonly used only two colours to vary their designs; most frequently dyed and undyed flax leaf used in a diagonal pattern. The Scottish tartan did not limit their colour palette over a range of tartans however a single tartan would rarely use more than six colours. It is suggested that the Scottish sourced the colours for their tartan from their region, for example the red and orange hues of sunsets. These colours were arranged in bands of differing size but always in a horizontal and vertical manner.

The aim of the research from this point 
was to transfer the main themes of the fabrics into a form that could both be implemented as ISF by the robotic arm and modelled in the Grasshopper 3D modelling process in order to allow variation and individual influence on the pattern. The process developed into a means to harmonise the components located in Grasshopper with the design intentions for abstracting Maori and Scottish patterns.

\section{Generating complexity}

As the new jig was able to form both sides of the sheet there was now a maximum of three states that the sheet could adopt: formed into the sheet, formed out of the sheet and not formed. This was important when imagining the patterns that could be drawn up in Grasshopper as this would define the number of states that the sheet could be split into.
The first stage was to divide the sheet into a smaller component whose state could be defined. The subdivided sheet was either split into diamond panels for illustrating Maori designs or squares for the illustration of Scottish patterns. The dispatch component was identified as the most effective method to organise the panels into different groups. This component worked through being fed a series of Boolean numbers (either ones or zeros) then organising the panels into two separate groups related to the Boolean numbers. Booleans numbers were chosen because they were successful at communicating the duality of the sheet state. When the panels were split into different groups it was possible to manipulate a group to form extrusions into or out of the sheet. This was done in a similar method to the original explorations where the base shape, be it diamond 
or oblong, was offset smaller than the original and moved out from the surface then joined with the original shape through a loft component.

Because the Maori pattern was not as constrained as the Scottish pattern, which had to form strict horizontal and vertical bands, it was more open to experimentation and interpretation with the dispatch component, whose input included a set of Booleans. The Boolean set became instrumental for imagining new configurations. It was discovered that a small set of Booleans could create simple patterns that, because of their repetition, were easy to visually digest. The aim in creating Boolean sets was to come up with complex states of being that would be visually stimulating, a careful balance between complexity and order that Gombrich suggests as a need of the human mind (Kolarevic, 20). To increase the complexity of the Boolean set, a number of strategies were used. One strategy was to type out all the possible Booleans into an excel spreadsheet which a component would read and relay back to the Grasshopper definition. Building off this strategy the next step was to weave multiple lists of Booleans together through the excel file to make lists upwards of 12 Boolean values changeable with a parametric slider.

The Scottish patterns were made by clustering strips of squares together and merging the faces. Because of the complexity and high resolution of the tartan only a crude representation could be made. The high resolution of weaving and thinness of the thread and flax that formed the patterns made it difficult to gain fidelity to the garments on the low 


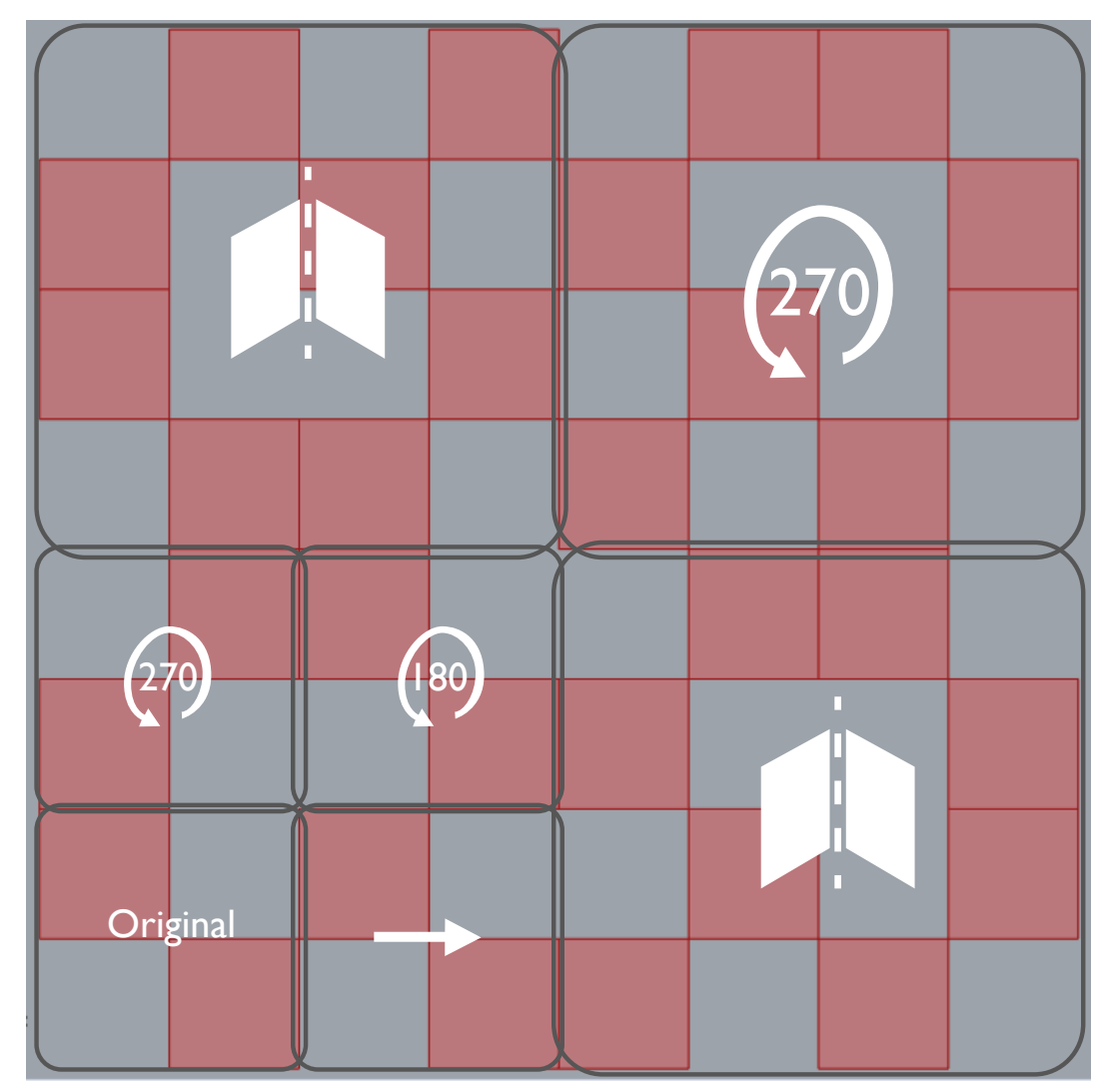

$\rightarrow$ Translate

Mirror

(180) Rotate

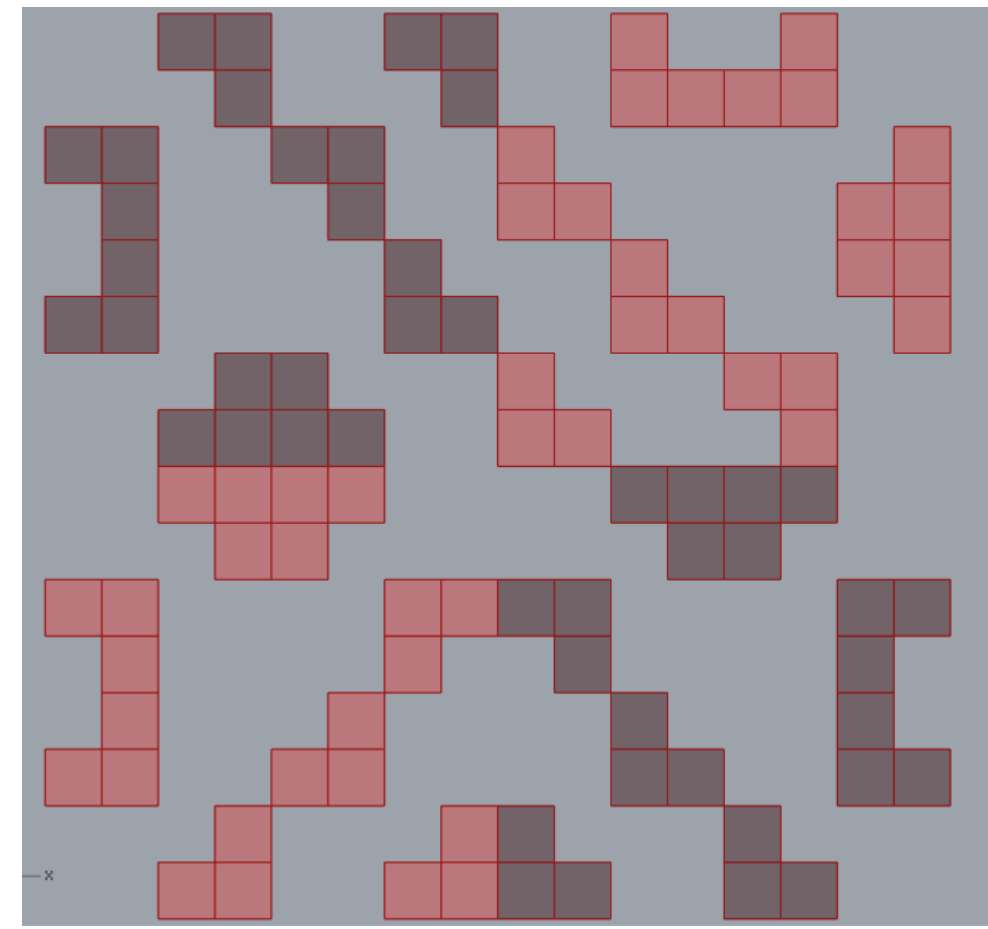

$0,0,1,0,0,1,0,0,0,0,1,0,0,1,0,0,0,0,1,1, I, I, 0,0,0,0,1, I, I, I, 0,0,1,0,0,0,0,0,0,1,1,1,0,0,0,0,0,0,0,1$,

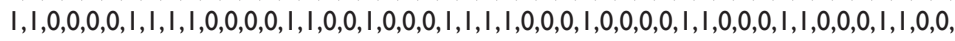
$\mathrm{I}, 0,0,0, \mathrm{I}, \mathrm{I}, 0,0,0,0, \mathrm{I}, \mathrm{I}, 0,0,0, \mathrm{I}, \mathrm{I}, \mathrm{I}, 0,0,0, \mathrm{I}, 0,0,0,0, \mathrm{I}, 0,0,0, \mathrm{I}, \mathrm{I}, \mathrm{I}, \mathrm{I}, 0,0,0, \mathrm{I}, 0,0, \mathrm{I}, \mathrm{I}, 0,0, \mathrm{I}, \mathrm{I}, 0,0$, $\mathrm{I}, 0,0,0, \mathrm{I}, \mathrm{I}, 0,0, \mathrm{I}, 0,0,0, \mathrm{I}, 0,0,0,0,0, \mathrm{I}, \mathrm{I}, 0,0,0, \mathrm{I}, 0,0, \mathrm{I}, \mathrm{I}, 0,0, \mathrm{I}, \mathrm{I}, 0,0, \mathrm{I}, 0,0,0, \mathrm{I}, \mathrm{I}, 0,0, \mathrm{I}, 0,0,0, \mathrm{I}, 0$, I, I, $0,0,0,0,1,1,0,1,0,0,0,0,1,0,1,0,0,0,0,0,0,1,1,1,0,0,0,0,1,1,0,0,1, I, I, I, 0,0,0,0,0,1,1,0,0,0$ $0,0,1,0,0,1,0,0,0,0,1,1, I, I, 0,0$

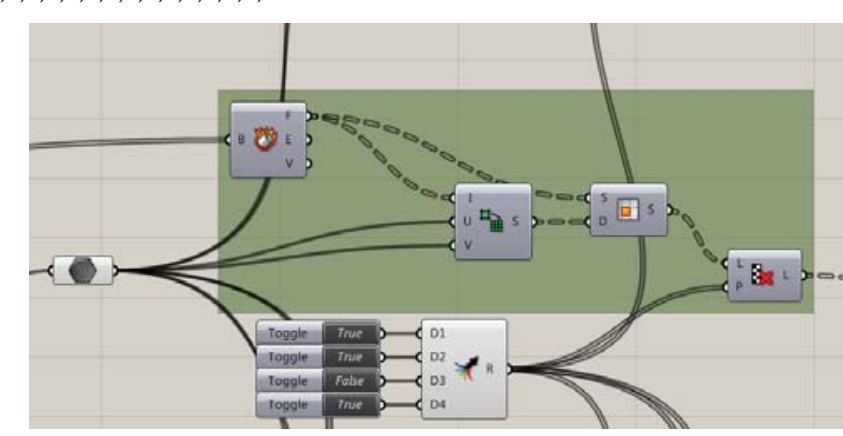

Kig 59. Configuration of 64 states defined by four original boolean values

1) Fig $60 . \quad$ Configuration of 256 states defined by eight original boolean

values with Grasshopper

values with Grasshopper
model illustrating dispatch component. 
resolution metal sheet. The sheet was low resolution because it could only be subdivided into components larger than the thickness of thread due to the forming limitations. If each square and diamond was to be extruded to a reasonable depth each cell could be no smaller than $30 \mathrm{~mm} 2$. Patterns were designed for the original jig which had a default setup of $400 \mathrm{~mm} \times 400 \mathrm{~mm}$ or workable sheet area of $360 \mathrm{~mm} \times 360 \mathrm{~mm}$. This meant that the sheet could only be divided into 12 in the $x$ and $y$ directions in contrast to the hundreds of threads that would comprise a garment of that size.

After this study, there was a period of reflection to reassess the direction of the work in finding contemporary ornamental patterns for sheet metal. It was decided that the research with Boolean operations held some promise for the generation of complex yet ordered patterns so this function was further investigated. Other means of generating patterns stemmed from this research into Booleans, with the premise being how to get a complex system from a small number of Booleans. One way to achieve this was to transform a base set of Booleans into different arrangements. Through this method a grid of 64 cells was defined by four original Booleans by either translating rotating or mirroring the original four cells (Fig 59). Each cell was then split into four parts defined by another four Booleans eventuating in 256 cells being defined by a mere eight Booleans (Fig 60). Although the panels were starting to gain the complexity sought it was still too accessible. The relevance to cultural imagery was missing in the intended narrative and the ability to generate complex patterns was constrained by the 
simplicity of the original four Booleans.

\section{Reimagining Cultural Data}

Therefore, once again the design process was restarted to try and create the contemporary pattern that was desired. A new component called image sampler was trialled. This component took a black and white image then transferred the colour values into numbers ranging from zero to one. A grid of points was then organised into different arrangements through techniques involving these numbers. The images used were different raranga patterns chosen specifically from a catalogue of patterns as prime examples of Maori imagery. The resulting grid of points was joined in most cases by a Surface from Points component. This component created an undulating surface that followed the height of the points. The resolution could be adjusted by increasing or decreasing the number of points in the grid. However the effect of increased resolution did not bring a clearer image, rather it intensified the perceived noise on the image creating a field that lacked fidelity with the original image. This lack of fidelity challenged the effectiveness of the image sampler therefore it was decided to try converting the images into panel design definitions using other freeform surface components.

$$
\begin{aligned}
& \text { bay interpolation between } \\
& \text { culutral pattern and site } \\
& \text { image }
\end{aligned}
$$$$
\text { bay interpotation bef Hicks }
$$

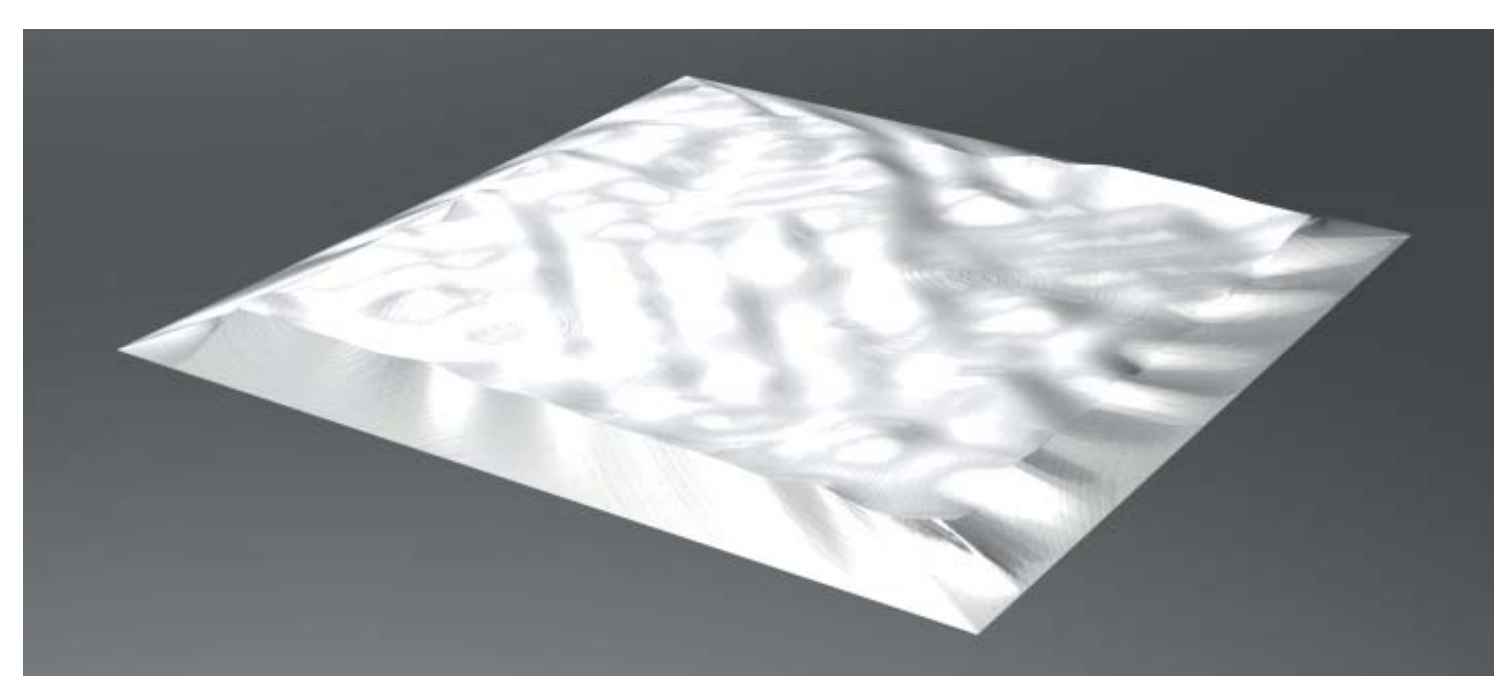




\section{Constructing Cultural \\ Patterns}

The final iteration to generate complex patterns was initiated by returning to the images that inspired cultural allusion.

Design began by trying to interpret images of both Maori patterns and Scottish tartan from 2D patterns to 3D forms. A simple code was created for the Maori patterns: dyed flax would translate into a shape that was formed into the sheet, plain flax would be a shape formed out of the sheet and shapes both dyed and undyed would mean that that space was left unformed. This code worked in theory when planning it out but there was difficulty realising it with the Grasshopper component.

The loft component was crucial in imagining the shapes made during the Exploration phase and the prototypes development. Therefore, it was logical to try and build complex pattern designs through this component. However, when creating a surface with forms projecting both in and out, the loft component showed some limitations, namely that each individual projection had to be modelled then assembled together creating unsightly seams between the extrusions. Ruled surface and sweep components were tested but neither of these produced the desired result. Finally, the component patch was discovered.

This component created a surface from a perimeter curve and points as infill to form the surface. This was compatible with the patterns that needed to be formed. There were two other relevant inputs into the patch component that needed to be controlled. These were the Number of Spans (S) and Flexibility (F). Number of Spans worked the same as a resolution bar, increasing the number of bands that could detect the change of point's 
distribution. This affected the time that the component took to calculate the solution, going beyond 40 spans would reduce the Grasshopper definition to an unworkable condition. The Flexibility input changed the flexibility of the surface into a tauter or loose solution. It was identified that the optimal flexibility ranged from one to 15 . Geneva Gray Paora was the first artist's image to be translated.

The patch component was used to transform 12 of the most suitable raranga whakairo patterns into Grasshopper definitions to prove that it was possible to translate images into 3D forms over a range of different images. After successfully creating cultural patterns from Maori images the focus shifted to the Scottish patterns. The simple code such as that used for the Maori patterns could not be copied for the tartan that
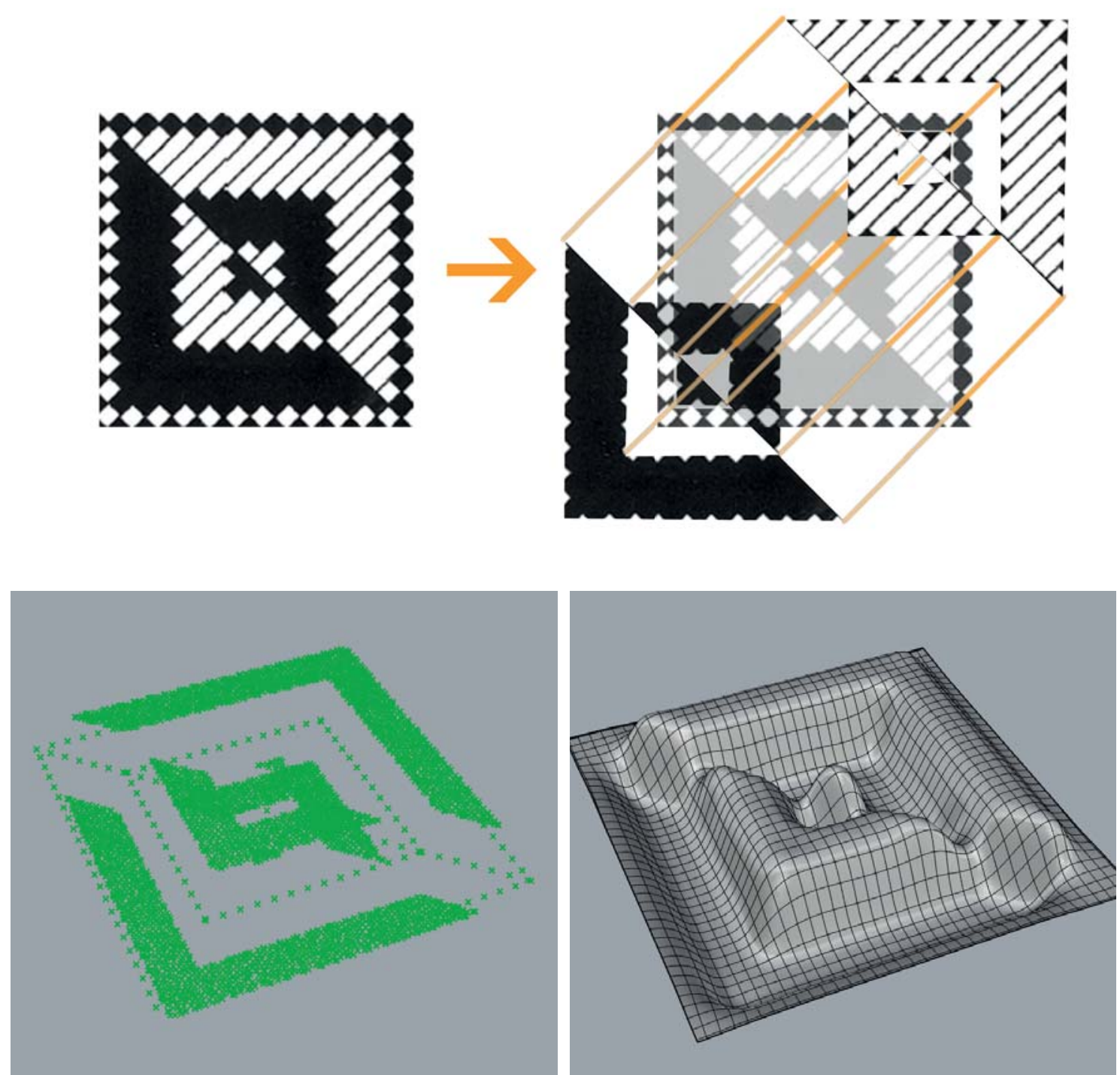

今 Fig 62. (Top) Geneva Gray Paora cultural pattern diagram of extruded image. (Bottom, Left) Point field determining patch command. (Bottom, Right) Patch component baked surface. 
had up to six different colours. Therefore the images were simplified and a gradient of black and white tones created. The lighter tones pushing the form out while the darker tones pushed the form in similar to the Maori patterns (Fig 63). The Cameron of Lochiel Tartan was the first tartan to be translated into a 3D form. All tartans that followed used a similar method to form the 3D forms. First the square was subdivided into equal parts, then bands were dispatched into groups and merged to form one surface. The bands then cut out spaces so that other bands or blocks of colour could fit with no overlap. All blocks and bands were offset to form smaller surfaces so that space was allowed for the change between high and low extrusions. The extrusions were then either moved in or out depending on their tone. The surfaces are then populated with points with the populate

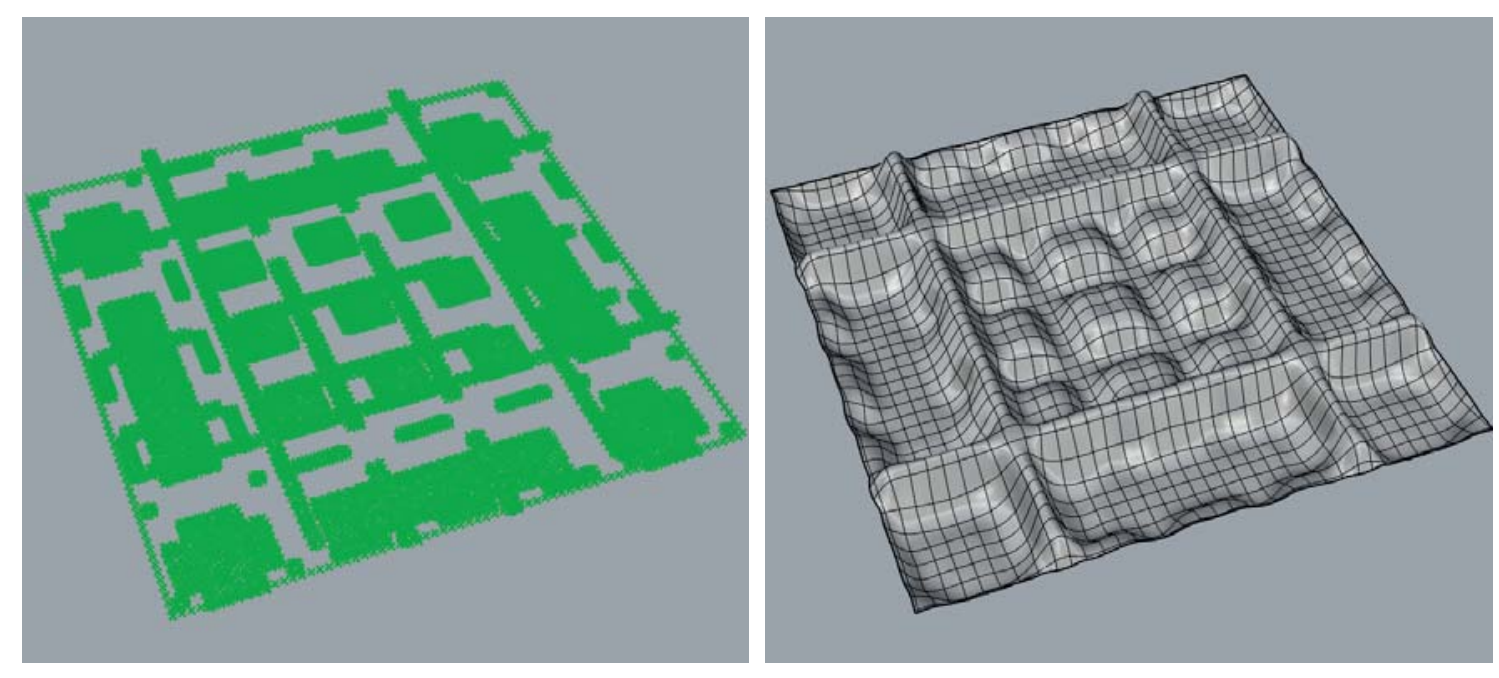

ヘ Fig 63. (Top) Cameron of Lochiel Tartan cultural pattern diagram of extruded image. (Bottom, Left) Point field determining patch command. (Bottom, Right) Patch component baked surface. 
geometry component. These points were then fed into the patch component with the original rectangle boundary. This component produced a surface that could then be translated into contours to be fed into the HAL components whereby it was turned into Rapidcode. 
Fig 64. Patterns

inspired by Geneva

Gray Paora
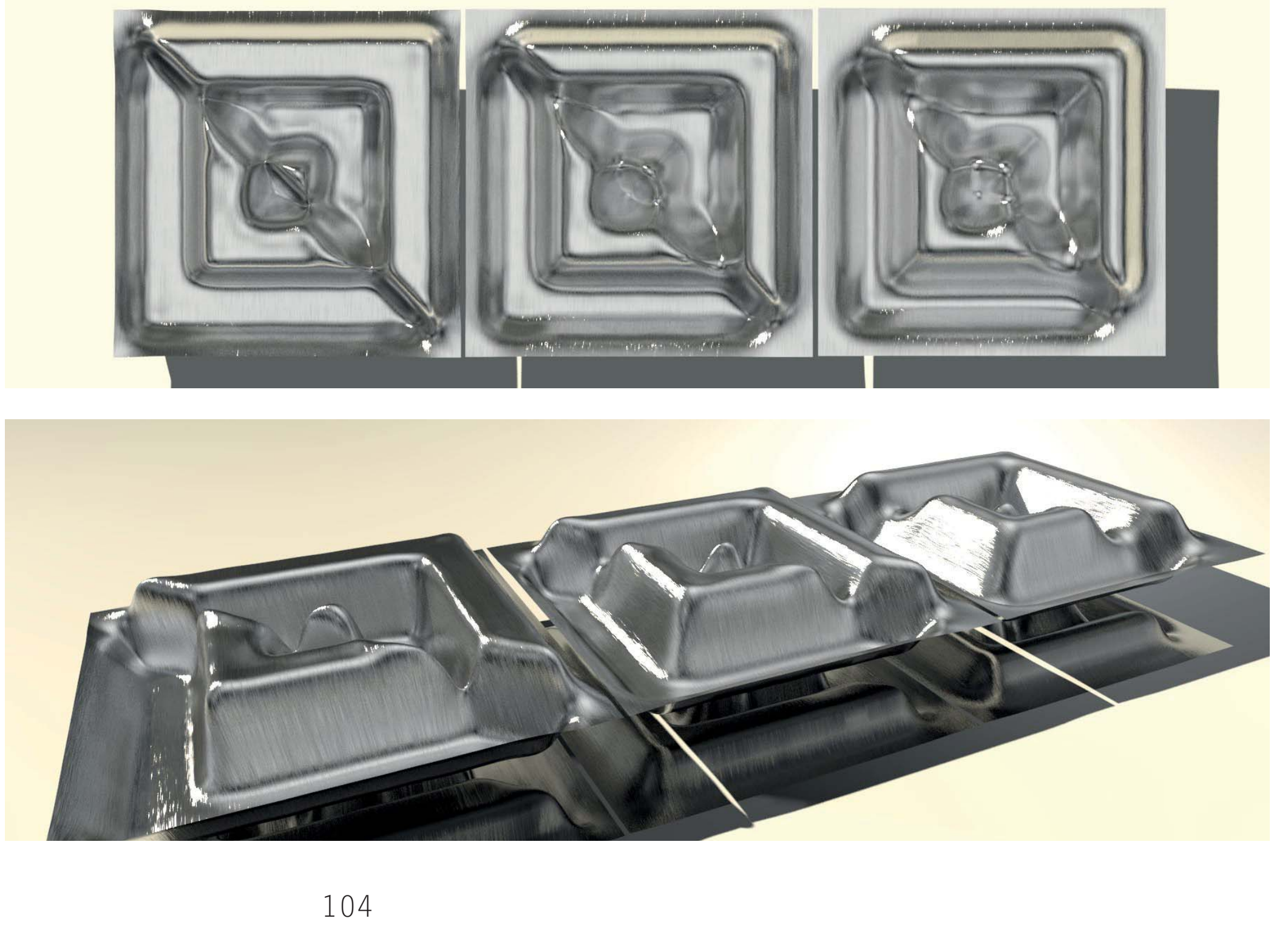


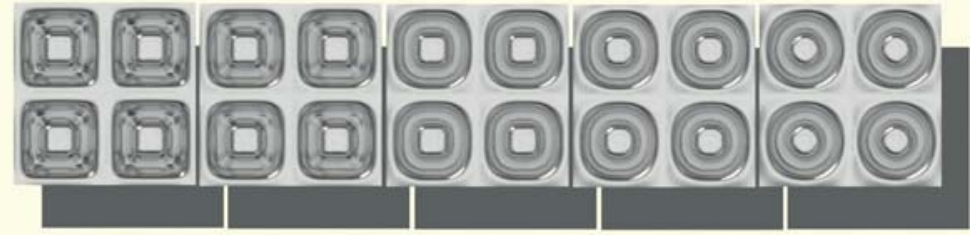

Fig 65. Patterns

inspired by Hine Tuhau

White nee Paul
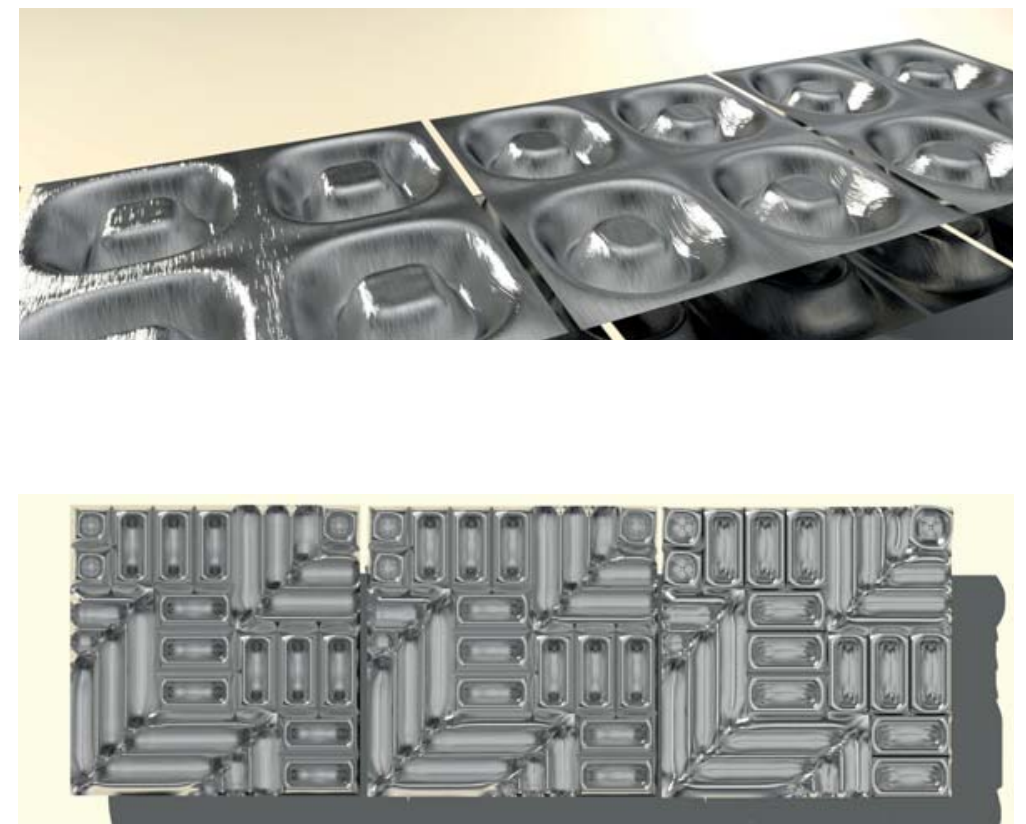

Fig 66. Patterns inspired by Katarina Konui nee Isherwood

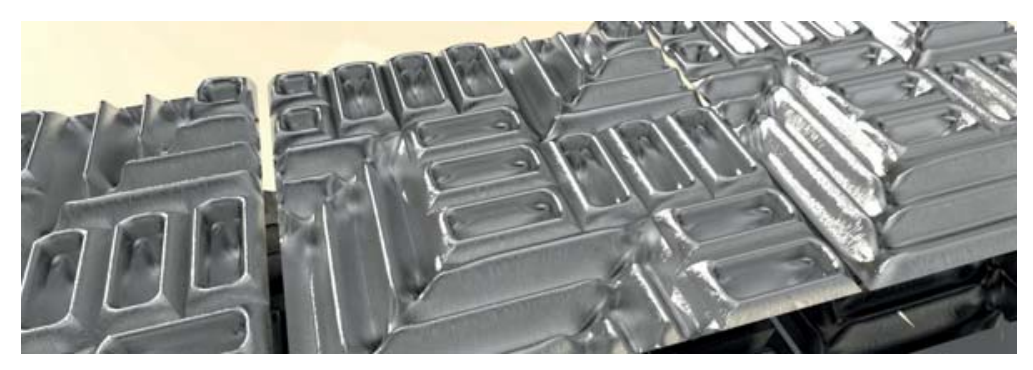

Fig 68. Patterns

inspired by Mau Hei

nee Haare

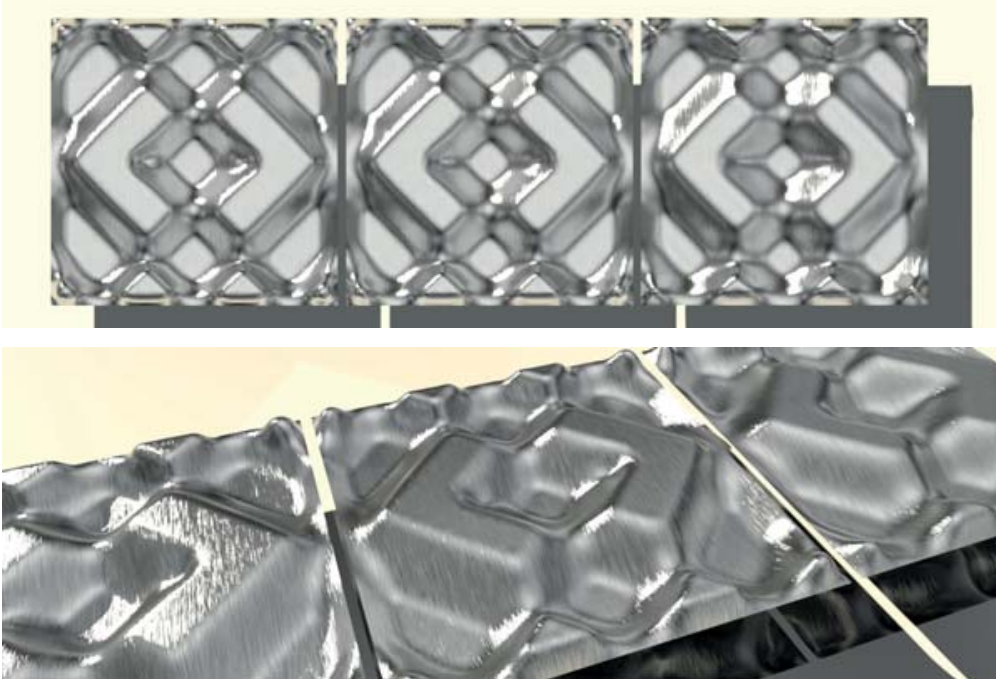

Fig 67. Patterns

inspired by Mrs

Rauhuia Tawhiwhirang
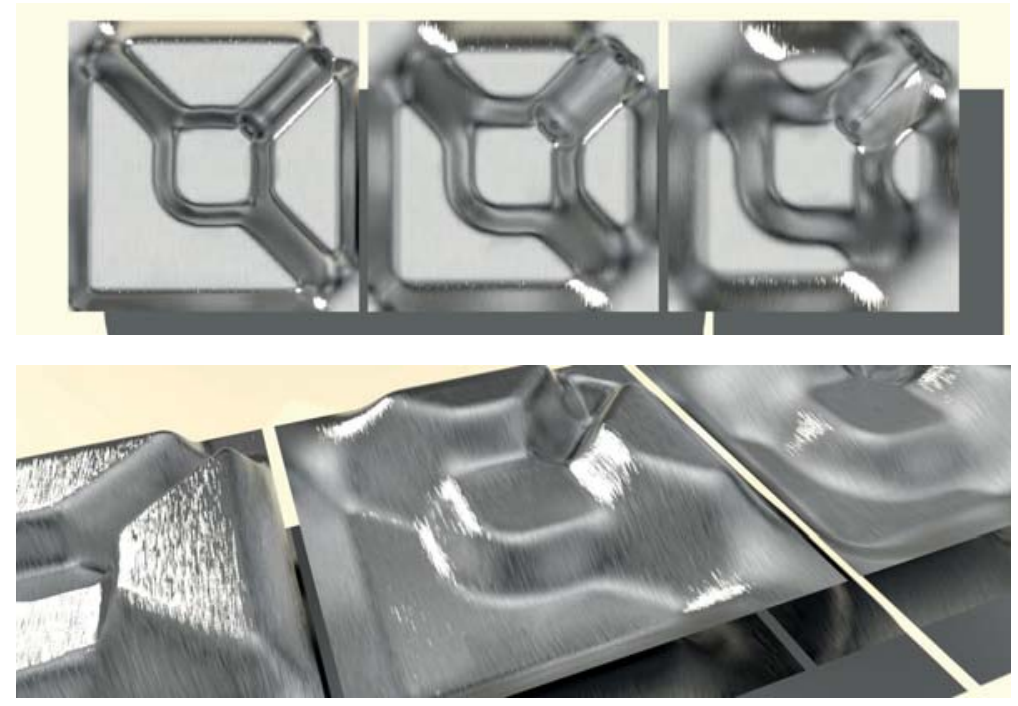
Fig 69. Patterns

inspired by Pani Tihore

nee McClutchie
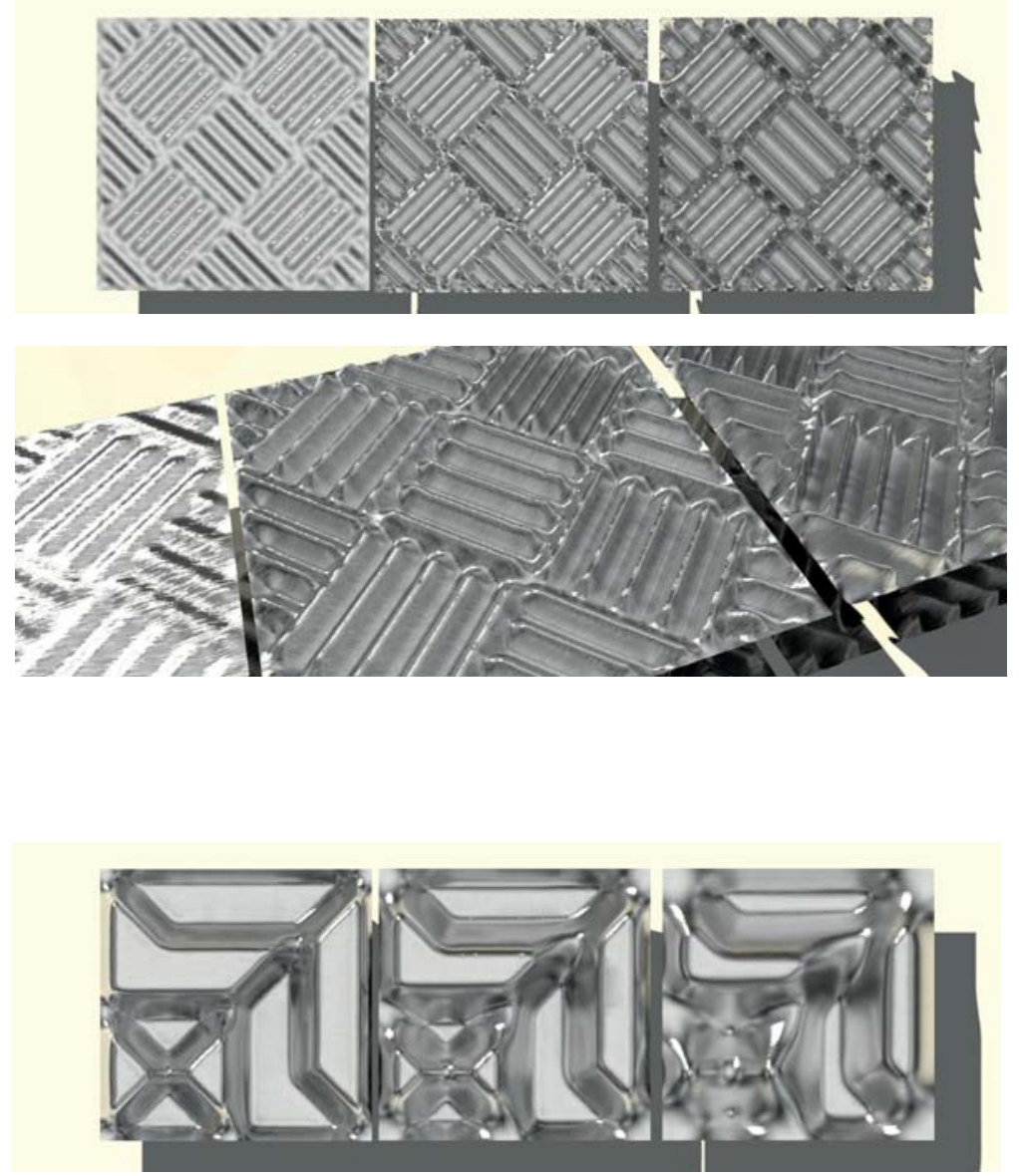

Fig 70. Patterns

inspired by

Papakahawai Herewini nee Williams

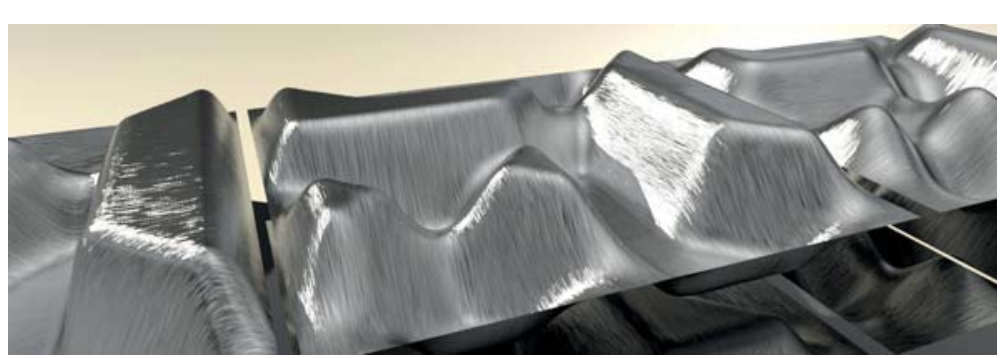

Fig 72. Patterns inspired by Rauhuia Tawhiwhirang

Fig 71. Pattern inspired by Rangimarie

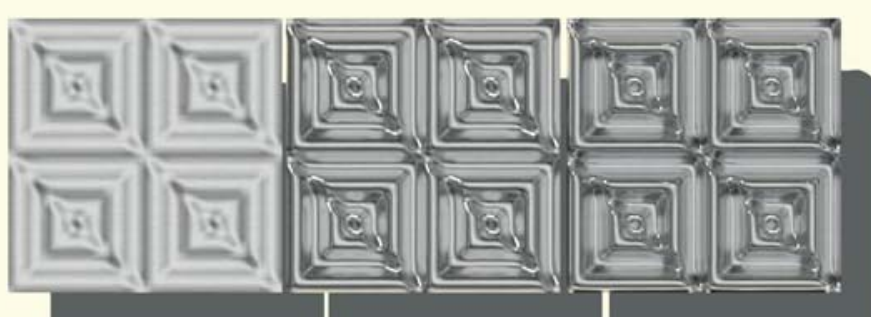

Hetet nee Hursthouse
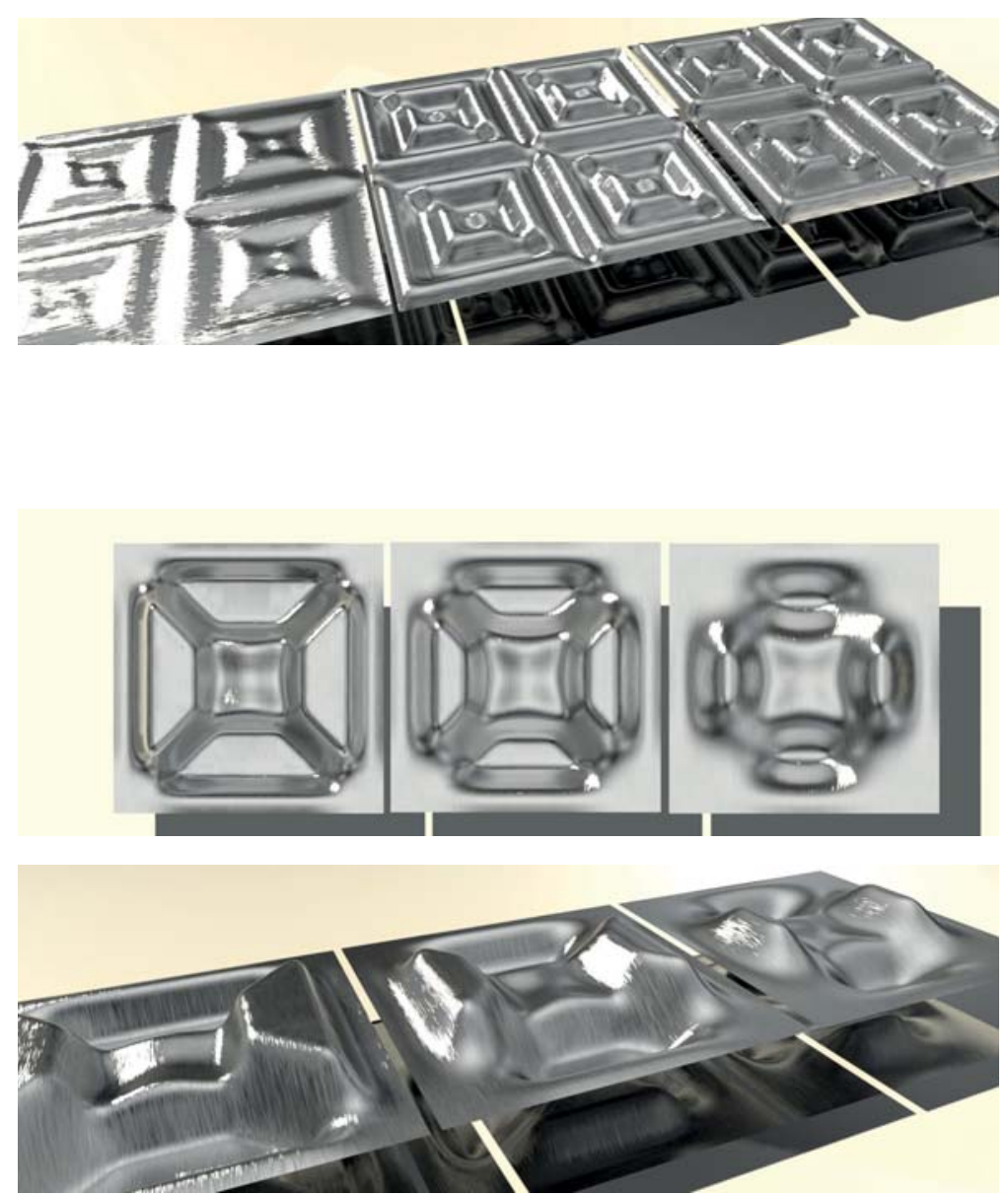
Fig 73. Patterns

inspired by Tauira
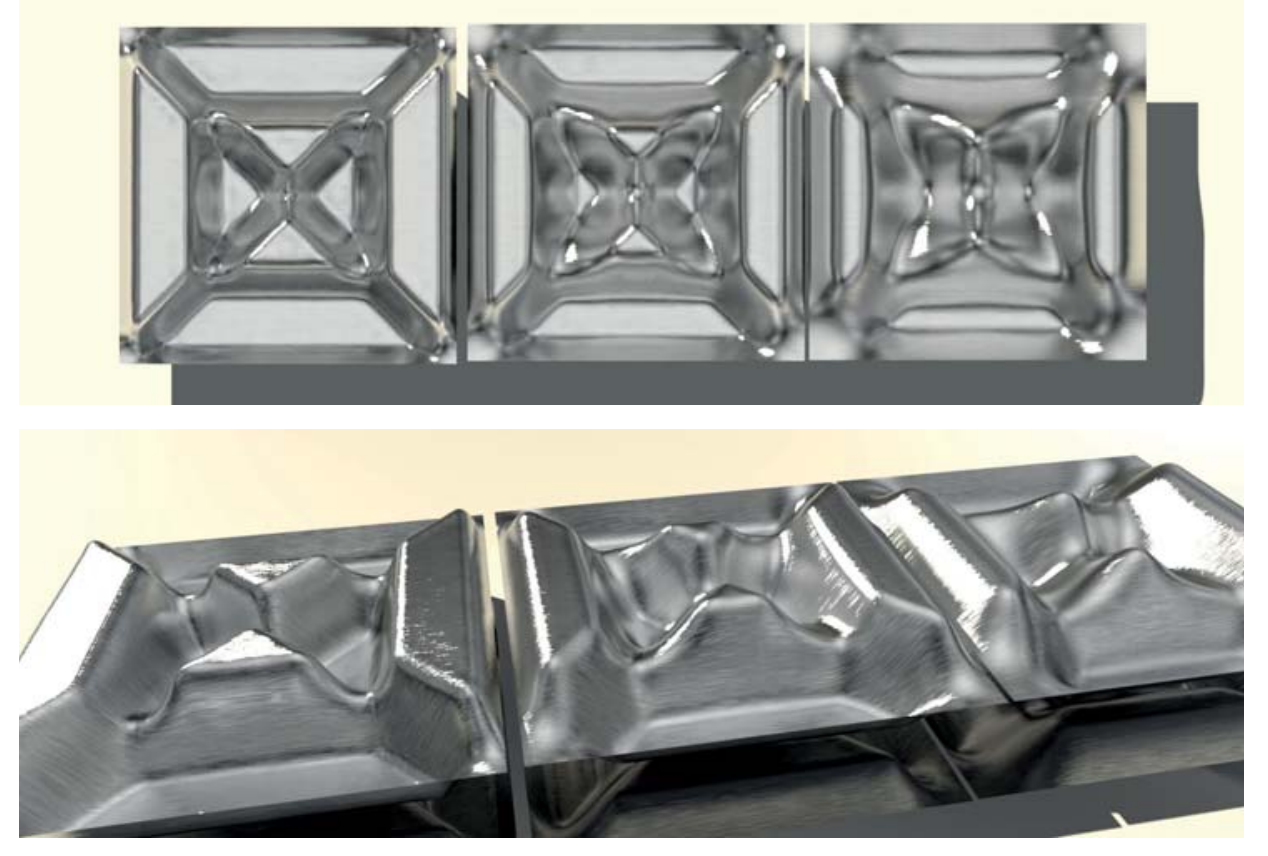

Fig 74. Patterns

inspired by $\mathrm{Te}$

Hikapuhi
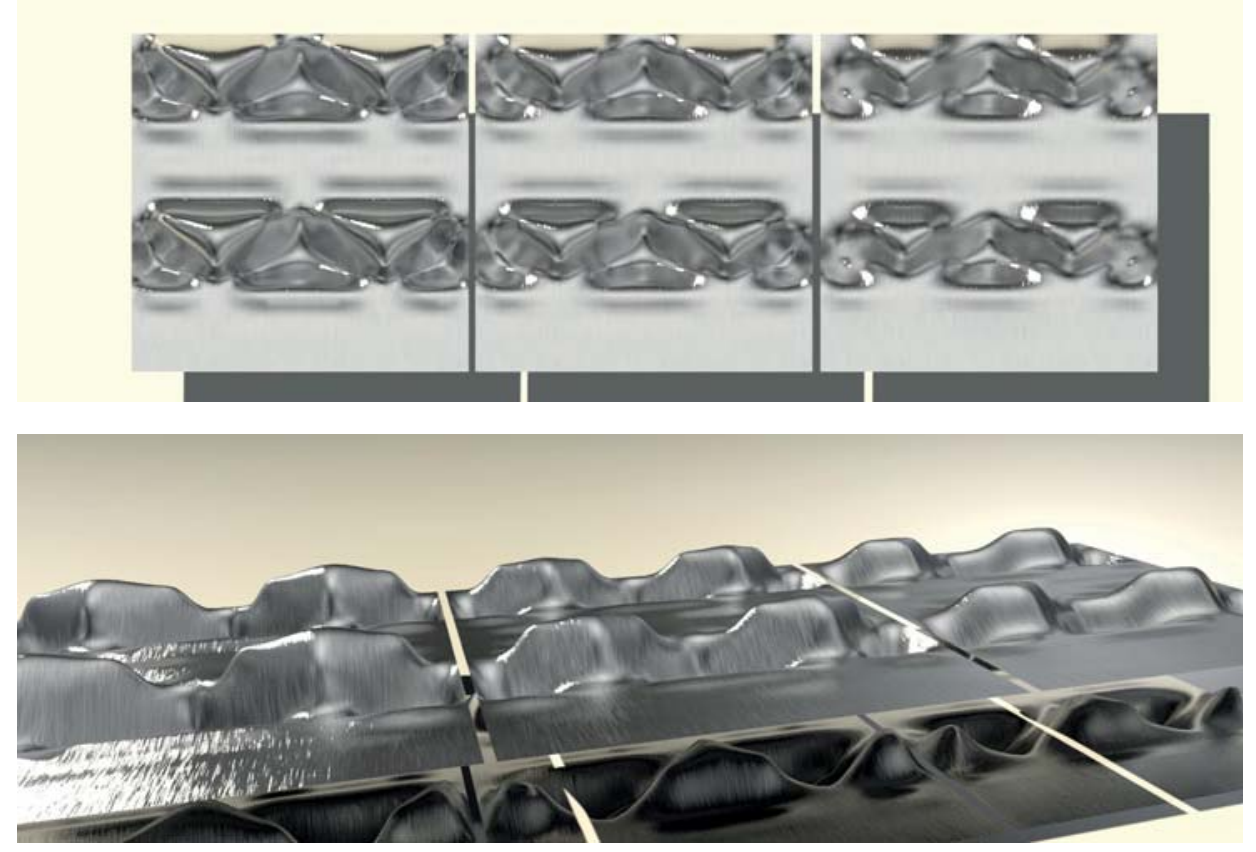

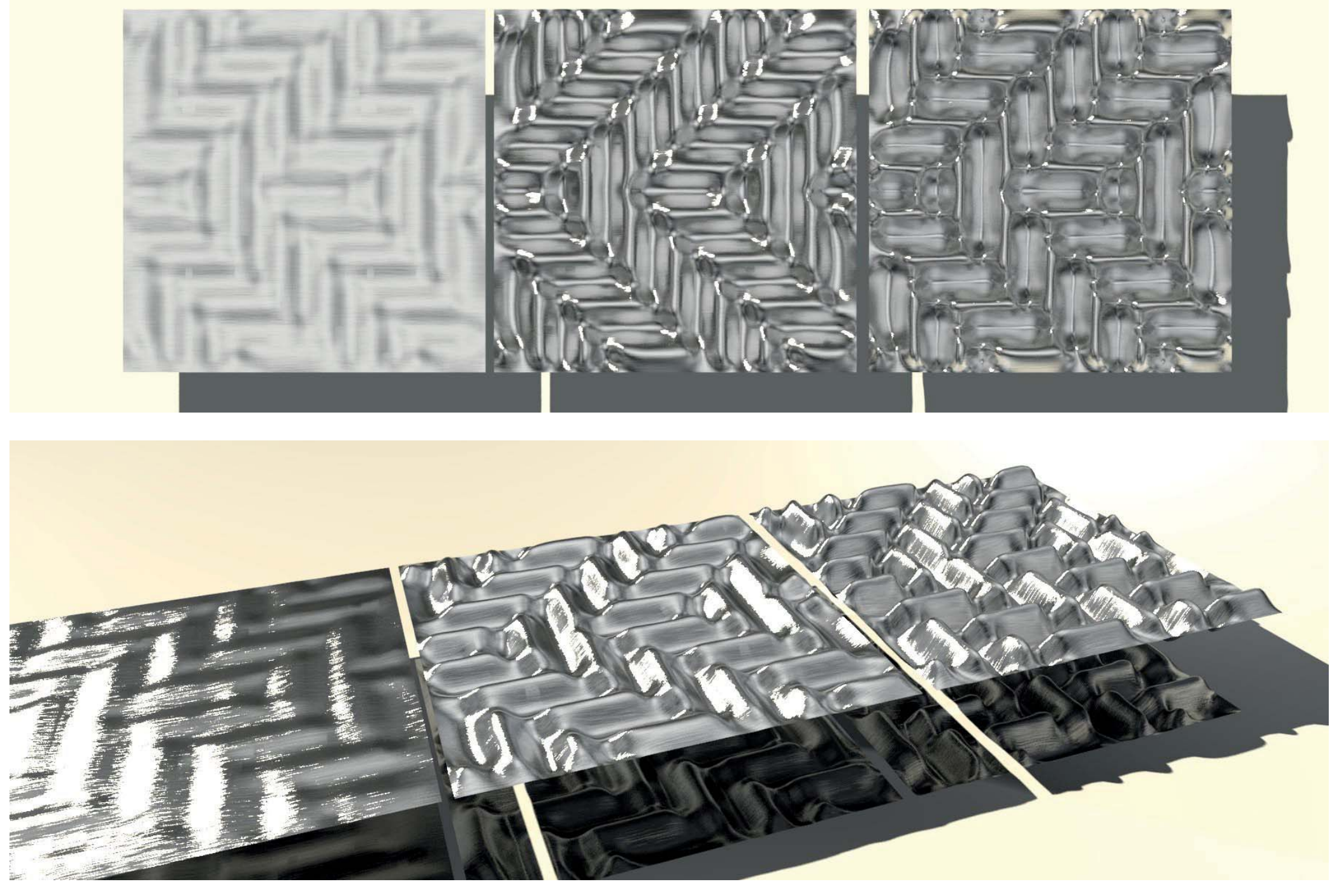

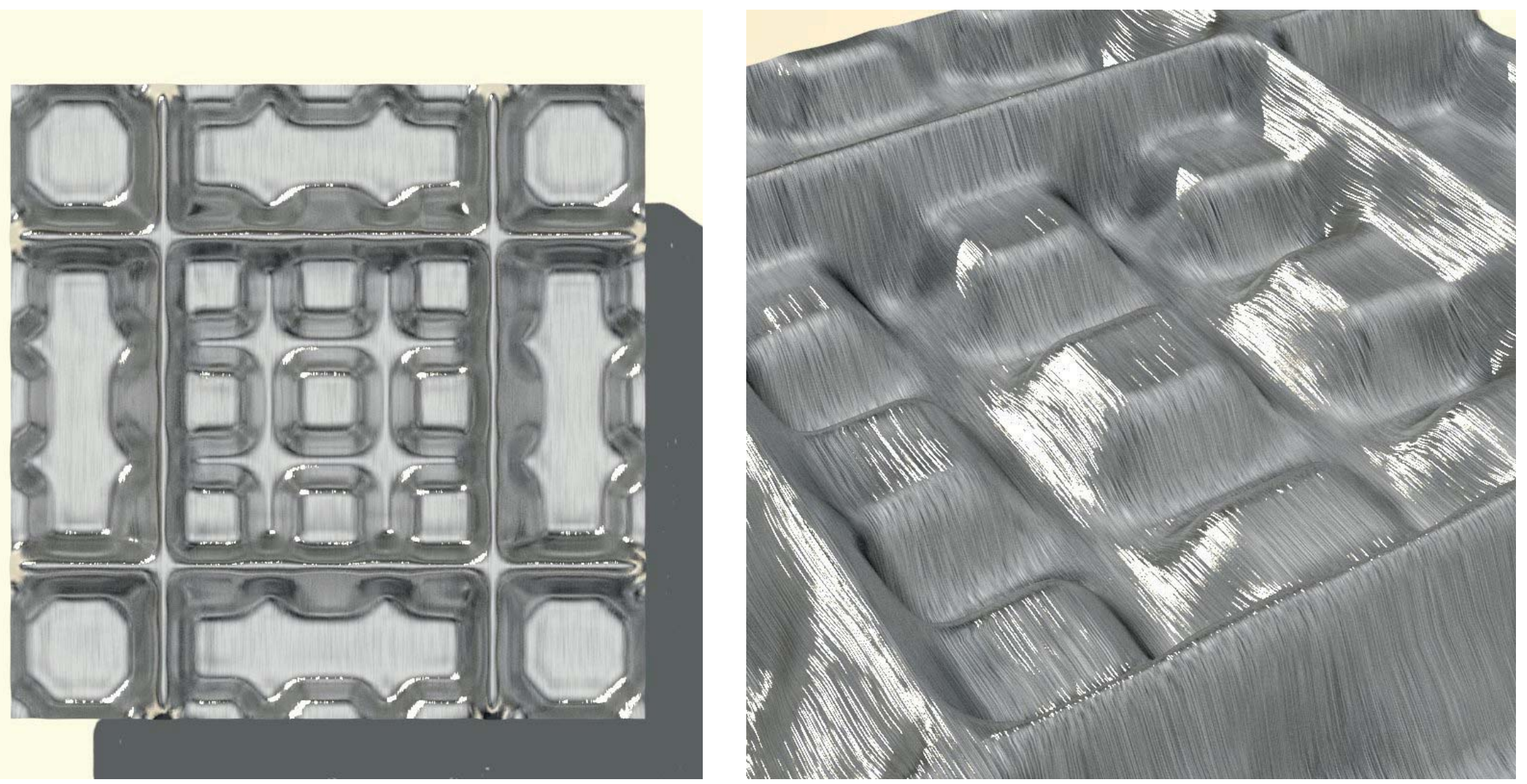
Fig 77. Pattern

inspired by Campbel

Tartan
Fig 78. Pattern

inspired by Douglas

Grey Tartan
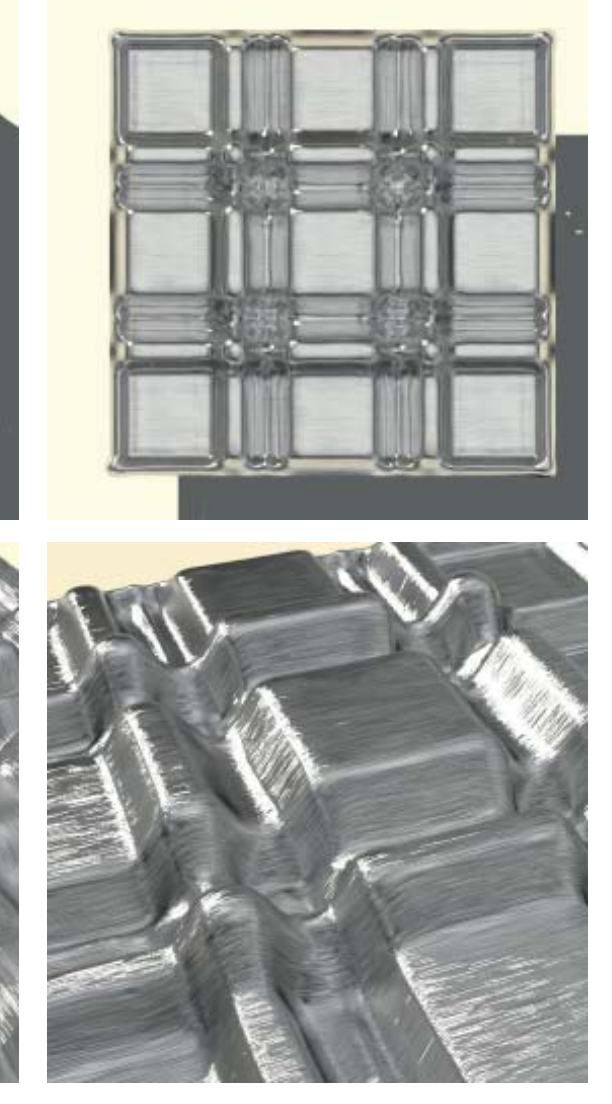

Fig 79. Pattern

inspired by

Isles Hunting Tartan
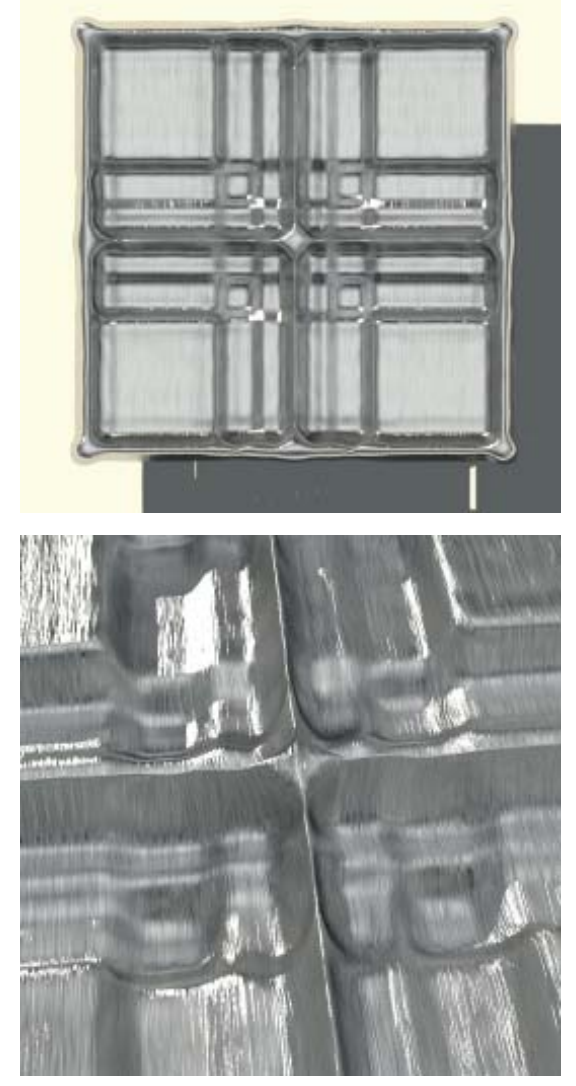

Fig 80. Pattern

inspired by Mackay

Ancient Tartan
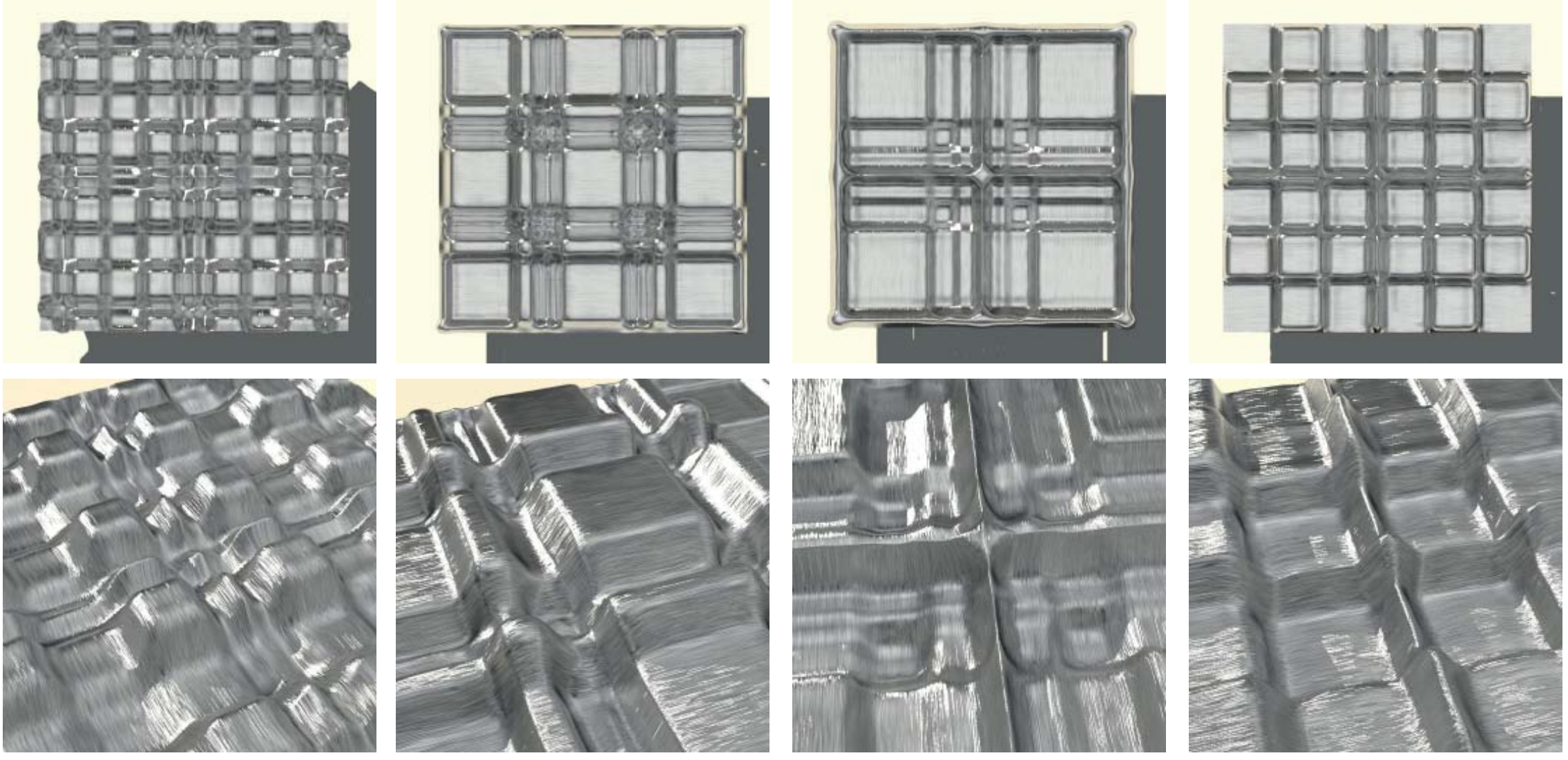

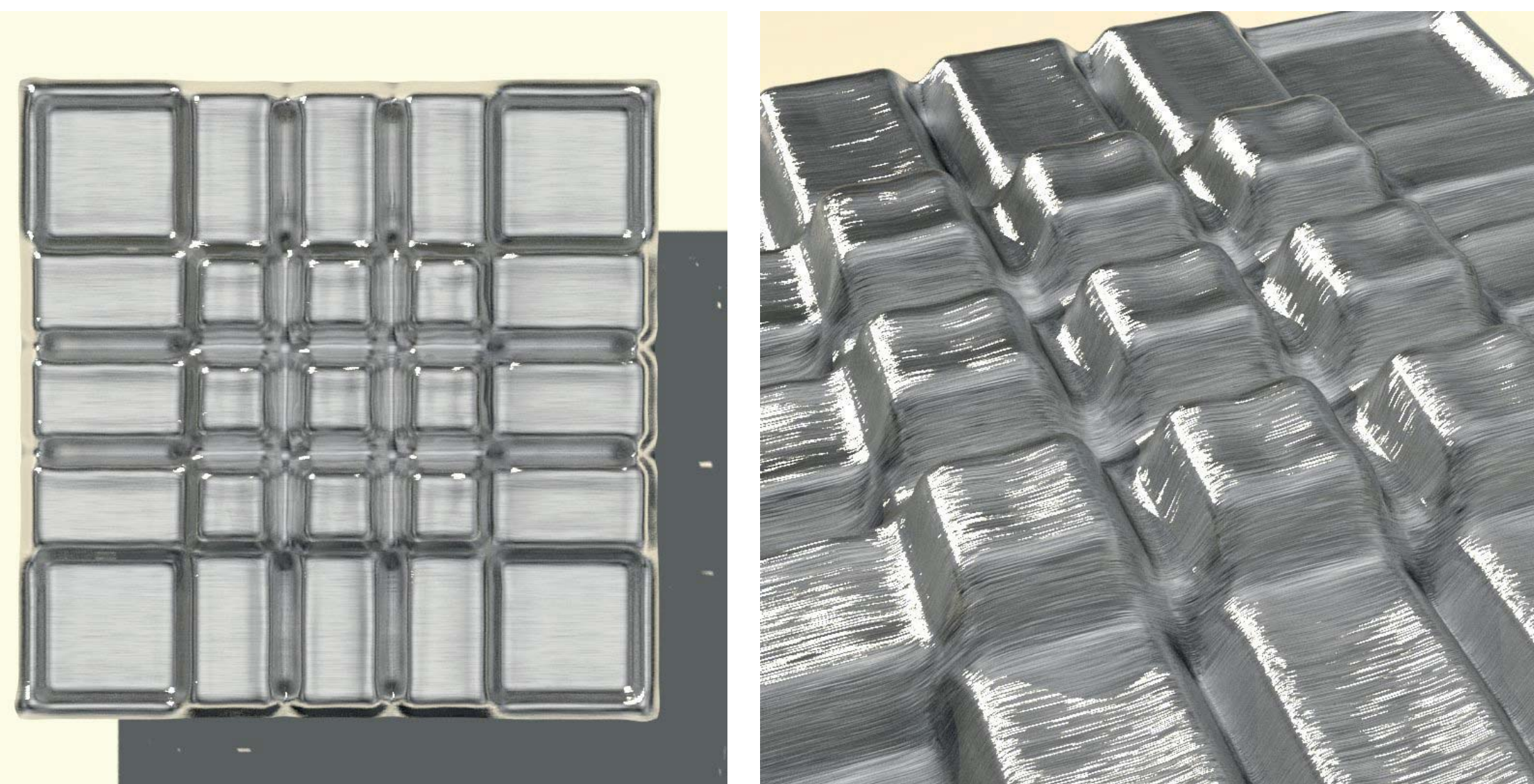

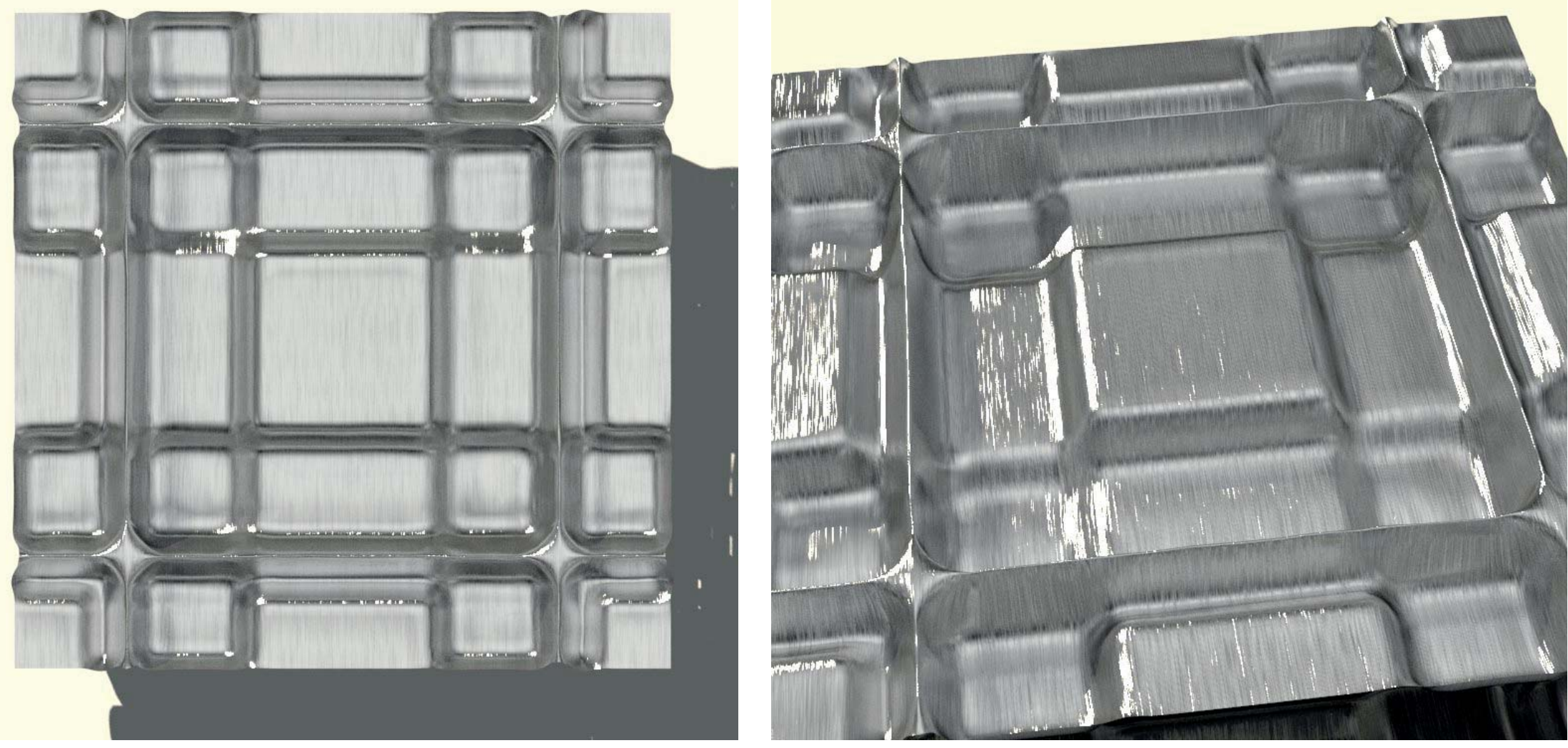


\section{Conclusion}

The final phase aimed to build patterns that conveyed a complex cultural

narrative. The first strategy to achieve this involved the use of Boolean values. The Maori patterns involved a much more experimental technique of finding patterns than the Scottish pattern. Whereas the Scottish pattern simplified the tartan into overlapping bands of extrusion the Maori patterns sought to generate new undiscovered Boolean arrangements that could appear as a complex order. However none of these approaches were deemed successful due to a lack of complexity, therefore a new approach was used. Consistently it seemed that approaching pattern formation through Booleans rules seemed to lack the complexity that would create an aesthetically pleasing pattern. The final change of design approach abstracted the pattern through a purpose-made code where shapes were either extruded out or in from the sheet metal. This approach was used for 12 Maori design and seven Scottish tartans to conclude the experiment to create complex cultural narratives. The final designs were then rendered digitally as incrementally formed sheets to show the digitally what the physical creations would look like. This strategy aimed to be simple enough to follow so that future research could use the learnings gained through this process to further their own research into ISF. 

Discussion 
This thesis has employed research through design to answer the question, How can Incremental Sheet Forming (ISF) aid in the production and communication of ornamental patterns to advance the resurgence of ornamentation and expression in contemporary architecture?

This thesis has shown that ISF has the ability to be applied to an architectural design process to produce and communicate ornamental patterns. Contemporary ornamentation has been defined as the intention of designers to express their virtuosity in design. In this thesis, the adoption of this intention is evident in the resulting products of design both in 'the prototype' - illustrating an ability to form an architectural output - and the 'cultural patterns' (seen in Parametric Patterns) - created to illustrate the range of patterns one could imagine through ISF. This research has aimed to sit alongside ornamental research conducted by the likes of Antoine Picon in his work, Ornament: The Politics of Architecture and Subjectivity. By being up to date in the contemporary definitions and social understandings of ornament, the thesis advances the resurgence of ornamentation in architecture today. The three objectives of this thesis have been addressed in the following ways.

Through analysis of the historical presence of ornament and its definition in today's society, the idea of ornament has been elucidated. Current architectural historians and practitioners have negotiated the relevance of ornament today to a point where its place in contemporary architecture is no longer questioned. This position was the basis for this investigation into the production 
and communication of ornamental

patterns in contemporary architecture. Ornament has been redefined from its historical understanding as an 'applied decoration added to a building' to the intention of designers to express their virtuosity in design. This redefinition clarified the meaning of ornament today before we evaluated the success of whether or not contemporary ornamentation has been achieved. It can be seen that this research successfully integrates the use of ornament into a contemporary discussion around the technique of ISF.

The creation of a full-scale prototype using a robotic arm shows that ISF can be used as a process to add ornamental character to architectural objects. The success of communicating ornamental patterns lay in fact that each pattern communicated an individual quality, unique to its nature. The speed of setup was also a success when compared to more laborious processes of machine stamping and drawing. Limitations of ISF production included the fidelity of the physical sheets produced which depends both on the robustness and extent of the setup in the machining cell. Together these caused a lack of accuracy compared to the digital forms. In addition the production time, while quick to set up, took longer to execute than more standard methods of metal sheet forming. Notwithstanding these limitations ornament was expressed through the creation of customised components of a parametric nature that, when added in aggregate, constitute a real-life testament towards the exuberance of ISF.

The parametric process combined with 
fabrication was crucial to realise the changing nature of the ornament over the prototype and ultimately crucial in defining the aesthetic success of the architecture. The creation of a prototype was successful in that it proved the ability of a contemporary workflow to create complex architecture, while ISF worked in the prototype to convert the plain sheets into high-performance ornamental pieces. The success of this parametric process allows any number of ornamental patterns to be inputted into the panel design process so that future cultural patterns (designed in Parametric Patterns or elsewhere) can be implemented into the design to increase its cultural relevance and therefore success of the Architecture.

The third phase of the research was labelled Parametric Patterns. This part's purpose was to give answers to the question of how ISF can aid in the communication of ornamental patterns. This process used cultural patterns to communicate the potential of the ISF process. These cultural patterns were transferred from $2 \mathrm{~d}$ images into $3 \mathrm{~d}$ forms. The constraints learned from the Exploration process were applied to the cultural patterns in the manner of a parameters defining the sheet size, depth of the extrusions, and other material properties. The resulting patterns were a combination of visual interpretation and parametric coding to create culturally relevant ornamental patterns that could be applied to sheet metal with the use of a robotic arm.

The place of ISF in the production and communication of ornamental patterns is undoubtedly important. ISF is a process that inherently imparts ornamental 
qualities to the material it forms. The resulting toolpath memory is one example of this (Fig. 01), while the forms it can produce (as seen in Parametric Patterns) provide further evidence to the ornamental nature of the process in the fact that it expresses the virtuosity and individuality of the designer or client. Not only does ISF open the limits for one to imagine any form of sheet metal shapes, it makes the whole process of metal forming more available to the layman by providing a preprogrammed library that is easily accessible. This is a significant role as those who would otherwise have no access to creating ornament from sheet metal can have access with the provision of a robotic arm. While not currently widely used, the lowering of knowledge threshold towards machining is a positive step forward in advancing the place of ornament in current society.
Had there been more time to continue experiments more extensive research into ISF with the final jig setup would have been beneficial. More funds could have enabled greater accuracy of the ISF. This would include research similar to the work conducted by Kalo and Newsum with Dual Side Incremental Forming (DSIF). Continuing development of the cultural patterns into some sort of structure would have also given more evidence to the benefit of ISF. In hindsight the research took several directions that were not profitable. These included the research into boolean patterns which proved too simple, image sampling which produced patterns that lacked cultural clarity and the attempt to punch holes which distorted the metal sheets.

In conclusion, this thesis illustrates 
through well-defined processes the state of contemporary ornament as a relevant discussion for academics building from the formative work of Antoine Picon in his book Ornament. It has sought to provide an example of the feasibility of ISF justifying its use as an experimental form of manufacture. It has been proven through the construction of a fullscale prototype that the process of ISF communicates ornamental qualities of sheet metal. Through the digital creation of parametric patterns a range of designs have been experimentally created to illustrate the vast range of possible forms that can take shape on sheet metal. This thesis suggests both client and architect could participate in resurgence of ornamentation expressed through ISF in today's marketplace. 

Bibliography 
Aubert, M. et al. "Pleistocene cave art from Sulawesi, Indonesia" Nature, Vol. 514, No. 7521, 2014, pp. 223-227. Nature.com, nature.com/nature/journal/v514/n7521/full/ nature13422.html

Balik, Deniz and Açalya Allmer "A critical review of ornament in contemporary architectural theory and practice" ITU A|Z, Vol. 13, No 1, March 2016, pp. 157-169

Brolin, Brent C. Flight of fancy: The Banishment and Return of Ornament. St Martin's Press New York, 1985

Butcher, David. "Robots vs. CNC Machine Tools: The Software Edge." Industry News, Thomasnet.com, 14 March 2006,news.thomasnet.com/imt/2006/03/14/robots_vs_ cnc_m/

Curry, Andrew. "The Cave Art Debate." Smithsonian Magazine, 2012, smithsonianmag. com/history/the-cave-art-debate-100617099/

Dalrymple, Theodore. "Tattooing Buildings: What do graffiti and tagging tell us?" Psychology Today, June 14 2015, psychologytoday.com/blog/psychiatricdisorder/201506/tattooing-buidings

Dunn, Nick. Digital Fabrication in Architecture. Laurence King Publishing Limited, 
Focillon Henri, The Life of Forms in Art (trans. George Kubler) New York: Zone books 1992

Garcia, Mark. The Patterns of Architecture. Wiley, 2009

Gombrich, E.H. The Sense of Order: A Study in the Psychology of Decorative Art. NY: Cornell University Press, 1979

Gramazio, Fabio. et al. editors. The Robotic Touch: How Robots Change Architecture. Park Books, 2014

Holston, James. The Modernist City: An Anthropological Critique of Brasilia. First ed. University of Chicago Press, 1989

Jensen, Robert, and Patricia Conway. Ornamentalism: The new decorativeness in Architecture \& Design. Clarkson N.Potter, Inc., 1982

Kalo A., and Michael J. Newsum. "An Investigation of Robotic Incremental Sheet Metal Forming as a Method for Prototyping Parametric Architectural Skins".Robotic Fabrication in Architecture, Art and Design 2014. 2014, pp. 33-49 
Kalo, Ammar, and Michael J. Newsum. "Robotic Incremental Sheet Metal Forming" 34th Annual Conference of the Association for Computer Aided Design in Architecture, Los Angeles, California, October 23-25, 2014, edited by David Greber, Alvin Huang, and Jose Sanchez, ACADIA and Riverside Architectural Press, 2014, pp. 71-74

Kolarevic, Branko Architecture in the Digital Age: Design and Manufacturing. Taylor \& Francis Group, 2003

Kolarevic, Branko, and Kevin Klinger Manufacturing Material Effects Rethinking Design and Making in Architecture. Routledge Taylor \& Francis Group, 2008

Kreimeier, Dieter. et al. "Robot-Based Incremental Sheet Metal Forming - Increasing the Geometrical Accuracy of Complex Parts." Key Engineering Materials, Vol. 473, 2011 , pp. $853-860$

Loos, Adolf., "Ornament and Crime." Ornament and Crime Selected Essays, Ariadne Press, 1998, pp. 167-176

Marble, Scott. editor. Digital workflows in Architecture: Design - Assembly - Industry. Birkhauser, 2012 
Moussavi, Farshid, and Michael Kubo The Function of Ornament. Actar, 2006

Morris, William. "Of the Origins of Ornamental Art." meeting sponsored by the Hammersmith Branch of the SDF, 21 December 1884, Kelmscott House, Hammersmith. marxists.org/archive/morris/works/1883/ornament.htm

Necipoğlu, Gülrul, and Alina Payne. Histories of Ornament: From Global to local. Princeton University Press, 2016

Nicholas, Paul. et al. "An Integrated Modelling and Toolpathing Approach for a Frameless Stressed Skin Structure, Fabricated Using Robotic Incremental Sheet Forming." Robotic Fabrication in Architecture, Art and Design 2016. Sydney, Australia, March 2016, edited by Dagmar Reinhardt, Rob Saunders, and Jane Burry, Springer, 2016, pp. 63-77

Pendergrast, Mick. Raranga Whakairo: Maori Plaiting Patterns. Reed Publishing, 2003

Picon, Antoine. Digital Culture in Architecture: An introduction for the design professions. Birkhauser, 2010

Picon, Antoine. Ornament: The Politics of Architecture and Subjectivity. John Wiley \& Sons Ltd, 2013 
Picon, Antoine "Ornament: Architecture, Subjectivity, Politics" - April 4, 2012 University in Buffalo School of Architecture and Planning, Buffalo. https://www.youtube.com/ watch? $v=$ KnwSoRUZEto

Pell, Ben. The Articulate Surface: Ornament and Technology in Contemporary Architecture. Birkhauser, 2010

Schafter, Debra. The Order of Ornament the Structure of Style: Theoretical Foundations of Modern Art and Architecture. Cambridge University Press, 2003

Spuybroek, Lars. The Sympathy of Things: Ruskin and the Ecology of Design. V2_ Publishing, 2011

Trilling, James. Ornament A Modern Perspective. University of Washington Press, 2003

Welch, Adrian. "HL23 Project New York." e-architect, 4 July 2016, e-architect.co.uk/ new-york/hl23-project 


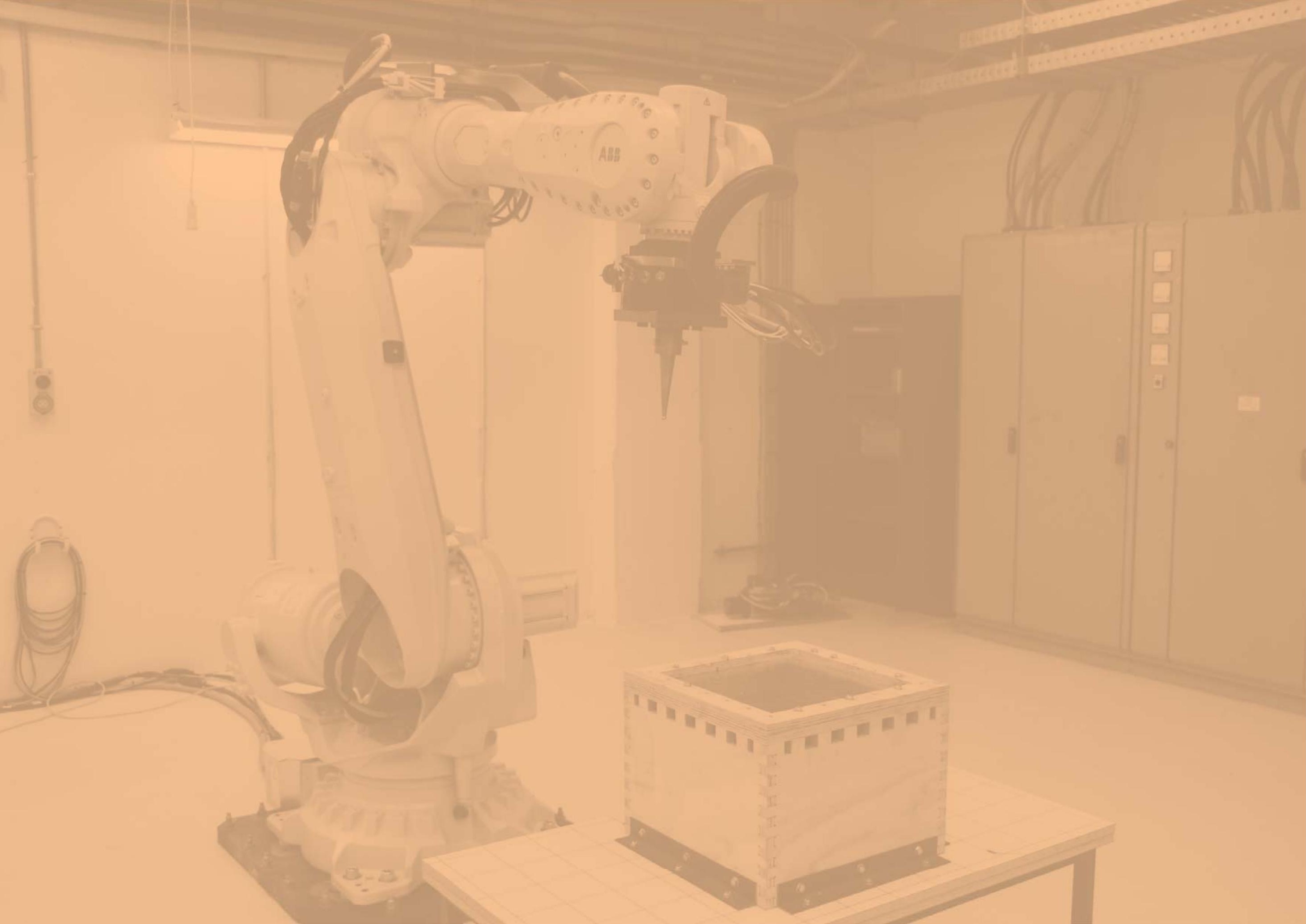


